\title{
NISTIR 5387
}

\section{Graphical Analysis of the CCRL Portland Cement Proficiency Sample Database (Samples 1 - 72)}

\author{
Curtis B. Spring \\ James H. Pielert \\ Stefan Leigh \\ N. Alan Heckert
}

U.S. DEPARTMENT OF COMMERCE Technology Administration National Institute of Standards and Technology Building and Fire Fiese:re: ; ithoratory Gaithersburg, MD $20<99$ 



\title{
Graphical Analysis of the CCRL Portland Cement Proficiency Sample Database (Samples 1 - 72)
}

\author{
Curtis B. Spring \\ James H. Pielert \\ Stefan Leigh \\ N. Alan Heckert
}

U.S. DEPARTMENT OF COMMERCE

Technology Administration

National Institute of Standards

and Technology

Building and Fire Research Laboratory

Gaithersburg, MD 20899

American Society for Testing and Materials

March 1994

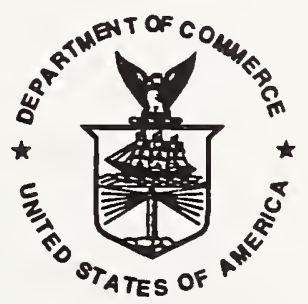

U.S. DEPARTMENT OF COMMERCE Ronald H. Brown, Secretary

TECHNOLOGY ADMINISTRATION

Mary L Good, Under Secretary for Technology

NATIONAL INSTITUTE OF STANDARDS

AND TECHNOLOGY

Arat Prabhakar, Director 



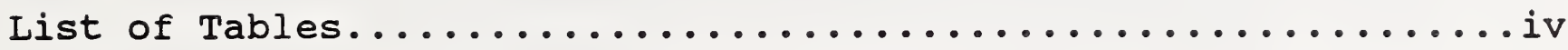

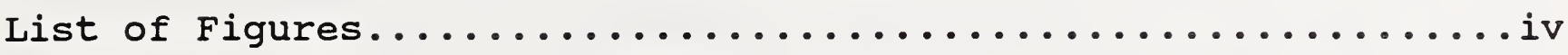

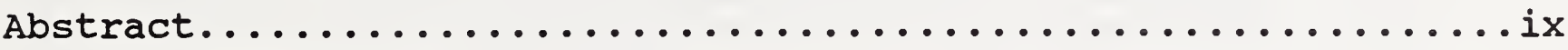

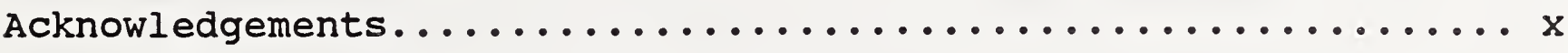

1. Background and Scope of Long-Term Study............... 1

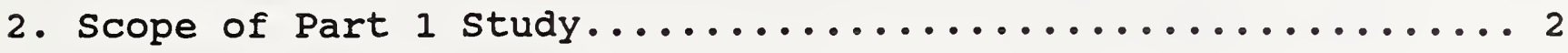

3. Statistical and Graphical Applications............... 4

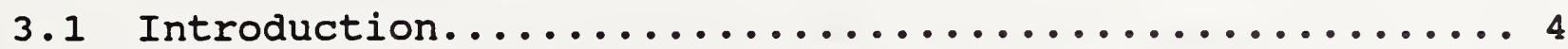

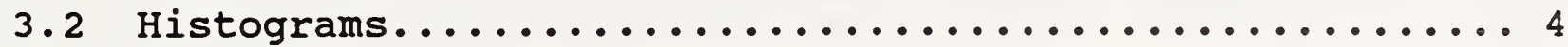

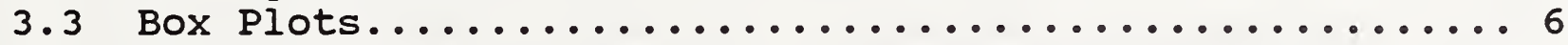

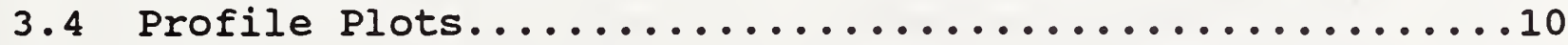

4. Portland Cement Physical Test Properties.................14

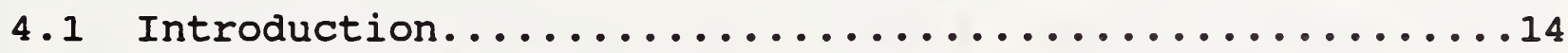

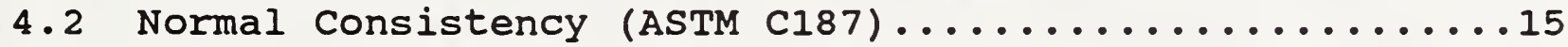

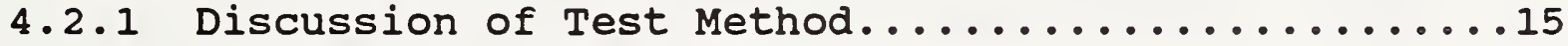

4.2.2 Statistical Presentation of Data................

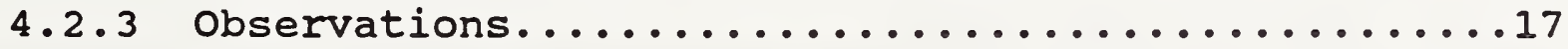

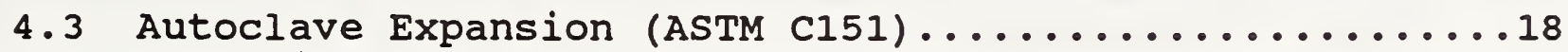

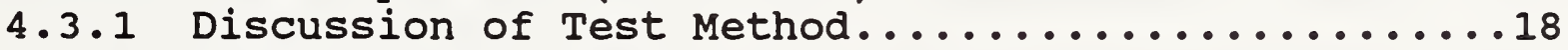

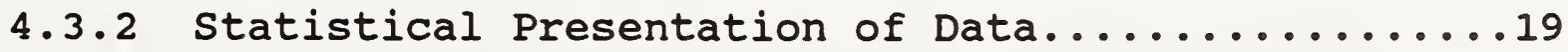

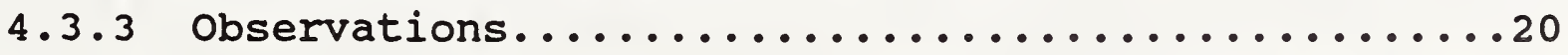

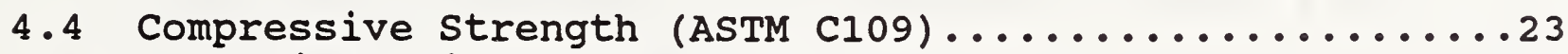

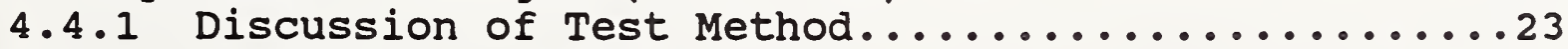
4.4.2 Statistical Presentation of Data.............24

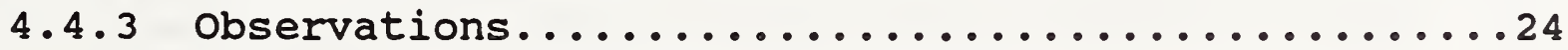
4.4.3.1 3-Day Compressive Strength............24 4.4.3.2 7-Day Compressive Strength............26

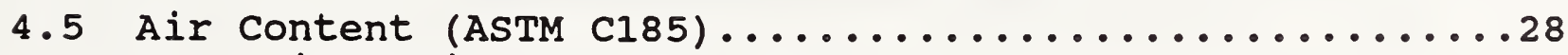

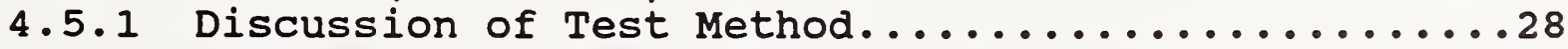

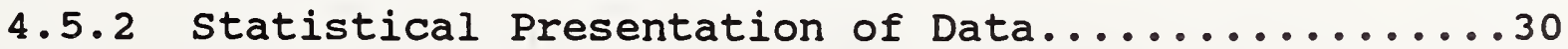

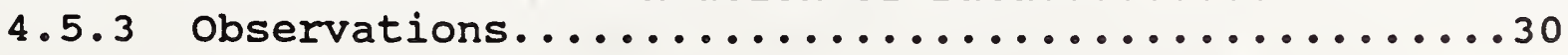

4.6 Time of Setting by Vicat Needle (ASTM C191) .........32

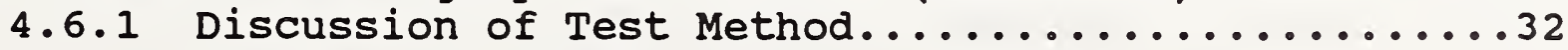

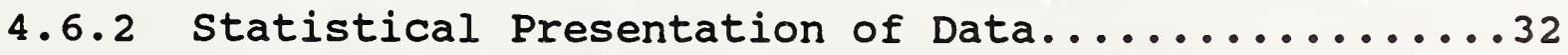

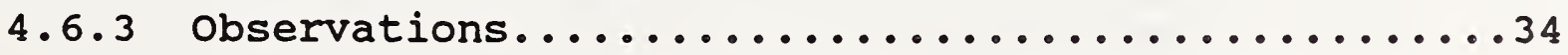




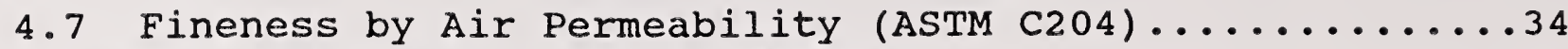

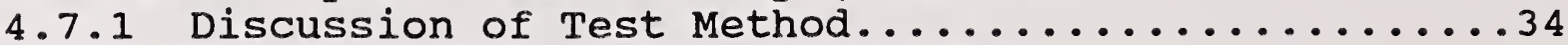

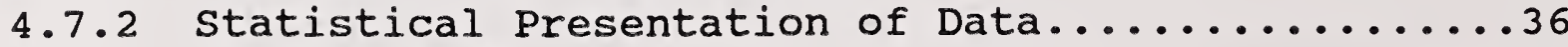

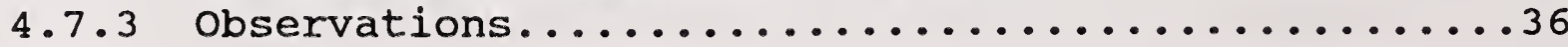

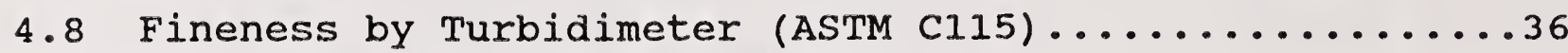

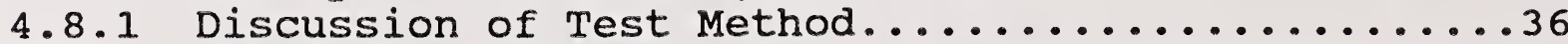

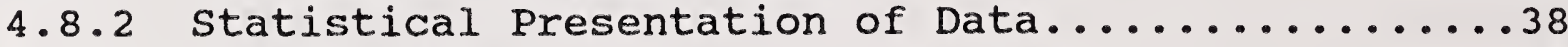

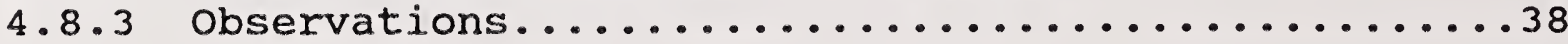

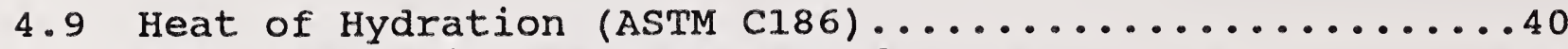

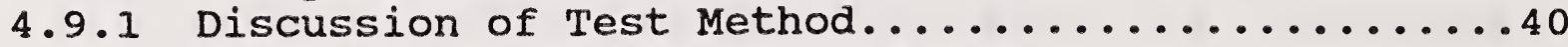

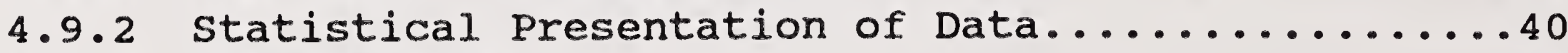

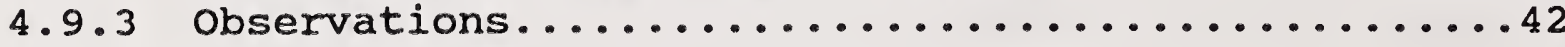

4.10 Summary of Physical Test Properties...............42

5. Portland Cement Chemical Composition..................42

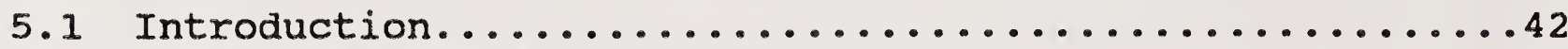

5.2 Silicon Dioxide $\left(\mathrm{SiO}_{2}\right) \ldots \ldots \ldots \ldots \ldots \ldots \ldots \ldots \ldots \ldots$

5.2.1 Statistical Presentation of Data............48

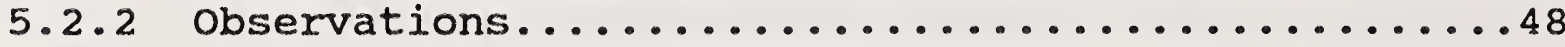

5.3 Aluminum oxide $\left(\mathrm{Al}_{2} \mathrm{O}_{3}\right) \ldots \ldots \ldots \ldots \ldots \ldots \ldots \ldots \ldots \ldots \ldots \ldots \ldots . \ldots \ldots \ldots$

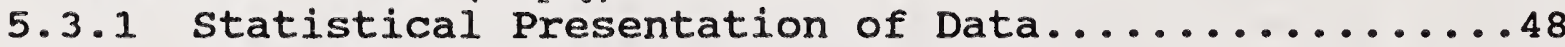

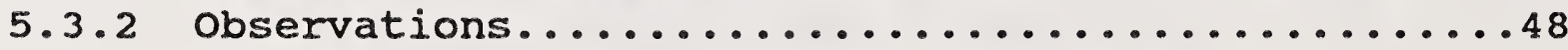

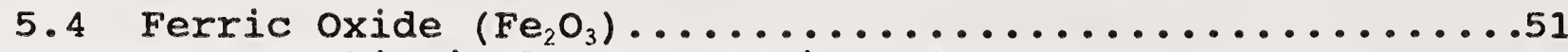

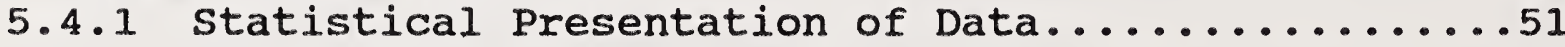

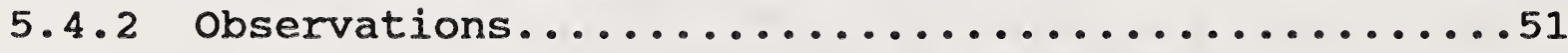

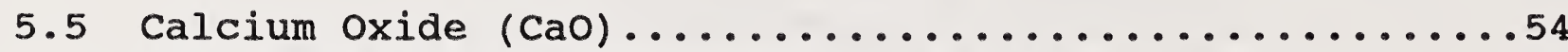

5.5 .1 Statistical Presentation of Data..............54

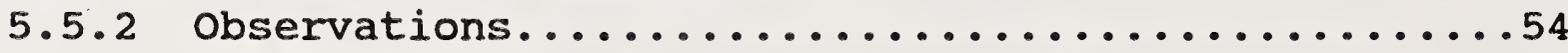

5.6 Free Lime................................. 54

5.6 .1 Statistical Presentation of Data..............54

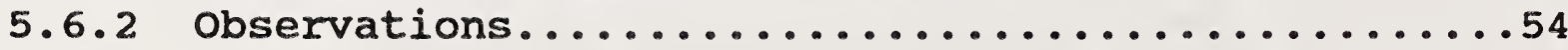

5.7 Magnesium oxide (Mgo) ......................... 54

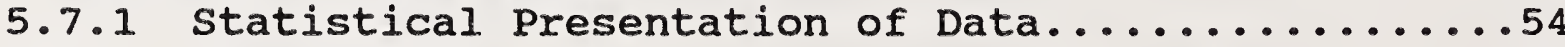

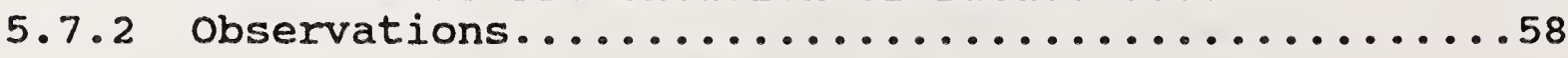

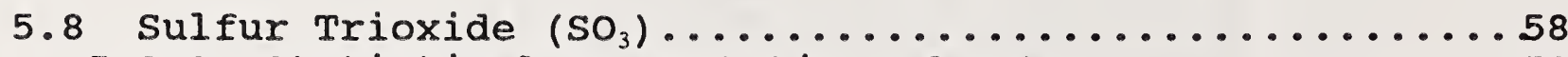

5.8 .1 statistical presentation of Data.............58

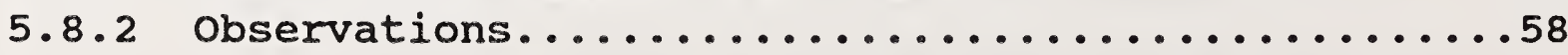

5.9 Loss on Ignition..........................61

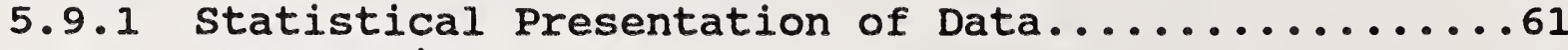

5.9 .2 Observations...........................61 


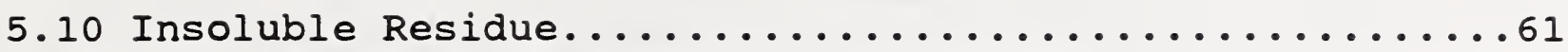

5.10 .1 Statistical Presentation of Data.............61

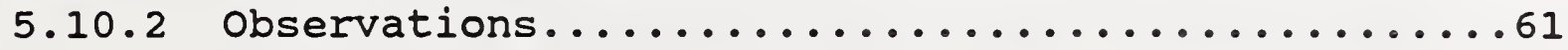

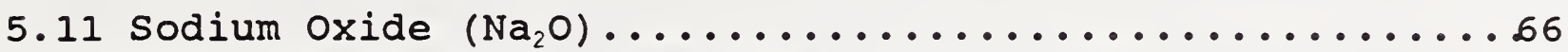

5.11 .1 Statistical Presentation of Data............66

5.11 .2 Observations........................66

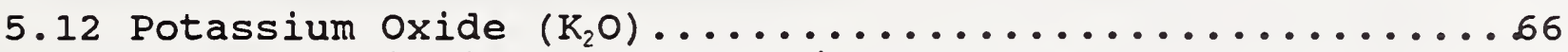

5.12 .1 Statistical Presentation of Data...........66

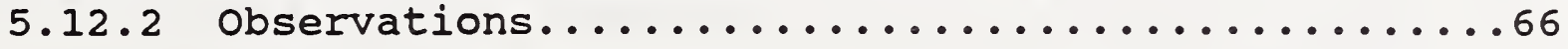

5.13 Summary of Chemical Component Test Data...........69

6. Relationships Between Properties of Portland Cement........69

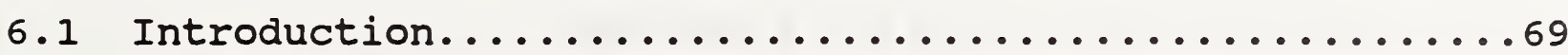

6.2 Assemblage of Sorted Box Plots.................69

6.2 .1 Box Plots of Physical Properties.............69

6.2 .2 Box Plots of Chemical Components...............76

6.2.3 Box Plots of Physical Properties Sorted

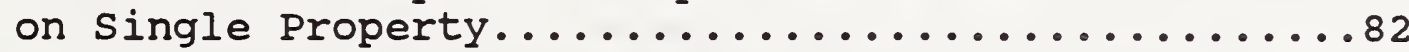

6.3 Studies of Specific Relationships.............86

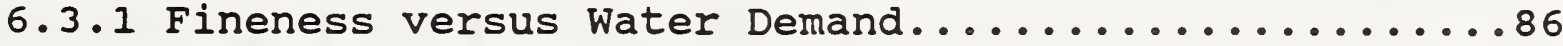

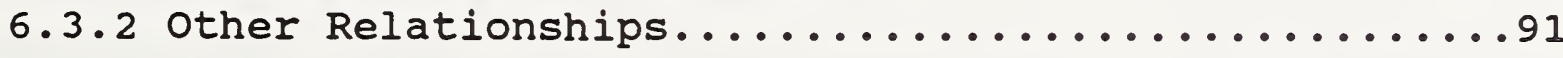

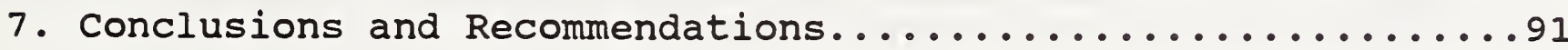

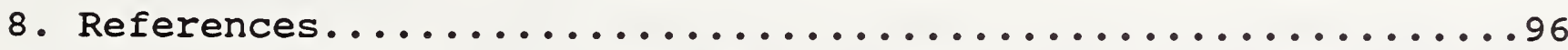

Appendices

A. Overview of the cement and concrete Reference

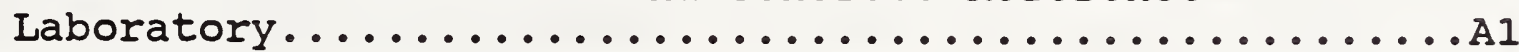

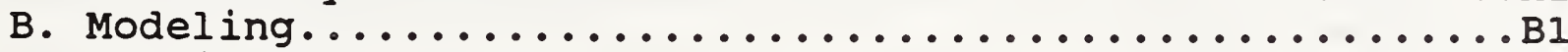

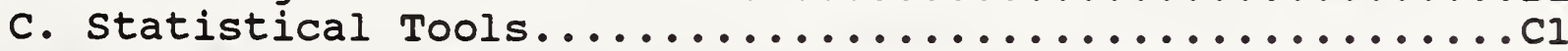

D. Comparison of Precision Statements in ASTM Standards to Those Computed From CCRL Data.................. 


\section{List of Tables}

1. Physical Properties and Chemical Components Determined in the CCRL Portland Cement Proficiency Sample Program

2. Cement Types Distributed by the CCRL Portland Cement Proficiency Sample Program (ASTM C150)

3. Spread of Medians and Interquartile (IQ) Ranges for Physical Test Results

4. Spread of Medians and Interquartile (IQ) Ranges for Chemical Test Results

5. Summary of Chemical Profiles for 14 Cements

\section{List of Figures}

3.1 Histogram of Turbidimeter Fineness (C115) Results for CCRL Portland Cement Sample 20

3.2 Compilation of Turbidimeter Fineness (ASTM C115) Histograms for CCRL Portland Cement Samples 1 Through 12.

3.3 Properties of a Box Plot Used in This Study

3.4 Box Plots of Turbidimeter Fineness (C115) Test Results for Samples in the order Distributed by CCRL

3.5 Box Plots of Turbidimeter Fineness (C115) Test Results for Samples Sorted on Increasing Median Values

3.6 Profile Plots for Chemical Properties of the $72 \mathrm{CCRL}$ Portland Cement Samples

3.7 Profile Plots for Physical Properties of the 72 CCRL Portland Cement Samples

4.1 Sequential Box Plots of Normal Consistency (ASTM C187) Test Results in the order Portland Cement Samples Were Distributed BY CCRI

4.2 Box Plots of Normal Consistency (ASTM C187) Test Results Sorted on Median Values

4.3 Sequential Box Plots of Autoclave Expansion (ASTM C151) Test Results in the order the Portland cement samples were Distributed BY CCRL

4.4 Box Plots of Autoclave Expansion (ASTM C151) Test Results Sorted on Median Values 
4.5 Interquartile Ranges for Autoclave Expansion (ASTM C151) Plotted by Samples sorted on Median Values

4.6 Sequential Box Plots of 3-Day Compressive Strength (ASTM C109) Test Results in the order the Portland Cement Samples Were Distributed BY CCRL

4.7 Box Plots of 3-Day Compressive strength (ASTM C109) Test Results Sorted on Median Values

4.8 Sequential Box Plots of 7-Day Compressive Strength (ASTM C109) Test Results in the order the Portland Cement samples Were Distributed BY CCRL

4.9 Box Plots of 7-Day Compressive Strength (ASTM C109) Test Results Sorted on Median Values

4.10 Plots of Skewness for 3-Day and 7-Day Compressive Strength (ASTM C109) Median Values

4.11 Sequential Box Plots of Air Content (ASTM C185) Test Results in the order the Portland Cement Samples Were Distributed By CCRI

4.12 Box Plots of Air Content (ASTM C185) Test Results Sorted on Median Values

4.13 Sequential Box Plots of Initial Vicat Time of set (ASTM C191) Test Results in the order the Portland Cement Samples were Distributed BY CCRL

4.14 Box Plots of Initial Vicat Time of set (ASTM C191) Test Results Sorted on Median Values

4.15 Sequential Box Plots of Fineness by Air Permeability (ASTM C204) Test Results in the order the Portland cement samples Were Distributed BY CCRL

4.16 Box Plots of Fineness by Air Permeability (ASTM C204) Test Results Sorted on Median Values

4.17 Sequential Box Plots of Fineness by Turbidimeter (ASTM C115) Test Results in the order the Portland Cement samples Were Distributed BY CCRL

4.18 Box Plots of Turbidimeter Fineness (ASTM C115) Test Results Sorted on Median Values

4.19 Sequential Box Plots of 7-Day Heat of Solution (ASTM C186) Test Results in the order the Portland cement samples Were Distributed BY CCRL 
4.20 Box Plots of 7-Day Heat of Solution (ASTM C186) Test Results Sorted on Median Values

4.21 Sequential Box Plots of 7-Day Heat of Hydration (ASTM C186) Test Results in the order Samples Were Distributed BY CCRL

4.22 Box Plots of 7-Day of Hydration (ASTM C186) Test Results Sorted on Median Values

5.1 Flow Chart of Reference Methods for Chemical Analysis of Portland Cement Using ASTM C114

5.2 Sequential Box Plots of Silicon Dioxide (ASTM C114) Test Results in the order the Portland Cement samples Were Distributed BY CCRL

5.3 Box Plots of Silicon Dioxide (ASTM C114) Test Results Sorted on Median Values

5.4 Sequential Box Plots of Aluminum oxide (ASTM C114) Test Results in the order the Portland cement samples Were Distributed BY CCRL

5.5 Box Plots of Aluminum Oxide (ASTM C114) Test Results Sorted on Median Values

5.6 Sequential Box Plots of Ferric Oxide (ASTM C114) Test Results in the Order the Portland Cement Samples Were Distributed By CCRL

5.7 Box Plots of Ferric Oxide (ASTM C114) Test Results Sorted on Median Values

5.8 Plots of Skewness for Ferric oxide (ASTM C114) Median Values

5.9 Sequential Box Plots of Calcium Oxide (ASTM C114) Test Results in the order the Portland Cement Samples Were Distributed By CCRL

5.10 Box Plots of Calcium Oxide (ASTM C114) Test Results Sorted on Median Values

5.11 Sequential Box Plots of Free Lime (ASTM C114) Test Results in the order the Portland Cement Samples Were Distributed BY CCRL

5.12 Box Plots of Free Lime (ASTM C114) Test Results Sorted on Median Values

5.13 Sequential Box Plots of Magnesium Oxide (ASTM C114) Test Results in the order the Portland Cement Samples Were Distributed BY CCRL 
5.14 Box Plots of Magnesium Oxide (ASTM C114) Test Results Sorted on Median Values

5.15 Interquartile Ranges for Magnesium Oxide (ASTM C114) Plotted by Samples Sorted on Median Values.

5.16 Sequential Box Plots of Sulfur Trioxide (ASTM C114) Test Results in the order the Portland Cement Samples Were Distributed BY CCRL

5.17 Box Plots of Sulfur Trioxide (ASTM C114) Test Results Sorted on Median Values

5.18 Sequential Box Plots of Loss on Ignition (ASTM C114) Test Results in the order the Portland cement samples Were Distributed BY CCRL

5.19 Box Plots of Loss on Ignition (ASTM C114) Test Results Sorted on Median Values

5.20 Plots of Skewness for Loss on Ignition (ASTM C114) Median Values

5.21 Sequential Box Plots of Insoluble Residue (ASTM C114) Test Results in the order the Portland Cement Samples Were Distributed BY CCRL

5.22 Box Plots of Insoluble Residue (ASTM C114) Test Results Sorted on Median Values

5.23 Plots of Skewness for Insoluble Residue (ASTM C114) Median Values

5.24 Sequential Box Plots of Sodium Oxide (ASTM C114) Test Results in the Order the Portland cement Samples Were Distributed By CCRL

5.25 Box Plots of Sodium Oxide (ASTM C114) Test Results Sorted on Median Values

5.26 Sequential Box Plots of Potassium Oxide (ASTM C114) Test Results in the order the Portland cement samples were Distributed BY CCRL

5.27 Box Plots of Potassium Oxide (ASTM C114) Test Results Sorted on Median Values

6.1a Assemblage of Sequential Box Plots for Physical Properties of CCRL Portland Cement Samples 1-72

6.1b Assemblage of Sequential Box Plots for Physical Properties of CCRL Portland Cement Samples 1-72 
6.2a Assemblage of Sorted Box Plots for Physical Properties of CCRL Portland Cement Samples 1-72

6.2b Assemblage of Sorted Box Plots for Physical Properties of CCRL Portland Cement Samples $1-72$

6.3a Assemblage of Sequential Box Plots for Chemical components of CCRI Portland Cement Samples 1-72

6.3b Assemblage of Sequential Box Plots for Chemical components of CCRI Portland Cement samples 1-72

6.4a Assemblage of Sorted Box Plots for Chemical. Properties of CCRL Portland Cement Samples $1-72$

6.4b Assemblage of Sorted Box Plots for Chemical Properties of CCRL Portland Cement Samples 1 - 72

6.5a Box Plots of Various Physical properties sorted by Air Permeability Fineness Results (ASTM C204)

6.5b Box Plots of Various Physical properties sorted by Air Permeability Fineness Results (ASTM C204)

6. 6 Box Plots of Normal Consistency Results (ASTM C187) Sorted by Air Permeability Fineness Results (ASTM C204)

6.7 Least Square Fit of Normal Consistency (ASTM C187) Median Values Sorted by Air Permeability Fineness Results (ASTM C204)

6.8 Chemical Profiles of 14 Cements Selected to Evaluate Chemical Composition and Water Requirement

6.9 Box Plots of 7-Day Compressive strength Sorted on 3-Day Compressive strength Results (ASTM C109)

6.10 Box Plots of Normal Consistency Results (ASTM C187) Sorted on Free Lime Results (ASTM C114)

C. 1 Generation of a Box Plot From a Histogram

C.2 Generation of a Profile Plot From Box Plots 
A large database of Portland cement and Portland cement concrete interlaboratory test results has been generated at the Cement and Concrete Reference Laboratory (CCRL) since 1965. The database represents a rich resource inasmuch as the cements tested were produced by many different production facilities, from raw materials obtained from different geological areas, and over a long period of time. Participation varies from 120 to over 200 laboratories located throughout the United States and in several other countries. Computer and statistical techniques are used to present the data from the first 72 Portland cement samples in graphical forms to better understand cement and cement testing. Data for each of 10 physical test properties and 11 chemical "compounds" of Portland cement are represented graphically through the use of box plots. For each property and compound, the box plots of data from multiple samples are plotted sequentially as distributed by CCRL and also sorted on median values. In several instances, box plots for one test property are ordered by the median values of another property to analyze possible relationships. Also, the characteristics of each of 72 cements are profiled (graphically) in relation to the population of results of other cements. These box plots and profiles provide insight for modeling cement performance which is the long-term goal of this study.

Reywords: construction; Portland cement; properties; standards; test methods 
The authors would like to recognize several individuals who contributed to the success of this project. Dr. James J. Filliben of the NIST Statistical Engineering Division, provided valuable insight into the best approach of the study, and the capabilities of Dataplot in the analysis and graphical presentation of the data. Dr. Geoffrey Frohnsdorff, Chief of the NIST Building Materials Division, provided encouragement and technical insight into cement technology. Robin Haupt, supervisor of the cement and concrete Reference Laboratory Proficiency Sample Program which produced the Portland cement data used in the study, provided insights into the nature of the database. Raymond Kolos, Assistant Manager of the CCRL, provided valuable support in working with the various computing systems used in the study. Darcy Barnett, supervisor of the NIST Center for Applied Mathematics VAX Computer, was most helpful in providing instructions and access to the computer. And finally, the authors would like to acknowledge the support of Richard Gaynor of the National Ready Mixed Concrete Association in reviewing this report and providing information concerning cement technology. 


\section{Background and Scope of Long-Term Study}

The cement and Concrete Reference Laboratory (CCRL), located at the National Institute of Standards and Technology (NIST) (formerly the National Bureau of Standards) began distribution of Portland cement proficiency samples on an informal basis in 1960. (See Appendix A for an overview of the CCRL.) An ongoing program of distributing cement samples was initiated by CCRL in 1966 with samples being distributed twice a year in pairs for physical and chemical tests. With the number of laboratories participating in this program currently exceeding 300 (from an initial 165 laboratories), these test data provide a rich basis for defining the properties of Portland cement in terms of current general test methods. Since 1971 some of the cements used in cement proficiency sample programs have been utilized in the CCRL concrete proficiency sample program, a program which currently has 320 participants.

This study is the first in a projected series of studies which will use the CCRL proficiency sample data to increase knowledge of cement and concrete science. This initial report presents the proficiency sample data collected between 1966 and 1984 in concise, graphical forms which can be used by standards developers, producers and users of cement, and others who may be interested in portland cement.

A related study was conducted by Blaine, Arni and others at NIST from 1953 to 1971. It involved a number of different portland cements produced in the United states tested by a number of testing laboratories, although appreciably less than those participating in the CCRL proficiency sample program. The goal of the Blaine-Arni study was to model important cement properties in terms of composition and other controlled variables. Results were reported in six papers published between 1965 and $1971[8.1,8.2,8.3,8.4$, 8.5 and 8.6 ]. In the forty years since that study was undertaken, computer capabilities and statistical techniques for evaluating large sets of data have improved significantly, allowing improved analysis of the expanded CCRL portland cement database.

The long-term study currently being conducted has four parts:

Part 1.

The CCRL portland cement proficiency sample database obtained between 1966 and 1984 will be depicted using descriptive statistics, mostly of a graphical nature, to display chemical and physical test results alone or in paired forms.

Part 2.

Relationships of paired transformations ${ }^{1}$ of variables, variables, and graphically and ored will be explored

1 See Appendix B for discussion of modeling including transformations. 
evaluating selected accepted relationships between properties of portland cement, or for discovering new relationships.

Part 3. An attempt will be made to model specific properties of portland cement based on the results of Parts 1 and 2. Models will be cross-validated against CCRL proficiency sample data collected after 1984.

Part 4. The CCRL portland cement concrete proficiency sample database will be analyzed in the same fashion as the portland cement proficiency sample database. The effect of variations in portland cement properties on concrete performance will be assessed.

\section{Scope of Part I study}

The objective of the study reported in this paper is to present data in a comprehensive visual form which is easily interpreted and useful to the cement and concrete community. The first 72 portland cement proficiency samples distributed by CCRL between 1966 and 1984 are used, with test results from samples distributed after January 1984 to be used for validation of the models to be prepared in Part 3. The chemical components and physical properties determined in the CCRL proficiency sample program, those selected for evaluation in this study, and the related ASTM test methods are listed in Table 1 . There are a total of 21 components and properties when 3-day and 7-day compressive strengths (C109) are counted separately. Portland cement types used to prepare the proficiency samples are listed in Table 2. There are 53 Type I, 10 Type Ia, I Type I/II, 4 Type II, and 4 Type III cements. The number of laboratories reporting results for each sample ranges from 30 for heat of solution (C186) to 280 for compressive strength (C109). The portland cements represented here were produced at 38 different plants located in 18 states east of the Mississippi River and in one Canadian province.

Chapter 3. and Appendix B of this report provide information on modeling, and Appendix $C$ discusses the computing and statistical tools used to analyze the test results. Chapters 4. and 5 . provide descriptions of portland cement test methods for determining physical properties and chemical components, graphical representation of the data, and general observations regarding the data. These graphical representations allow rapid visual interpretation of the test results, which may identify areas for more in-depth study. Chapter 6. provides discussion of selected relationships between the physical properties and chemical components of portland cements included in the study, and Chapter 7. provides conclusions and recommendations. 
Table 1 - Physical Properties and Chemical components Determined in the CCRL Portland Cement Proficiency Sample Program [8.7]

Physical Properties

*Normal Consistency, C187

*Time of Setting by Vicat Needle, C191

Time of Setting by Gillmore Needles, C266

*Autoclave Expansion, C151

*Air content of Mortar, C185

*Compressive Strength of Mortar, Cl09 (3, 7 and 28 days)

*Fineness by Air Permeability Apparatus, C204

*Fineness by Turbidimeter, C115

Fineness by the $45 \mathrm{~mm}$ (No. 325) Sieve, C430

Early stiffening (Paste Method), C451

* Heat of Hydration ( 7 and 28 days), C186

*Heat of Solution, C186

Chemical Components

*Silicon Dioxide $\left(\mathrm{SiO}_{2}\right)$
*Aluminum oxide $\left(\mathrm{Al}_{2} \mathrm{O}_{3}\right)$
*Ferric oxide $\left(\mathrm{Fe}_{2} \mathrm{O}_{3}\right)$
*Calcium Oxide ( $\mathrm{CaO})$
*Free Lime
*Magnesium oxide (MgO)

*Sulfur Trioxide $\left(\mathrm{SO}_{3}\right)$ *Loss on Ignition

*Insoluble Residue *Sodium Oxide $\left(\mathrm{Na}_{2} \mathrm{O}\right)$

*Potassium Oxide $\left(\mathrm{K}_{2} \mathrm{O}\right)$

* Properties and components included in the Part 1 study (Exceptions are Vicat Final Time of set - C191, 28 day strength - C109, 28 day Heat of Hydration - C186, water content and flow - C185, heat of solution of dry cement and partially hydrated cement - C186, and chemical rapid method groups - C114)

Table 2 - Cement Types Distributed by the CCRL Portland Cement Proficiency Sample Program (ASTM C150)

Sample No.

$$
\begin{gathered}
1-4 \\
5-8 \\
9-12 \\
13-16 \\
17-60 \\
61-66 \\
67 \\
68
\end{gathered}
$$

$69-72$
Type

I

IA

III

II

$I$

IA

$I$

$I / I I$

I
Year (4 samples/yr.)

1966-67

1967-68

1968-69

1969-70

1970-81

1981-82

1983

1983

1983-84 
It is believed that the results of this study will be useful in advancing cement and concrete technology by: (1) determining new relationships among various cement properties and components and validating those which are currently used; (2) identifying critical components and combination of components which regulate physical attributes of portland cement and portland cement concrete: evaluating the performance of different types of portland cement; (4) characterizing portland cement produced in the eastern United States; (5) evaluating standard test methods or suggesting the need for new methods; (6) providing information that will assist in the development of high performance concrete technology; and (7) identifying the impact of individual laboratory bias on test precision.

The readers of this report are encouraged to apply their knowledge of the testing and behavior of portland cements to provide the authors with additional observations and recommendations for use in later parts of this study.

\section{Statistical and Graphical Applications}

\subsection{Introduction}

Statistical and graphical techniques are used to present the portland cement properties and components in a clear and utilizable manner. Box plots and profile plots are used to study relationships between properties and the underlying test methods. The histogram, a well known statistical tool, has been used for initial data analysis.

Dataplot, a computer software package developed at NIST by James Filliben, was used to do statistical computations and to generate the plots. [8.8]. A VAX 11/780(VMS) computer and a Cyber 855 were used.

\subsection{Histograms}

Histograms depict the distribution of data using vertical bar charts. The width of each bar represents a class interval (each interval representing an equal portion of the range) of the test results and the height represents the frequency (number in the class interval). [8.9] Histograms can be used, for example, to determine if data are normally distributed (Gaussian distribution). This is done by observing the profile formed by the mid-points of the tops of the bars to determine if the normal bell shaped curve is formed. Figure 3.1 is a histogram of the data from 87 laboratories conducting the Turbidimeter Fineness Test (ASTM C115) on portland cement sample No. 20. The class interval is $40 \mathrm{~cm}^{2} / \mathrm{g}$. The first test result is for a class interval of 1651 to $1690 \mathrm{~cm}^{2} / \mathrm{g}$ with one sample being noted for that interval. There are 22 laboratories reporting results within the class interval of 


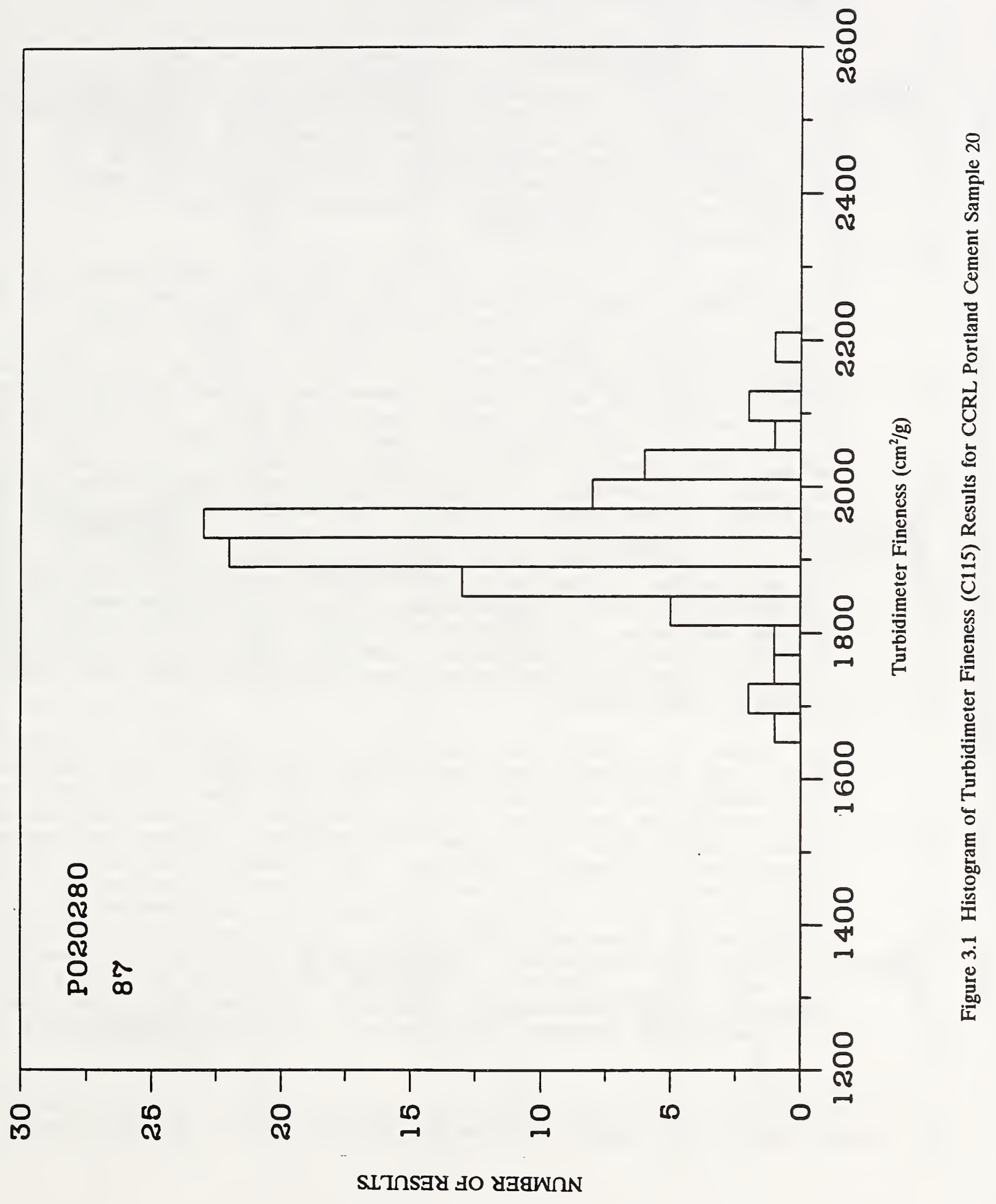


1851 to $1890 \mathrm{~cm}^{2} / \mathrm{g}$. Figure 3.2 is a compilation of histograms for 12 samples tested for Turbidimeter Fineness. It should be noted that some of these histograms demonstrate skewness and possibly multimodal behavior. ${ }^{2}$

\subsection{Box Plots}

A box plot is a schematic diagram, first proposed by Tukey [8.10], which is useful for comparing the empirical distributions represented by various batches of numbers. It is a visual one-way analysis of variance, providing all the information obtainable from such an analysis and more. It provides a quick impression of certain prominent features of the distributions depicted.

Box plots are normally vertical figures consisting of a central box section, vertical lines projecting above and below the box, and circles above and below the lines (Figure 3.3). The box section represents the middle 50 percent of the test results (Interquartile Range), with the range of the results determined by the difference between the highest feature above the box and the lowest feature below the box. (In this paper a box is not used because of space limitations, and the gap between the vertical lines is the mid-range.) The center of the data, the median, is represented in this publication by an asterisk or the sample number. The vertical lines represent data lying outside the middle 50 percent, and circles are typically used to represent outlying (extreme) results at the top and bottom of the box plot. In this report outliers above the median are called highliers and those below the median are called lowliers. The generation of box plots from histograms is illustrated in Appendix C. Results more than $1.5 \mathrm{x}$ IQ and $3.0 \times$ IQ distance from the box are shown with small and large circles respectively.

Box plots for individual samples can be grouped in various ways. Two different representations are used in this report. The "sequential box plots" show the individual box plots for each sample in the order that the samples were distributed by CCRL. Such plots can show time related changes in cement properties and testing methods. The "sorted box plots" show the individual box plots sorted on increasing median values. Figure 3.4 is a typical "sequential" representation for Turbidimeter Fineness (ASTM C115), and Figure 3.5 is a typical "sorted" representation. The resulting visual display enables the eye at a glance to perform relatively sophisticated comparisons of the distributional information previously represented by batches of numbers. The remarkable degree of

${ }^{2}$ The mode(s) is the most frequently occurring value(s) of a distribution. skewness refers to an absence of symmetry about the mode of the distribution. 

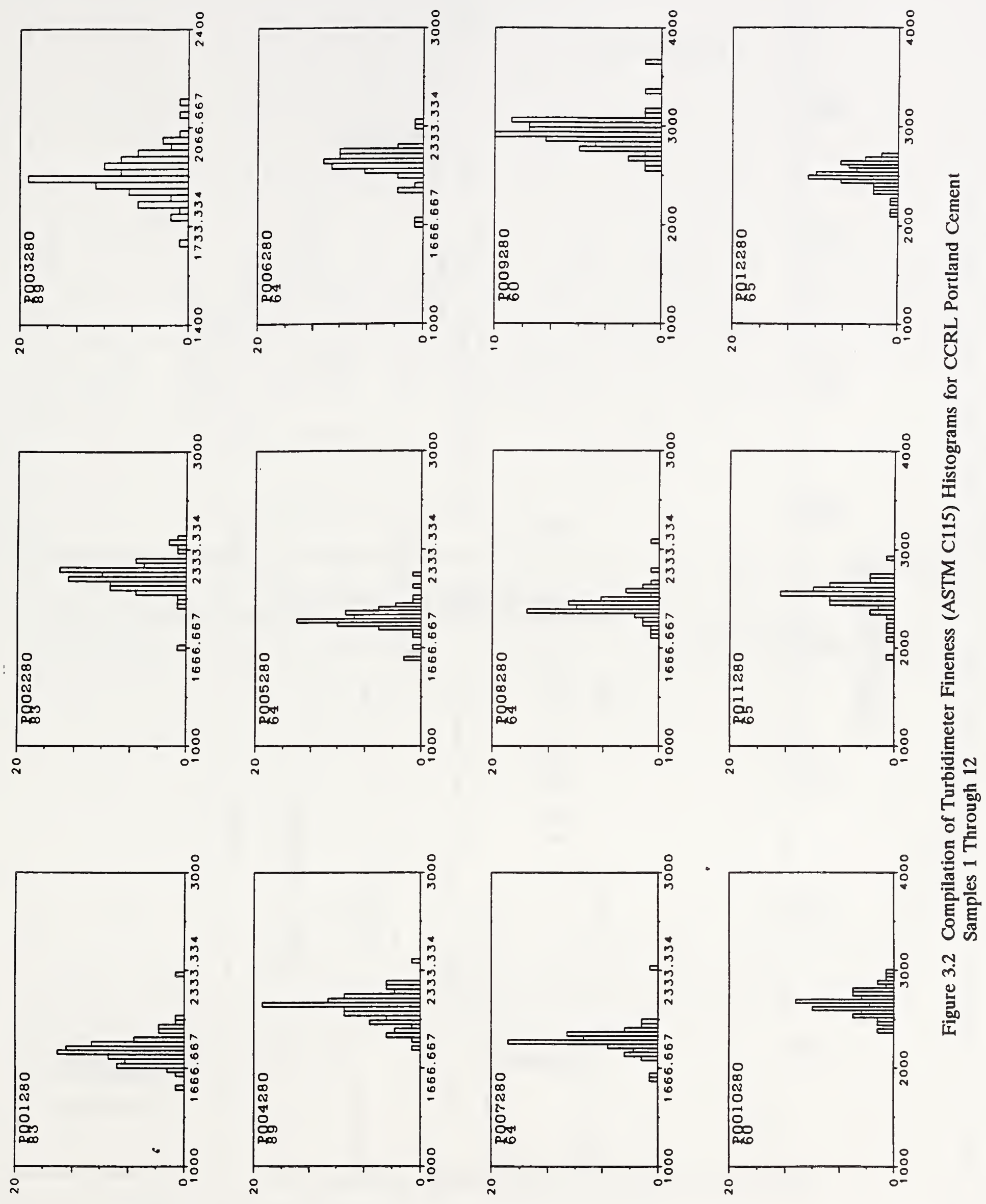


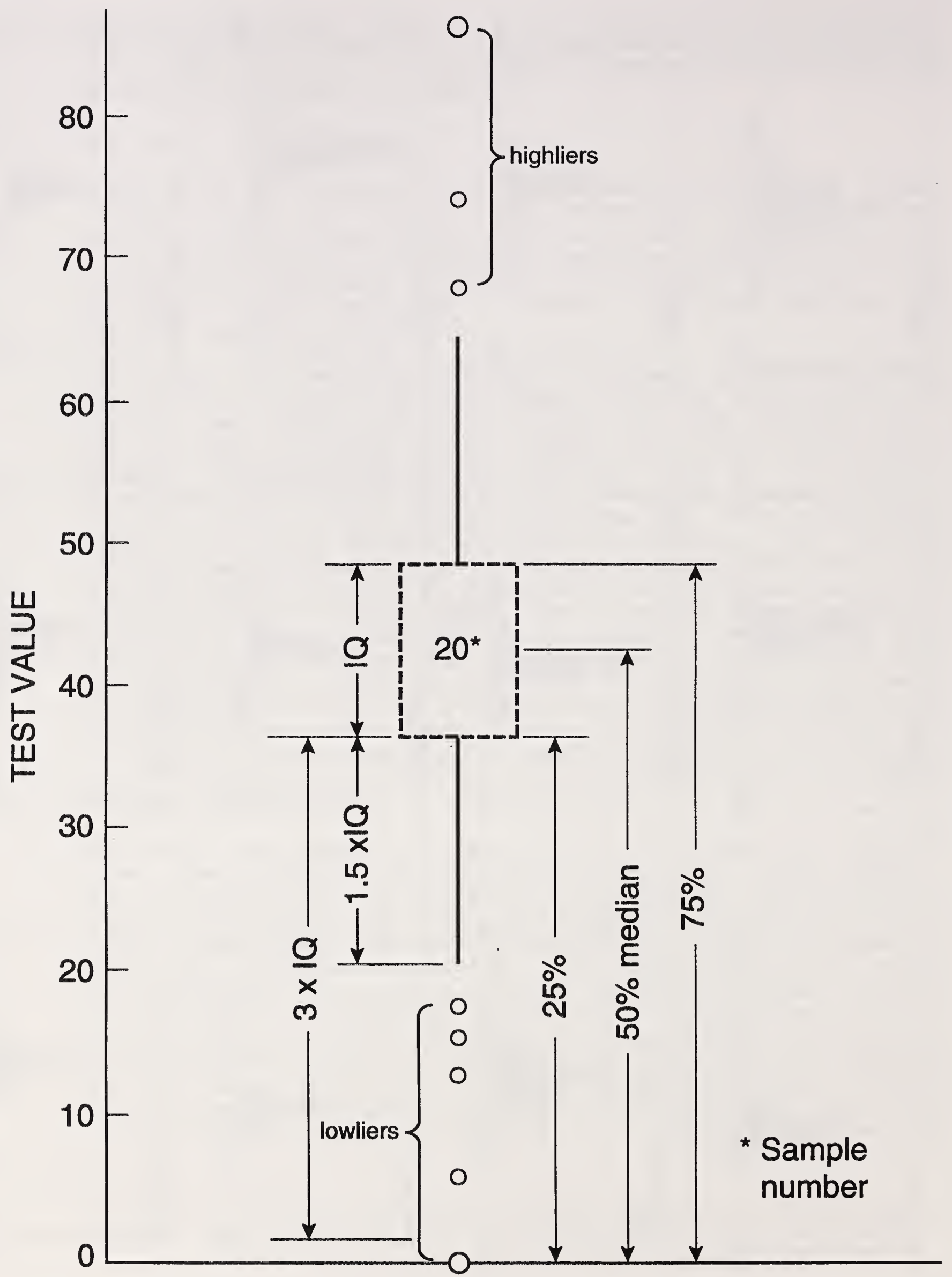

Figure 3.3 Properties of a Box Plot Used in This Study 
compaction provided by a box plot clearly identifies important characteristics of the data taken as a whole. One can quickly check for alignment or disalignment of the medians, and discrepancies in spread among the different batches. Most of the box plots in this report summarize over 14,000 pieces of test data (representing an average of about 200 laboratories testing 72 portland cement samples).

Some of the characteristics of the test results which can be observed from box plots include:

a. range and scope of the numerical values available in the data;

b. precision, repeatability and reproducibility of test results;

c. pattern of distributions of repeated values of test results in any given CCRL biyearly test cycle;

d. tendencies of extreme results to be repeatedly either high or low;

e. discretization effects ${ }^{3}$;

f. anomalous patterns that might be observed with any given test method; and

g. test methods that exhibits a tendency to display a higher variability at one end of the range of data or the other (heteroscedasticity).

\subsection{Profile Plots}

Profile plots provide a means of examining multiple properties of a group of samples at the same time. There are groups of cements which stand out in box plot representations as being different. A profile plot incorporating various chemical components and physical properties may be useful in determining why this difference exists. Profile plots are used in this study to compare the relative values of various properties of a portland cement sample to those of other samples in the database. Samples are ranked by location within the 72 samples sorted by median test values. For example, the rank percent of the 36 th sample in the sorted list would be represented as 50 percent $(36 / 72 \times 100)$ on the profile plot. See Appendix $C$ for a detailed description of profile plots.

Figure 3.6 shows a series of profile plots of the chemical components for the 72 portland cement samples in the study, and Figure 3.7 shows profile plots for physical properties. This presentation allows a visual comparison of sample characteristics and can be used to identify areas for further study. Results are depicted with horizontal bars orienting

The term discretization refers to the effect on various kinds of plots when one bins real-valued data points by, for example, rounding the numbers down to the nearest integer, or nearest integer divisible by 5 , or nearest integer divisible by 10 . In histogram-type representations, discretization appears as pile-up of plot points near integer (or integers divisible by 5 , or integers divisible by 10) values. In serially arranged plots, such as the box plots in this report, discretization manifests itself as a step pattern in plots, as the serially plotted points avoid the data values that are censored by the data recordation process. 


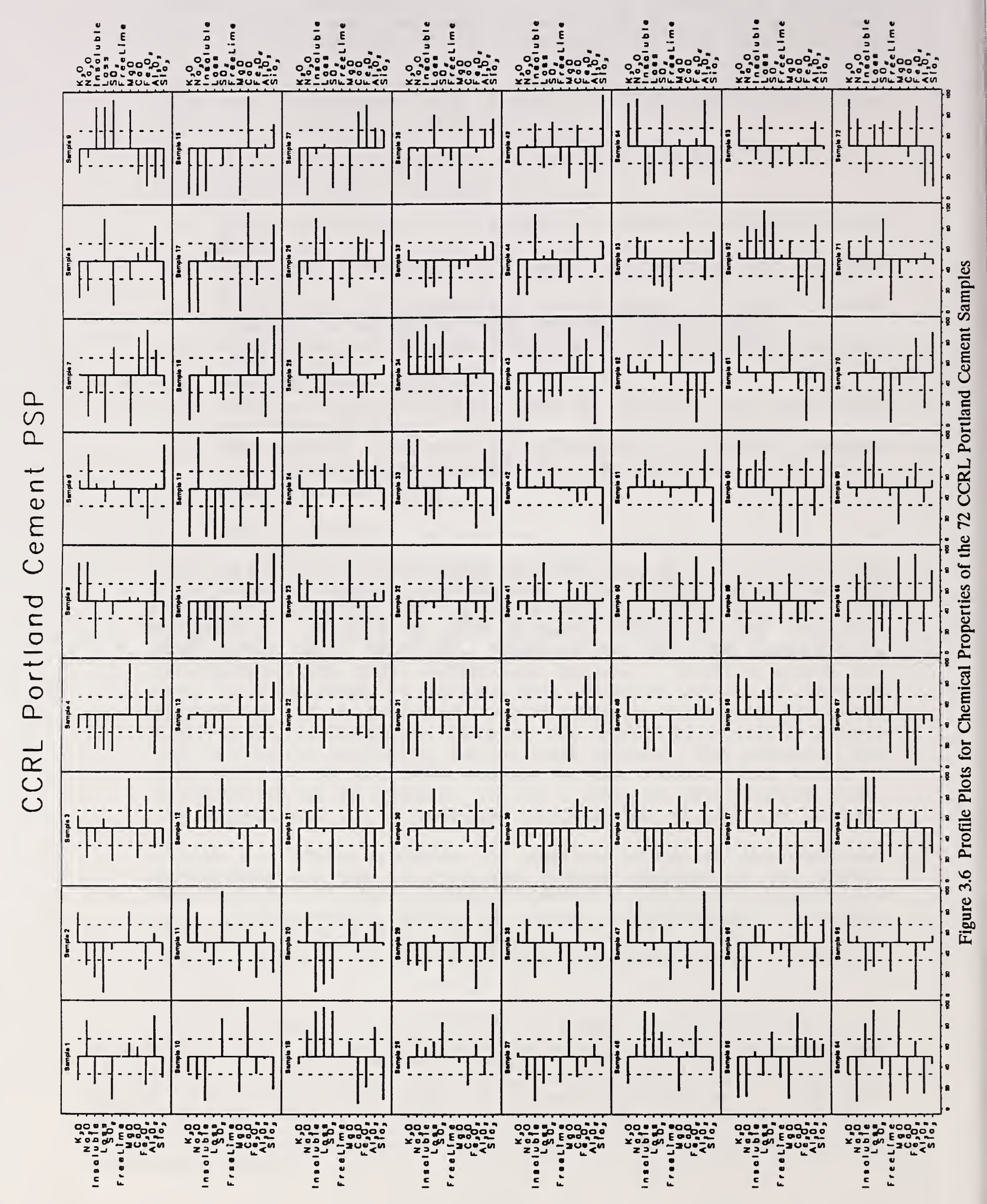


from the $50 \%$ percentage rank with dashed lines at the onethird portions. A horizontal bar to the left indicates that the sample value is below the 50 percent rank. The length of the bar indicates how fax the sample rank is from the 50 percent rank. See the rank scale from 0 to 100 on the $X$ axis. The parameters are labeled at both the left and right margins of the plots. The relative values for test parameters for nine consecutive samples are aligned horizontally across the page and the reader can compare samples by using a straightedge and aligning it with specific choices of bars across the page. Figure 3.7 shows that samples 2, 9, 10, 12, 52 and 59 have most of the test results appreciably above $50 \%$, while samples $14,15,16,36$ and 45 have most results below $50 \%$. It should be noted that bars will be absent when there are no test results, as in the case of samples 1 to 34 for Free Lime and samples 1 to 20 for 7-day Heat of Solution.

The information contained in the profile plots can be used to compare properties of selected samples. A example of such an analysis is provided in Chapter 6.

4. Portland Cement Physical Test Properties

\subsection{Introduction}

The first serious attempts in the United states to devise a uniform system of tests of hydraulic cements was under the auspices of the American Society of Civil Engineers (ASCE) [8.11]. A report submitted by the ASCE Committee on Uniform Tests on Cement in January 1885 recommended that tests for hydraulic cements be confined to methods for determining fineness, susceptibility to checking or cracking, and tensile strength. The inadequacy of the requirements in the 1885 report became apparent after a few years, and ASCE established a new committee to study the matter. A progress report prepared by the committee became the basis for the ASTM Standard Specifications for Portland Cement published in 1904 . The final report of the ASCE committee presented in 1912 included the following methods for sampling and testing Portland Cement: sampling, chemical analysis, specific gravity, fineness, normal consistency, time of setting, standard sand, tensile and compressive strength, and constancy of volume.

The physical test properties of the CCRL portland cement proficiency samples shown in Table 1 are evaluated in this study using the graphical techniques described in Chapter 3. and Appendix $c$. Where possible, the following information is provided for each of the ASTM test methods used to determine these properties: historical information on the development of the method, description of the method, factors affecting results, and observations concerning the results. While 
covered somewhat in the historical information, there has been no comprehensive attempt to track changes in test methods over time and to relate them to the test results presented.

4.2 ASTM C187 Standard Test Method for Normal Consistency of Hydraulic Cement [8.7]

\subsubsection{Discussion of Test Method}

It is widely accepted that the performance of hydraulic cement in paste, mortar, or concrete is greatly influenced by the amount of water present. The amount of water prescribed for the pastes used in several tests is established by a "normal consistency", a property ascertained by a test developed by L.J. Vicat in France in 1818. [8.12] The cohesiveness of the particles of cement in the presence of water affect the consistency of a cement paste, and the degree of fineness and the size of particles affect the cohesiveness. [8.13] The Vicat method was used for many years in the United states and Europe prior to its adoption in the initial ASTM Standard specifications for cement in 1904. The method has been modified only slightly in spite of much experience during intervening years. The most significant recent change occurred around 1971 when the cement mix sample size was increased from $500 \mathrm{~g}$ to $650 \mathrm{~g}$.

ASTM test method $\mathrm{C} 187$ is used to determine the water required to prepare hydraulic cement pastes for testing. Normal consistency is that amount of water, expressed in percent by weight of dry cement, which when mixed thoroughly with the cement will permit the plunger of the Vicat apparatus to penetrate $10 \pm 1 \mathrm{~mm}$ into the cement paste in 30 seconds. A trial and error approach is used to determine the normal consistency. Through reference to other ASTM standards, C187 specifies limits on temperature and humidity requirements for the laboratory atmosphere in the vicinity of the mixing area, and lists specifications for the weighing devices and glass graduates.

The normal consistency test is used in the determination of other cement properties considered in this study, including autoclave expansion (section 4.3) and time of setting (section 4.6 ).

\subsubsection{Statistical Presentation of Data}

Figure 4.1 is a box plot representation of the normal consistency test results for the first 72 portland cement proficiency samples. The individual plots are sequential in the order in which the samples were distributed by 


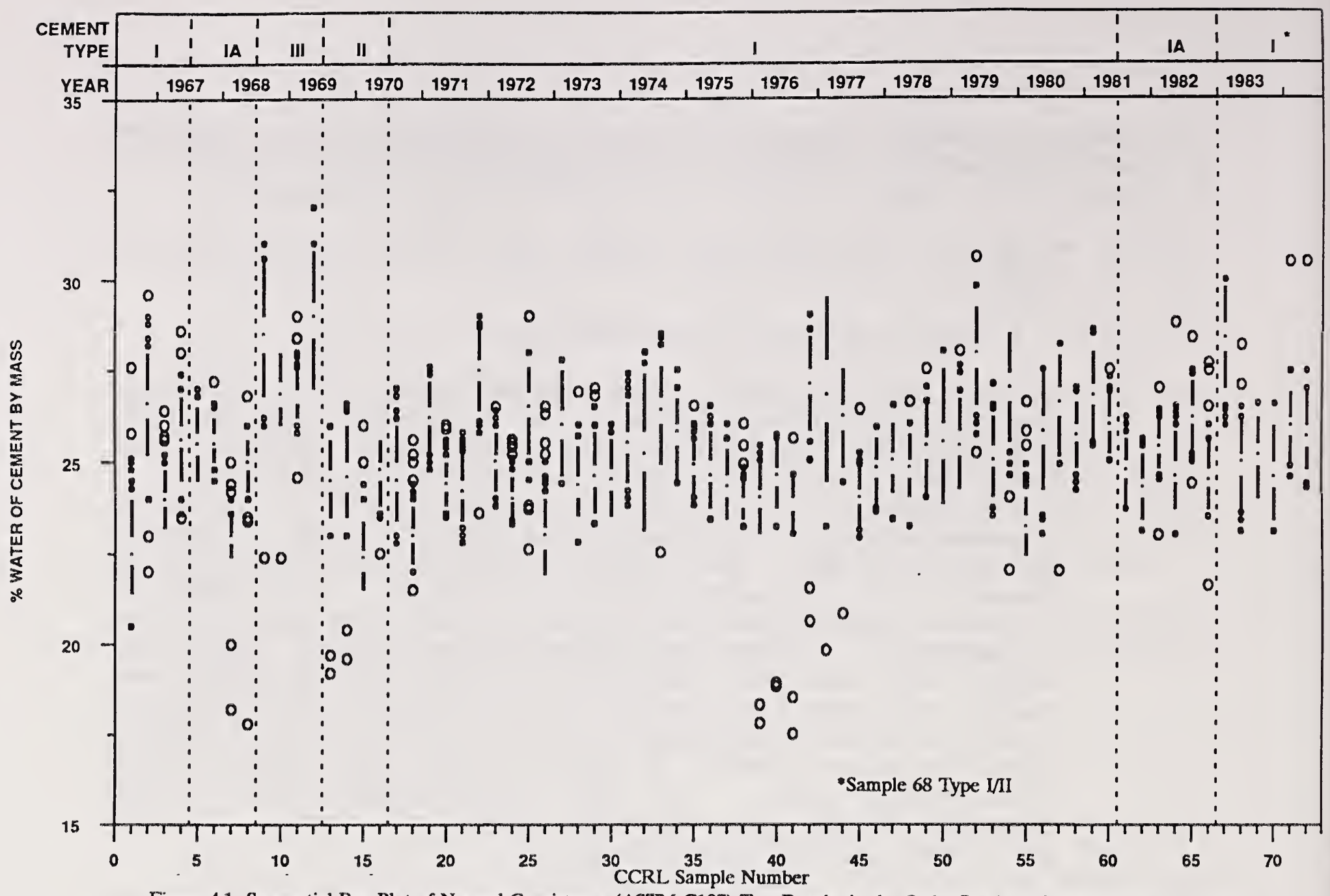

Figure 4.1 Sequential Box Plot of Normal Consistency (ASTM C187) Test Results in the Order Portland Cement Samples Were Distributed by CCRL

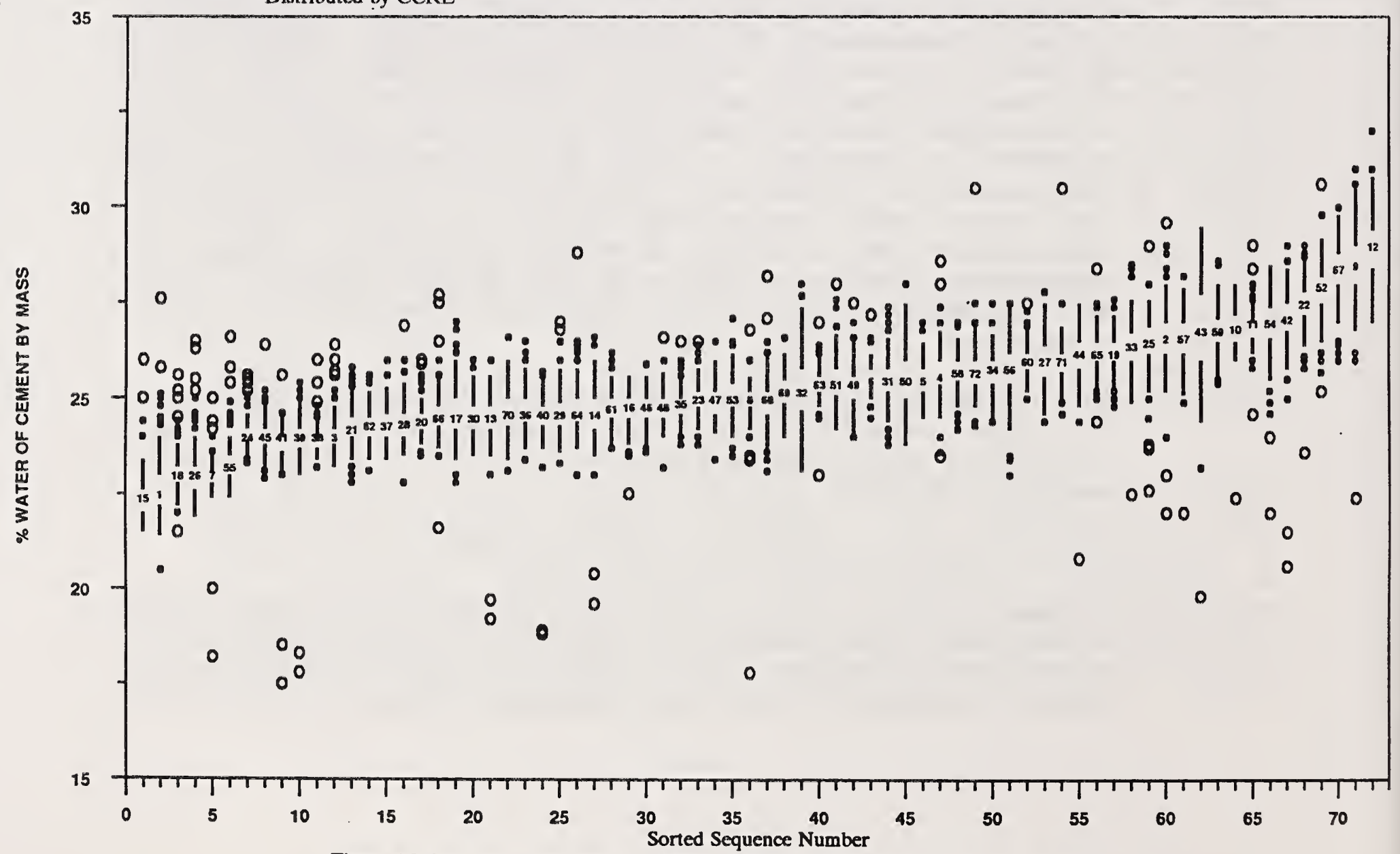

Figure 4.2 Box Plot of Normal Consistency (ASTM C187) Test Results Sorted on Median Values 
CCRL between 1966 and 1984. The percentages of water by mass of cement required to obtain a normal consistency are plotted by sample number. Figure 4.2 is a similar plot except that percentages of water are plotted by samples sorted on median values.

\section{2 .3 Observations}

a. Figure 4.1 shows that Type III cements (samples 9 through 12) give evidence of higher water requirements than other cement types included in the study. This is to be expected since Type III cements are typically ground finer than other cement types. [8.14] Figure 4.15 shows Type III cements having air permeability finenesses of 4200 to $6700 \mathrm{~cm}^{2} / \mathrm{g}$ while other cement types vary from 2800 to $4400 \mathrm{~cm}^{2} / \mathrm{g}$.

b. Figure 4.1 shows a number of extreme lowliers (representing values more than $3 \mathrm{x}$ IQ range distance from the median) for samples distributed in 1968 (Type IA cements, samples 7 through 10), 1969 (Type II cements, samples 13 and 14), and 1976 and 1977 (Type I cements, samples 39 through 44). (See Section 3.3 and Appendix $C$ for description of the IQ range.)

c. Figure 4.2 shows some plateauing 4 on the sorted median values which may be a discretization effect since normal consistencies are reported to the nearest \pm 0.1 percent. There is no clear funneling ${ }^{5}$ pattern in the data except that the last 15 samples have slightly larger IQ ranges than the other samples. Samples 32,43 and 50 have much higher IQ ranges than the other samples. There is a definite preponderance of large lowliers, particularly for samples with median normal consistency values above

4 Plateauing refers to the series of extended horizontal levels one observes in the plot. This can be indicative of a discretization or quantization effect, or may represent the natural occurrence of a number of similar [close] numerical values in the data.

s Standard deviations, variances, IQ range, or the multiples thereof, are all measures of the spread of a distribution. Heteroscedasticity, or funneling, in the spreads of the distributions depicted in the box plots refers to a gradual increase (or possibly, decrease) in a spread statistic through the range of the data plotted. It is often the case that when such an increase in, e.g., variance, is observed the variance is actually proportional to the level of the data. Heteroscedasticity is often dealt with in classical least squares statistical procedures such as regression or ANOVA by transforming the data with a log transform, or by the mathematically equivalent procedure of weighted least squares. 
26 percent. Also, a large number of highliers appear closer to the principal range of the data at normal consistency values less than 24 percent.

d. Figure 4.2 shows that the data present an available range $^{6}$ of data in normal consistency values from approximately 21 to 31 percent. The IQ range typically fluctuates between 0.4 and 0.8 percent.

4.3 ASTM C151 Standard Test Method for Autoclave Expansion of Portland Cement [8.7]

\subsubsection{Discussion of Test Method}

Periodically, specimens made with some cement pastes crack after a period and become unsound. Soundness is defined as "freedom of a solid from cracks, flaws, fissure, or variations from an accepted standard." [8.15] Such cracking may come from expansion caused by delayed hydration of complex constituents of $\mathrm{CaO}$ and Mgo. The tendency to expand due to delayed hydration of excess free lime can be evaluated by ASTM Method C151.

The development of the autoclave test by ASTM began in the early 1900's. $[8.16,8.17,8.18]$ Three key papers were presented between 1908 and 1913: "The Influence of Fine Grinding on the Physical Properties of Portland Cement" by R. K. Meade (1908); "The Expansion and Contraction of Cement Mortars" by A. H. White (1911); and "The Autoclave Test for Cement" by H. J. Force (1913). In 1914, ASTM Committee Cl set up a subcommittee to investigate the accelerated test of constancy of volume of cements. The subcommittee dropped consideration of the test the following year after concluding that "the autoclave test does not show appreciable merit as a test for soundness." The apparent reason was the lack of knowledge relating the independent expansions of free lime, periclase and tricalcium aluminate. Committee Cl again considered a soundness standard after $A$. H. White reported a study of volume change of neat portland cement mortars in 1928. The autoclave test was shown to detect expansion arising from both free $\mathrm{CaO}$ and $\mathrm{MgO}$. The autoclave test was eventually published by committee $\mathrm{Cl}$ as a tentative standard in 1940 and adopted as a standard in 1943. The original maximum permissible limit of

\footnotetext{
"Available Range" is the range from the lowest datum in a multiple box plot figure to the highest, excluding outliers. It is the range from the lowest point of the vertical lines to the highest, expressed by stating the lowest and highest results rather than the difference between the two numbers. The "Available Range" contains the bulk of the data.
} 
volume change was 0.50 percent. This was relaxed to 1.0 percent during World War II and, in 1961, was established at its current value of 0.80 percent in ASTM C150, standard specification for Portland cement.

ASTM Test Method C151 involves the forming of bars of neat cement with a $25.4 \times 25.4 \mathrm{~mm}$ ( $1 \times 1$ inch) crosssection with a steel measuring stud in each end. They are cured for 24 hours in moist air at approximately $23^{\circ} \mathrm{C}$ and their lengths measured on a suitable comparator with a dial micrometer. The bars are then placed in an autoclave which is raised to a steam pressure of $2 \mathrm{MPa}$ $(295 \mathrm{psi})$ at $216^{\circ} \mathrm{C}\left(420^{\circ} \mathrm{F}\right)$ in 45 to 75 minutes and maintained at this pressure for three hours. This environment greatly accelerates the hydration of deadburned uncombined lime ( $\mathrm{CaO}$ ) or crystalline magnesia (MgO) which causes expansion. After cooling in the autoclave and then in water, the length is again measured. The expansion which is typically measured over a 254-mm (10-in) gage length must not exceed 0.8 percent.

Factors believed to affect 0151 test results are [8.19]:

a. Unsoundness as measured by deleterious expansion may be caused by the presence of free lime. Free lime may arise from an over-limed mix, inadequate burning, or insufficiently fine grinding and mixing of the raw materials fed to the kiln.

b. Magnesia content of the cement will affect expansion.

c. Calcium sulphate is liable to cause expansion.

d. Although behavior in the autoclave test is related in a general way to the potential for long-term expansion, in practice it is not an exact guide and various anomalies are apparent in the available data. The addition of pozzolans or granulated slag have been shown to reduce expansion in the autoclave test.

\subsubsection{Statistical Presentation of Data}

Figure 4.3 is the sequential box plot of autoclave expansion (ASTM C151) for the first 72 CCRL Portland Cement proficiency samples. Figure 4.4 is a similar plot except that percentage expansion is plotted against samples sorted on median values. 


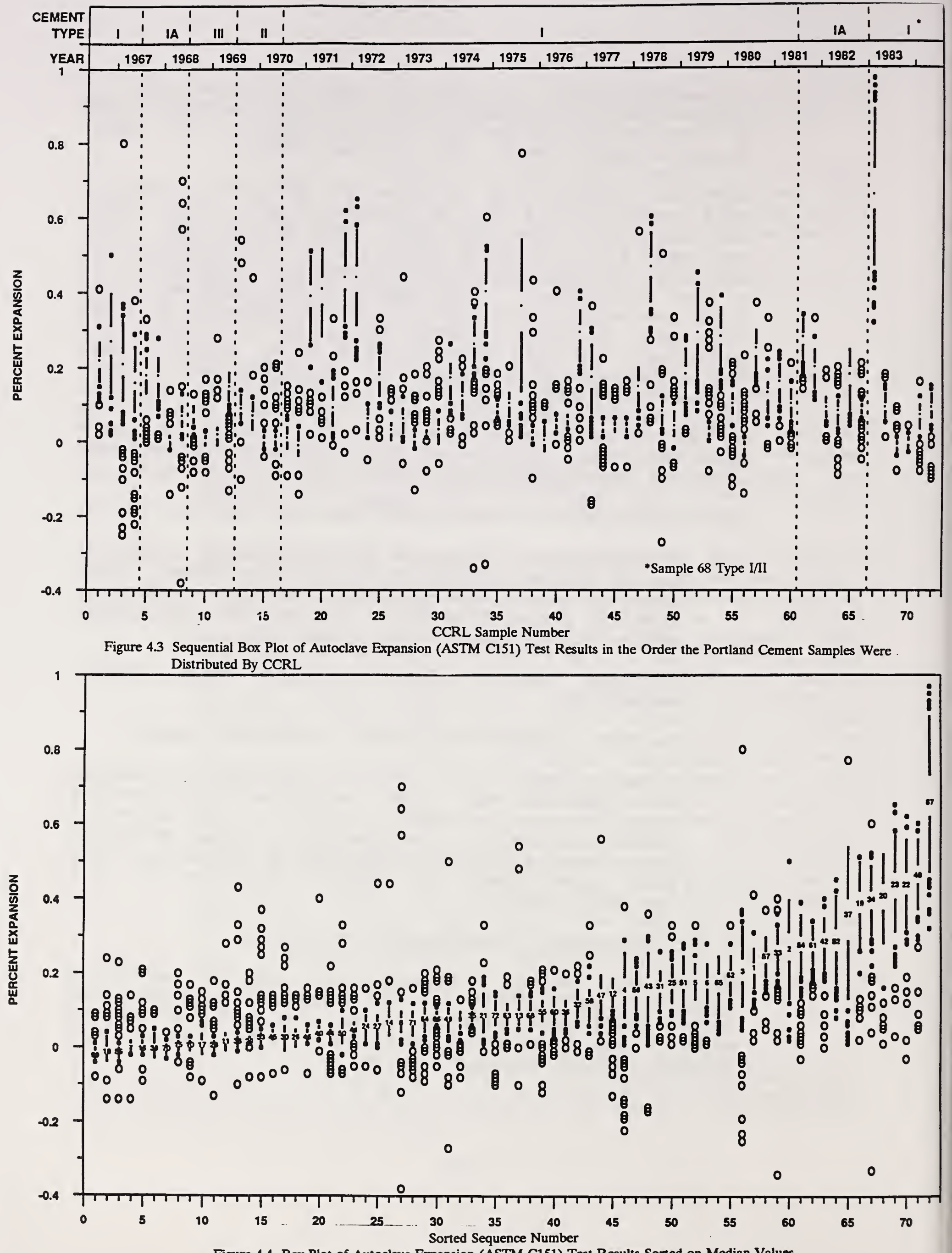

Figure 4.4 Box Plot of Autoclave Expansion (ASTM C151) Test Results Sorted on Median Values 
a. Figure 4.3 shows samples $19,20,22,23,34,37,42$ and 48 (Type I cements) with upward displaced distributions. It should be noted that sample 67 exhibits unusual behavior with a distribution well above all others.

b. Figure 4.3 shows the first 12 samples have an appreciable number of lowliers representing values more than $3.0 \mathrm{x}$ IQ range distance from the lower quartile.

c. Figure 4.3 shows a number of negative values, indicating shrinkage of the specimens under autoclaving rather than the more typical expansion.

d. Figure 4.4 shows obvious funneling of the IQ ranges which becomes more pronounced above 0.1 percent expansion. This is shown more clearly on Figure 4.5 where IQ ranges are plotted by samples sorted on median values.

It is believed that the precision of the instruments remains the same across the entire expansion region. The indicated variation of the expansion in the higher expansion region is a physical-chemical phenomenon within the cement paste, i.e. most of the variation in the measurements is due to variation in the expansion of the cement paste. Since there is evidence of expansion and the degree of expansion varies as the median expansion increases, it is likely that the curing procedure currently employed by the method allows an appreciable number of incomplete hydrations. Preliminary work in this area was done by Klein and Phillips. [8.20] An investigation could be carried out to attempt to determine the optimum curing temperature and time. Another explanation for the variation in hydration could be hydration inhibitors or accelerators in the water used in the test. It is believed that instrument precision can not be a factor in this phenomenon but that the indicated variation is due to physical/chemical processes.

e. Figure 4.4 shows a preponderance of large highliers at the lower end of the autoclave expansion range (below 0.07 percent expansion), while there is a preponderance of large lowliers above 0.07 percent expansion.

f. Figure 4.4 shows the available range of the data (ignoring sample 67) is an autoclave length change 


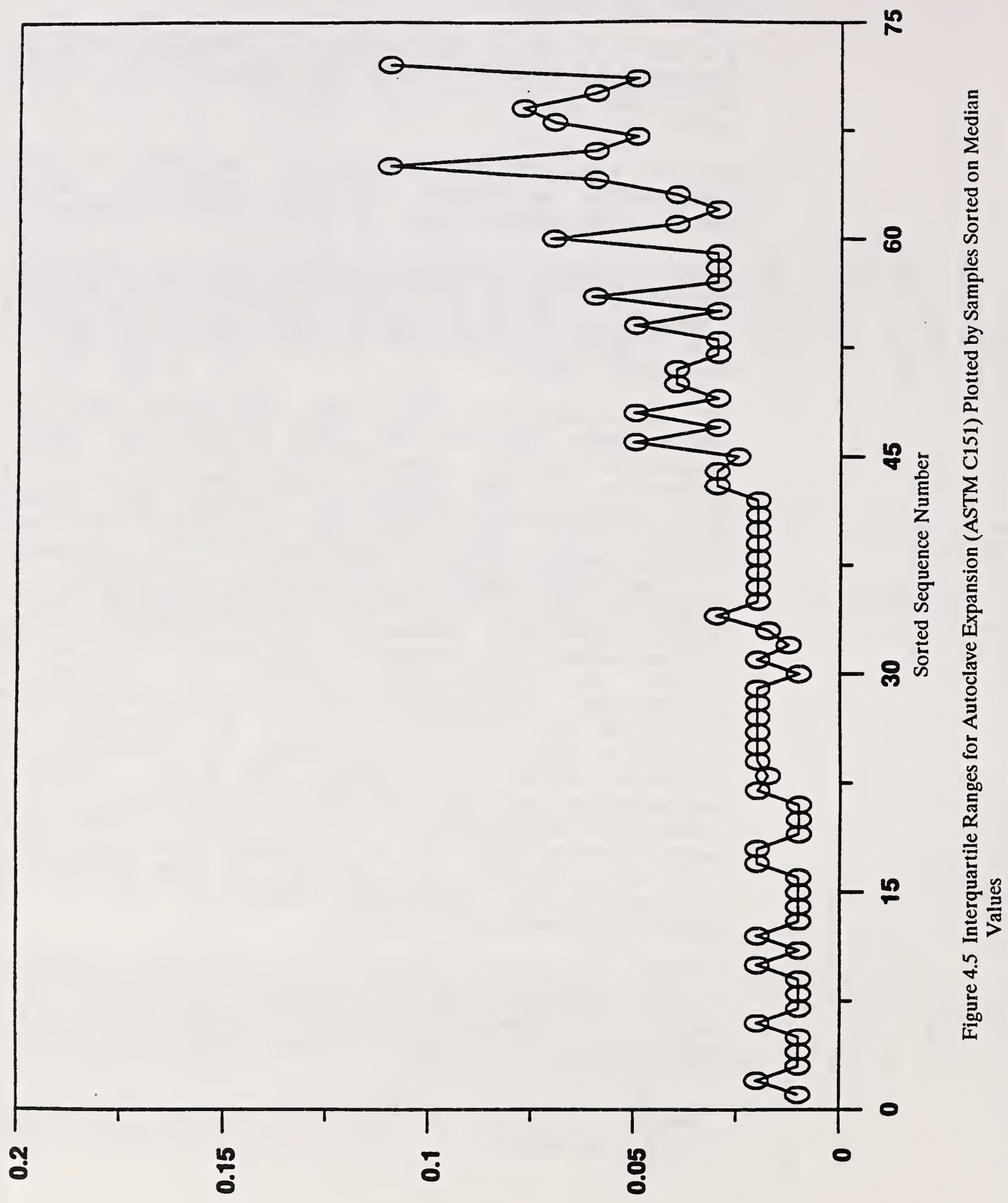

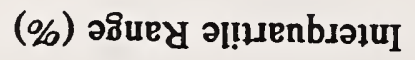


of from -0.05 to +0.55 percent. Typical IQ ranges vary from approximately 0.01 to 0.05 percent.

4.4 ASTM C109-90 Standard Test Method for Compressive Strength of Hydraulic Cement Mortars (Using 2-in or 50-mm Cube Specimens) [8.7]

\subsubsection{Discussion of Test Method}

Strength characteristics of portland cements are affected by the chemical make-up, the burning conditions in the kiln, the cooling treatment of the clinker, and constituent particle size distribution. [8.13] Compressive strength tests of portland cement mortars, though in use since the early 1900's in research, were not widely used until the mid-1930's. [8.21] Key dates in the development of tests for cement strength determination are:

1934 Tests were made using mortars with water contents based on the water requirements of cement paste at normal consistency.

1934 Tests were made containing 1 part of cement to 2.77 parts of standard graded (Ottawa) sand mixed at constant water-cement ratio of 0.53 , by mass.

1944 Mortar proportions were adjusted to 1:2.75.

1944 Water was gaged to a consistency measurement based on a flow determination of 100 to 115 percent.

1953 Mixing method for mortar was changed from hand to machine mixing.

1970 Water content of mortar reverted to a fixed water-cement ratio. (This is around the time of distribution of CCRL samples 19 and 20, although some laboratories may have changed somewhat earlier or later.)

Compressive testing of hydraulic cement has been the governing strength test method since 1953. The replacement of hand mixing by machine mixing, and improved instructions for the molding of specimens have resulted in increased reliability of test results.

ASTM C109 provides a means of determining the compressive 
strength of hydraulic cement mortars, and the results may be used to determine compliance with specifications. The mortar used in the specimens consists of 1 part cement and 2.75 parts of graded standard sand apportioned by mass. Since 1970, portland or air-entraining portland cements are mixed at specified water-cement ratios, while the amount of water used for other cements is that sufficient to obtain a flow of $110 \pm 5$ in 25 drops of the flow table using the procedure specified in ASTM C109. Prior to 1970, water usage for portland cements was determined to be that sufficient to give mortar flow in the range of 105 to 115 .

C109 specifies $50-\mathrm{mm}$ (2-in) test cubes be compacted by tamping in two layers. The cubes are cured one day in molds and stripped from the molds and tested or immersed in lime water until tested in compression at 3,7 , and 28 days. Compressive strength is calculated by dividing the total maximum load by the cross-sectional area of the cube.

Causes of variation in test results related to equipment have been identified by Bean and Dise [8.12]. Problems with molds are related to lack of planeness of interior faces: failure to keep corners of molds clean; types and amounts of release agents; and inadequate sealing of molds. Inadequate design and maintenance of testing machines also cause variations in test results. Procedural type problems include use of incorrect amounts of cement or sand; variations in tamping pressures; improper positioning of the specimen in the testing machine; failure to zero the testing machine properly at the start of test; improper rate of loading of specimens; and errors in reporting test results. Another variation to consider is the air content of the mortar; higher air contents give lower strengths.

\subsubsection{Statistical Presentation of Data}

Figure 4.6 is a sequential box plot of the 3-day compressive strength results for the first 72 CCRL Portland Cement proficiency samples, and Figure 4.7 presents the same data sorted on median values. Figure 4.8 shows the sequential 7-day compressive strength data, and Figure 4.9 the sorted 7-day compressive strength data.

4.4.3 Observations

4.4.3.1 3-Day Compressive Strength

a. Figure 4.6 shows strengths of Type III cements to 


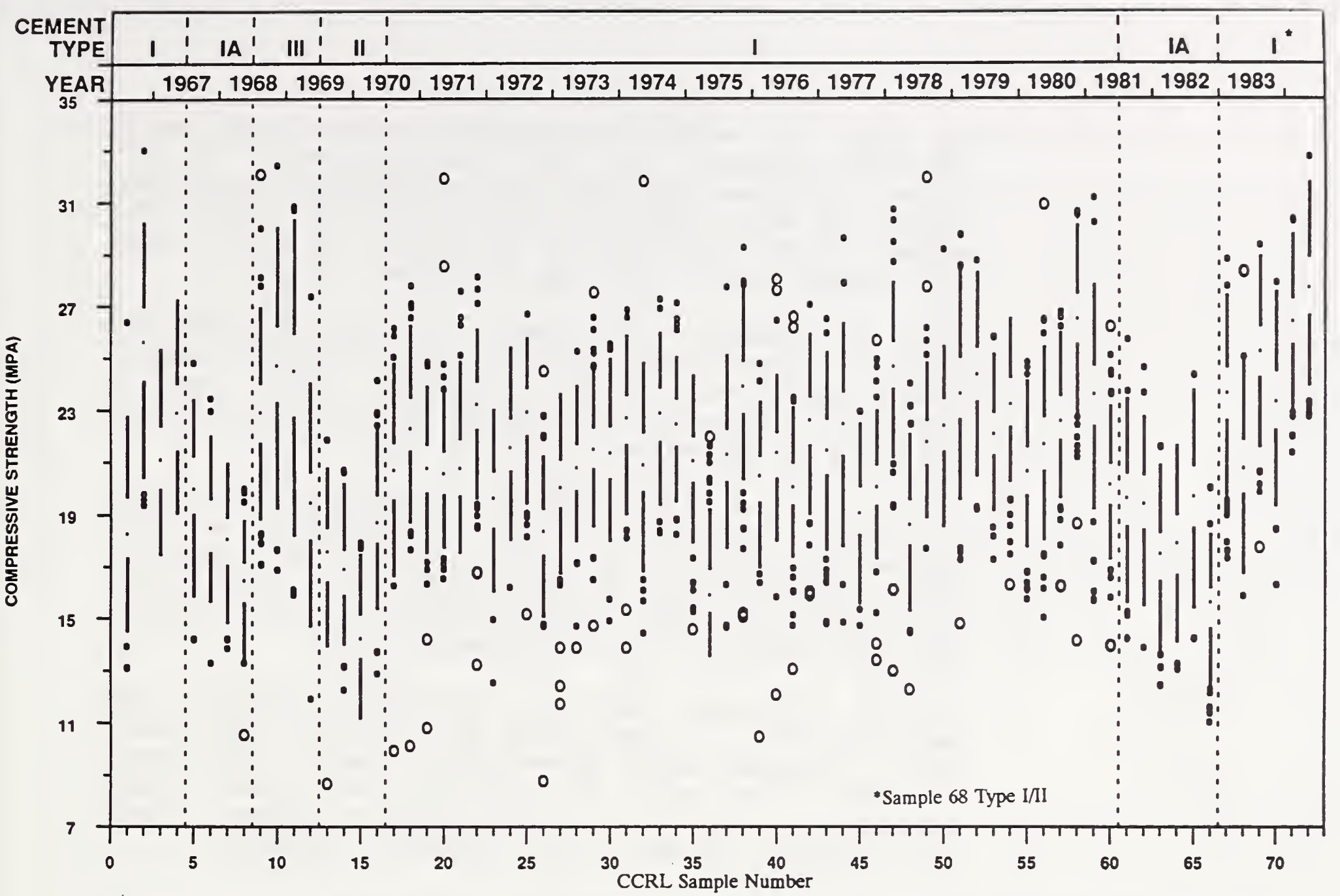

Figure 4.6 Sequential Box Plot of 3-Day Compressive Strength (ASTM C109) Test Results in the Order the Portland Cement Samples Were Distributed By CCRL

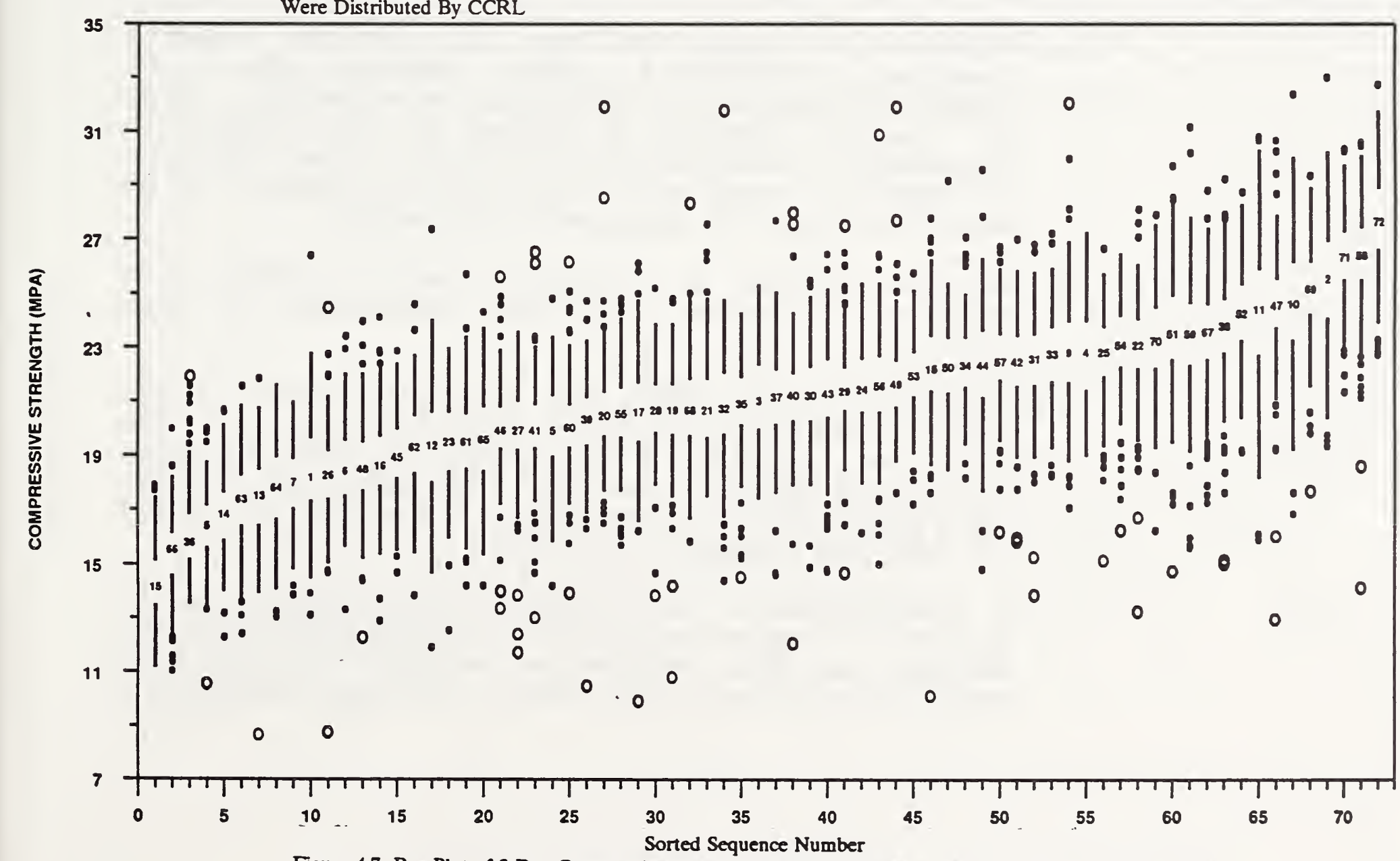

Figure 4.7 Bax Plot of 3-Day Compressive Strength (ASTM C109) Test Results Sorted on Median Values 
be high, as would be expected since high early strength cements are more finely ground [8.14]. Higher fineness increases the strengths of portland cement at early ages and up to about 28 days. The effect is most pronounced at ages of 10 to 20 hours and diminishes as the age increases [8.13].

Type II cements are lower in 3-day compressive strength than Type I cements, and Type IA cements have lower compressive strength than Type I cements. This is consistent with the standard physical requirements in Table 3 of C150-92.

b. Figure 4.6 indicates gradually increasing strengths of Type I portland cements distributed by CCRL between 1966 and 1984. As a test of this apparent visual trend, a least squares fit of a line to the sequential ordered medians shows a significantly non zero slope at the 95 percent level.

c. Figure 4.7 shows that the available range in the data is from $11 \mathrm{MPa}(1600 \mathrm{psi})$ to $31.7 \mathrm{MPa}(4600$ psi.) The IQ range generally extends from about $1.4 \mathrm{MPa}(200 \mathrm{psi})$ to $2.8 \mathrm{MPa}$ (400 psi), with samples 2 , 10 and 11 having larger ranges. Note that samples 10 and 11 are Type III cements.

\subsubsection{7-Day Compressive Strength}

a. Figure 4.8 shows the Type IA portland cements (samples 5 through 8 , and 61 through 66) to be lower in compressive strength as expected. Type III cements (samples 9 through 12) are higher in compressive strength than the other types, and Type II cements (samples 13 through 16) appear to be somewhat lower in compressive strength.

b. Figures 4.8 and 4.9 display fewer outliers than many of the other variables considered in this study.

c. Figure 4.9 shows that the available range in the data varies from $17.9 \mathrm{MPa}(2600 \mathrm{psi})$ to $41.4 \mathrm{MPa}$ (6000 psi) when ignoring sample 66. The IQ range fluctuates between $2.1 \mathrm{MPa}(300 \mathrm{psi})$ and $3.4 \mathrm{MPa}$ (500 psi) with some funneling. Samples 2,10 and 17 have the largest IQ ranges.

d. A preponderance of lowliers over highliers in Figure 4.9 may be explained as a cube-mold problem. It may be that successive wearing on the mold provides specimens with convex surfaces causing the 


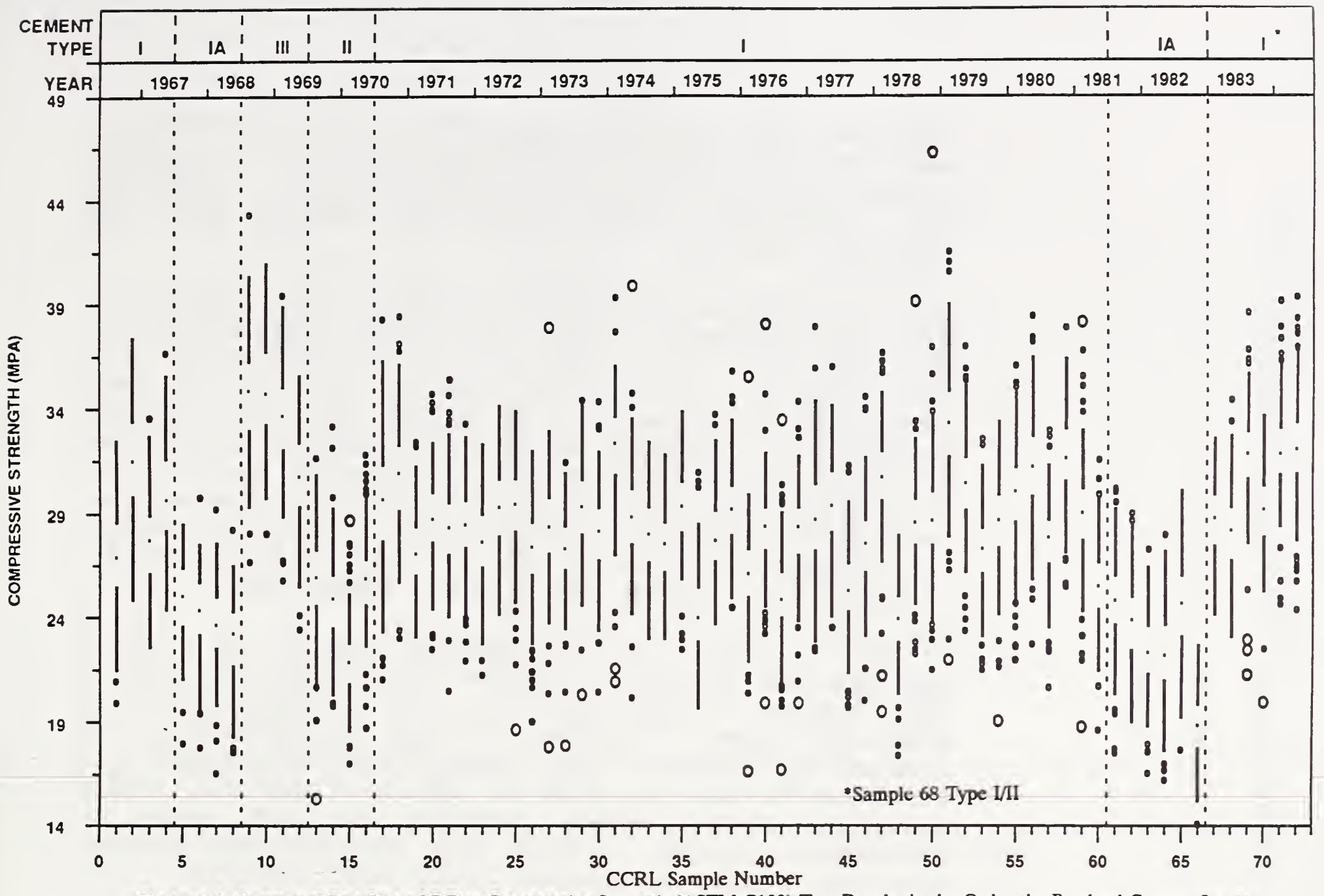

Figure 4.8 Sequential Box Plot of 7-Day Compressive Strength (ASTM C109) Test Results in the Order the Portland Cement Samples Were Distributed By CCRL

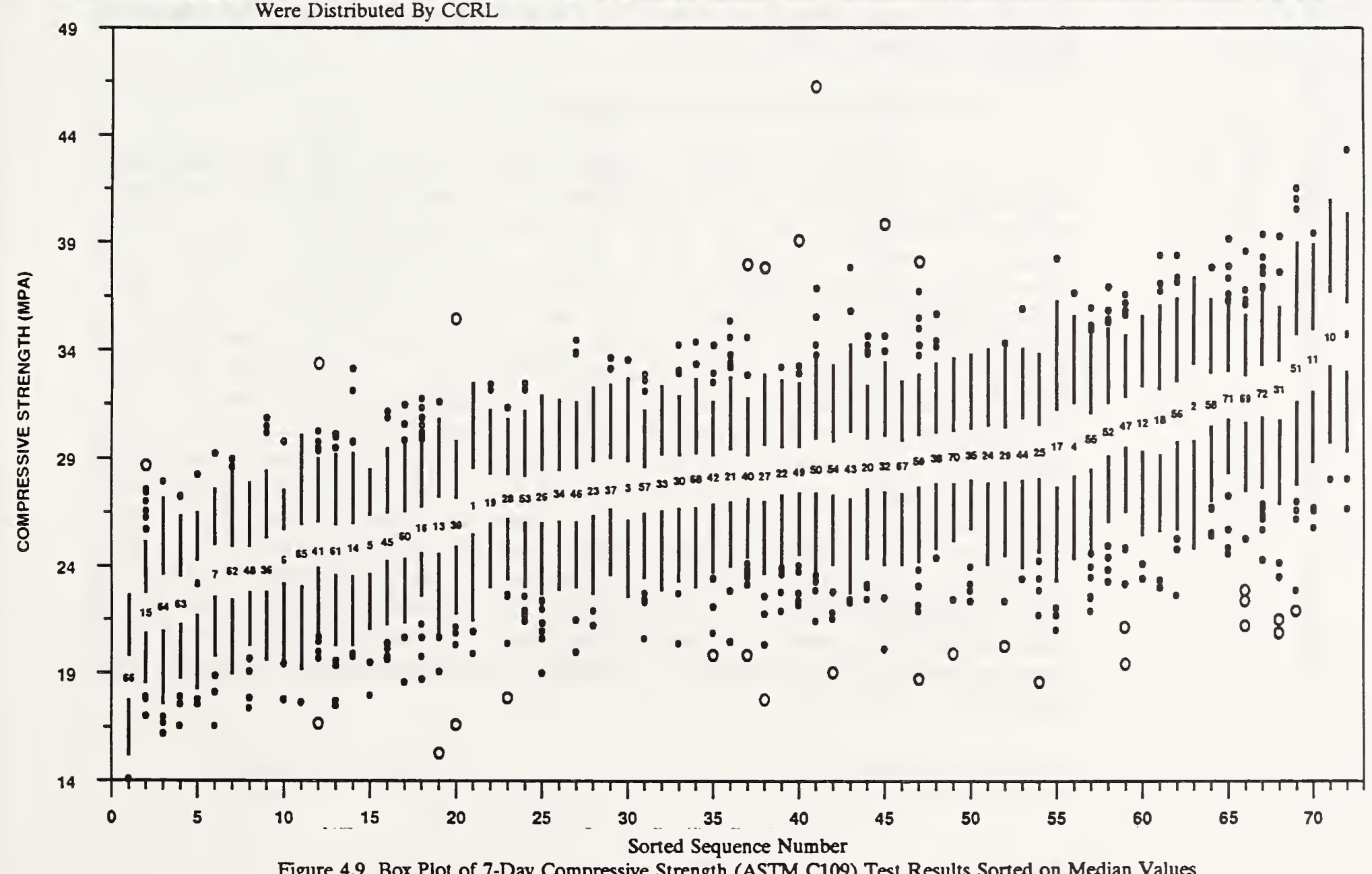

Figure 4.9 Box Plot of 7-Day Compressive Strength (ASTM C109) Test Results Sorted on Median Values 
applied test load to bear on a smaller crosssection resulting in premature failure. Another cause may be nonplane bearing blocks. Section 4.4.1 provides other possible reasons for low strength results.

This is further amplified by Figure 4.10 which is a plot of skewness of the test data represented by the position of medians within the IQ range for each sample. Considering the IQ range as 100 per cent, the lowest point as 0 percent and the highest point as 100 percent, any intermediate point can be represented as the percentage of the IQ range. For example, if the $I Q$ range is 12 units and the median is 3 units above the lowest point, the position of the median is $3 / 12$ or 25 per cent. Skewness is indicated by values other than 50 per cent.

Figure $4.10(\mathrm{a})$ is a skewness plot of 3-day compressive strength results in sequential order, and Figure $4.10(\mathrm{~b})$ is the same data sorted on median values. Figures $4.10(\mathrm{c})$ and $4.10(\mathrm{~d})$ are similar plots for 7-day compressive strength. A skewness to the low side is apparent for the 3-day results, while 7-day results do not show a consistent trend. This may be due to convex specimen surfaces causing lower test results.

4.5 Standard Test Method for Air Content of Hydraulic Cement Mortar (ASTM C185) [8.7]

\subsubsection{Discussion of Test Method}

In the 1930's it was noted that the use of calcium chloride to melt ice on highways constructed of concrete often resulted in serious surface scaling [8.17]. This scaling was caused by water penetrating into the concrete, freezing and expanding. Eventually, it was found that air bubbles entrained in the concrete provided cushioning for the expansion of water due to freezing and thereby improved concrete durability. This led to the development of various air entraining agents for intergrinding with the cement or as an addition to the concrete mix. Such materials reduce the surface tension of water and form very small air bubbles in the concrete mix which increase frost resistance, improve the workability, and reduce segregation and bleeding. Two characteristics of portland cement are known to influence air entrainment; an increase in cement fineness or a decrease in cement alkali content generally increase the amount of air entraining agents required for a given air content. $[8.13]$ 


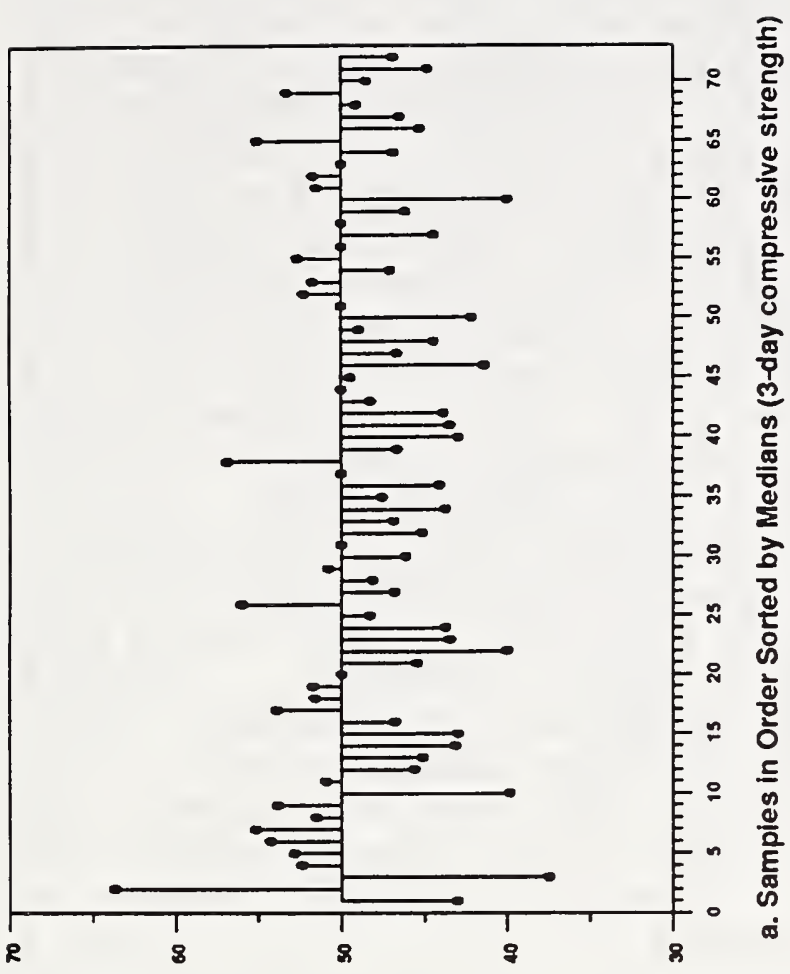

JONVY OI NI NOULSOd NVIOaW - $\%$

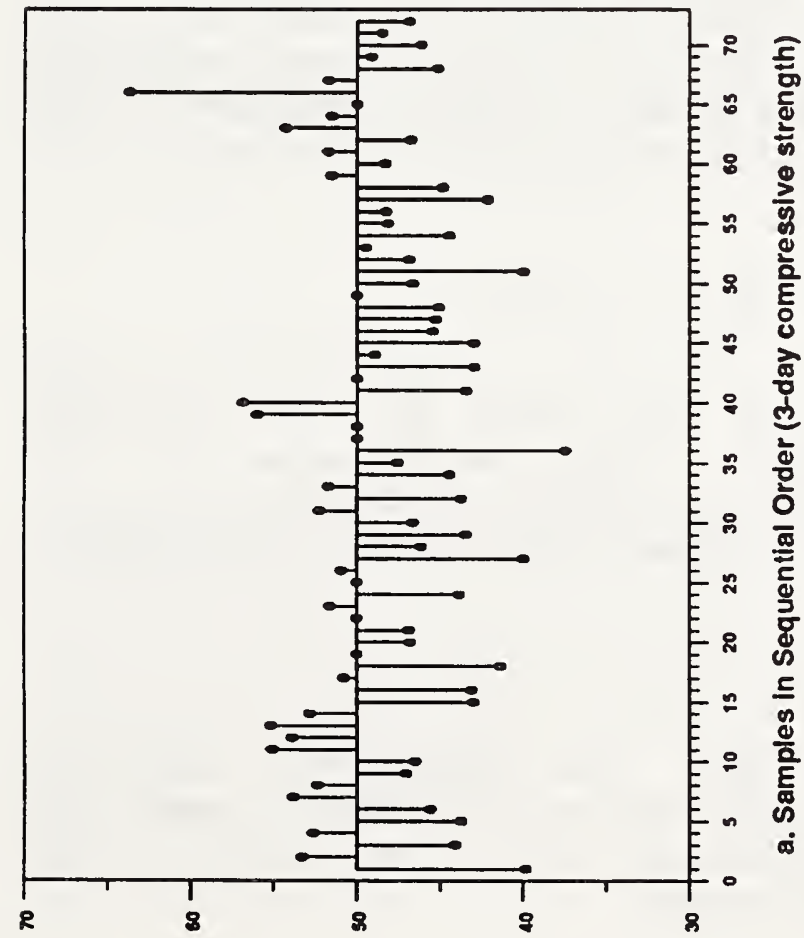

JONVY OI NI NOLISOd NVIOJW - $*$

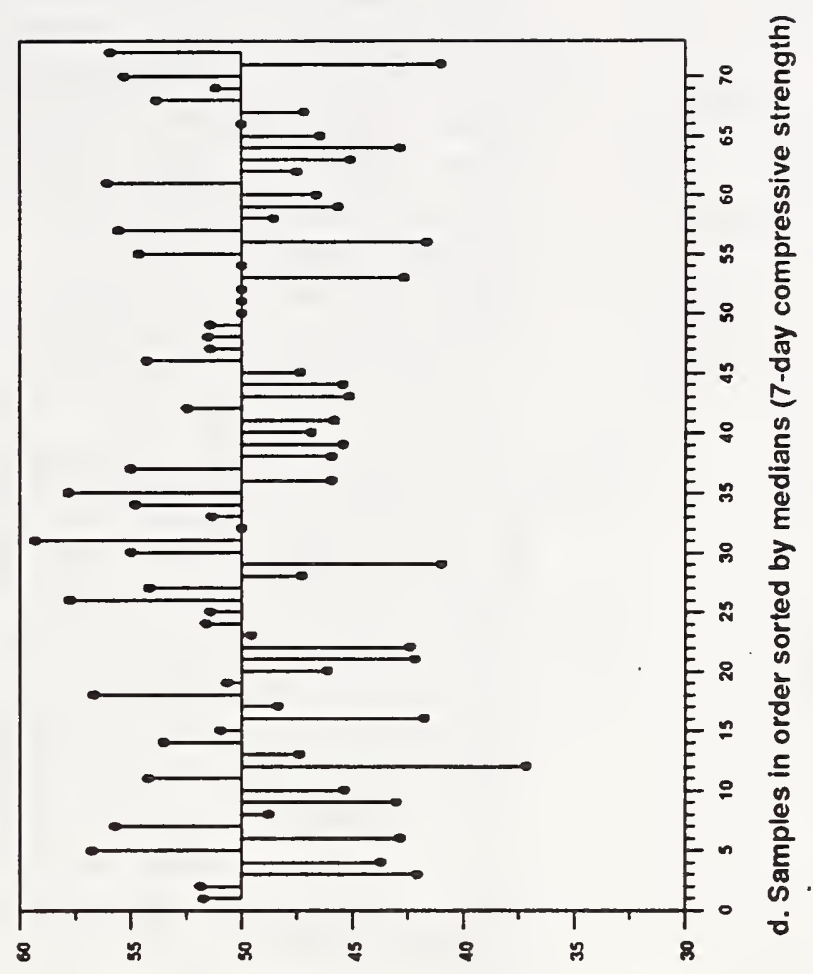

3ONYY OI NI NOUISOd NVICכM - \%

ํํำ

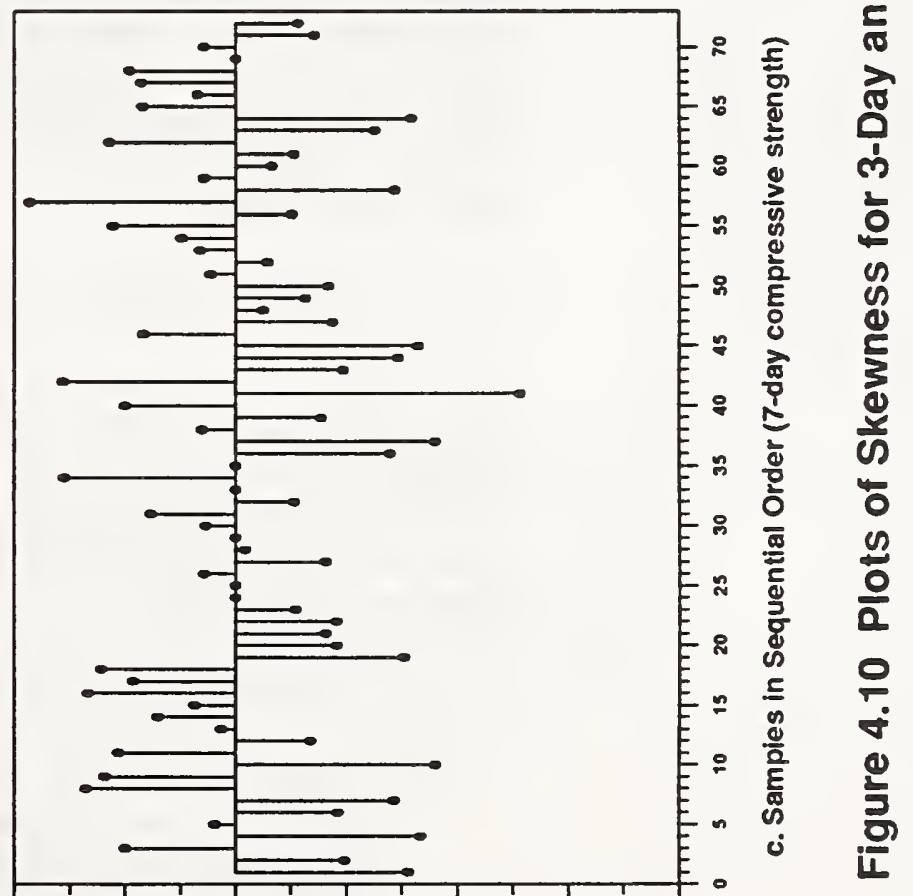

JONVY OI NI NOUISOd NVICGW • * 
ASTM Test Method C185 was first adopted in 1944 in response to the need for a rapid test for determining the air-entrainment characteristics of both air-entraining and non air-entraining hydraulic cements. The method is used to decide whether or not a hydraulic cement under test meets the air-entraining or non air-entraining requirements of the specification for which the test is being performed. The procedure provides for the determination of the air content of machine mixed mortar. Mortar is prepared using $350 \mathrm{~g}$ of cement and $1400 \mathrm{~g}$ of 20 30 standard sand with a sufficient quantity of water to give a flow of 87.5 per cent \pm 7.5 percent when determined using ASTM C185. The mortar is compacted into a 400-ml measure and its mass determined. It is important that the mortar uniformly fill the measure. Prior to october 1988, the prescribed method of working the mortar into the measure was to spade around the circumference of each layer with a spatula. C185-88 changed the mortar compaction method to tamping. (All CCRL samples included in this study were spaded.) The air content is calculated from the measured density of the mortar, the known densities of the constituents, and the mixture proportions. The air content value is reported to the nearest percent.

Bean and Dise [8.12] report that variation in test results may be caused by 400-ml measures which do not conform to the requirements, or use of a balance with an inadequate capacity. Test procedure problems may be caused by use of an incorrect amount of cement; sand or water; failure to place mortar gently in the measure; failure to observe specified time limits on test operations; improper handling of the 400-ml measure; failure to use specified equipment in performance of the test; variations in mass determinations; and errors in calculations.

\subsubsection{Statistical Presentation of Data}

Figure 4.11 is a sequential box plot presentation of the air content test results for the first 72 CCRL Portland Cement proficiency samples. The percentages of air content are plotted by sample number. Figure 4.12 is a plot of percentages of air content with samples sorted on median values.

\section{5 .3 Observations}

a. Figure 4.11 shows that, as expected, the air content of Type IA air-entrained cements (samples 5 through 8 , and 61 through 66) to be higher than other cements in the study. 


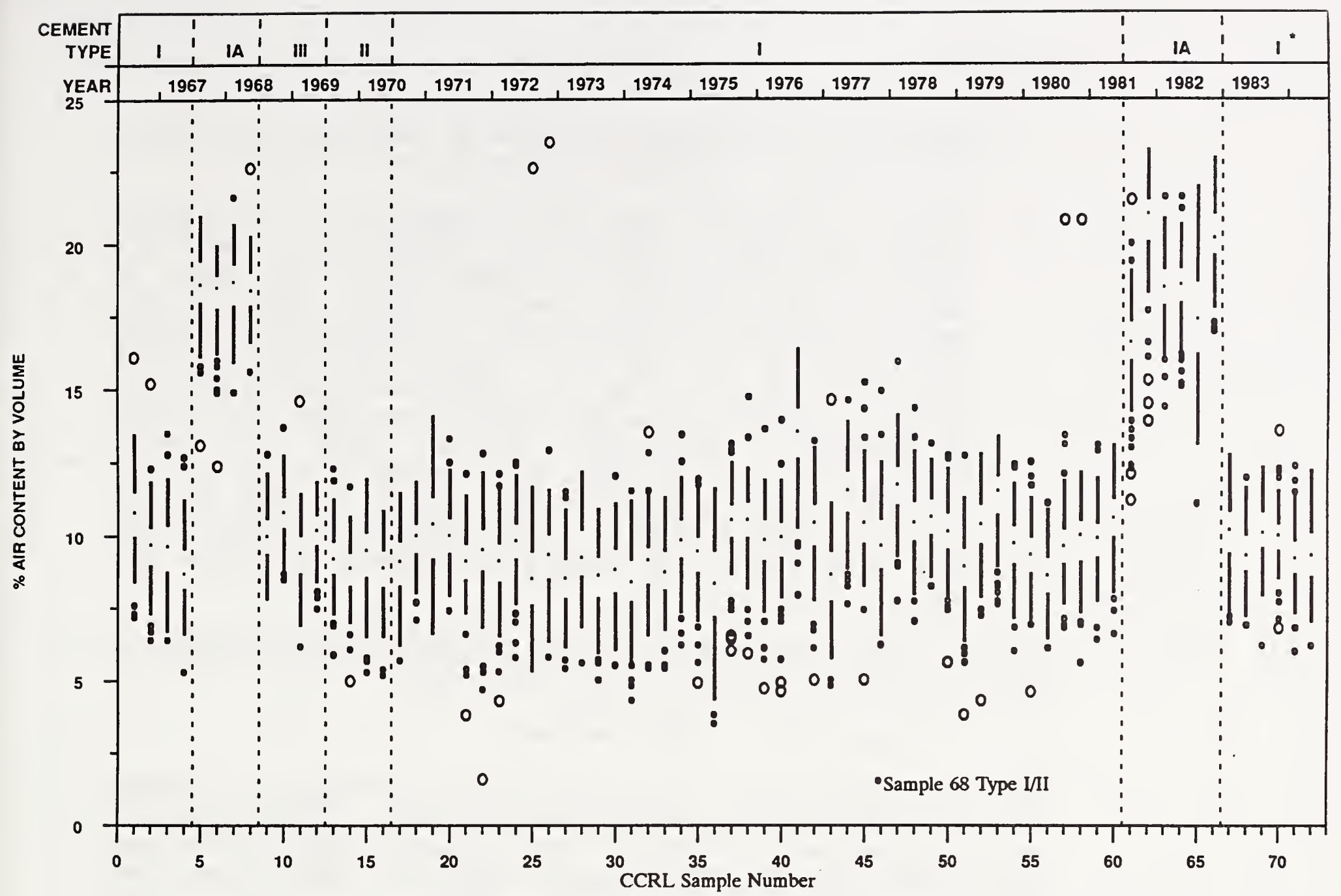

Figure 4.11 Sequential Box Plot of Air Content (ASTM C185) Test Results in the Order the Portland Cement Samples Were Distributed

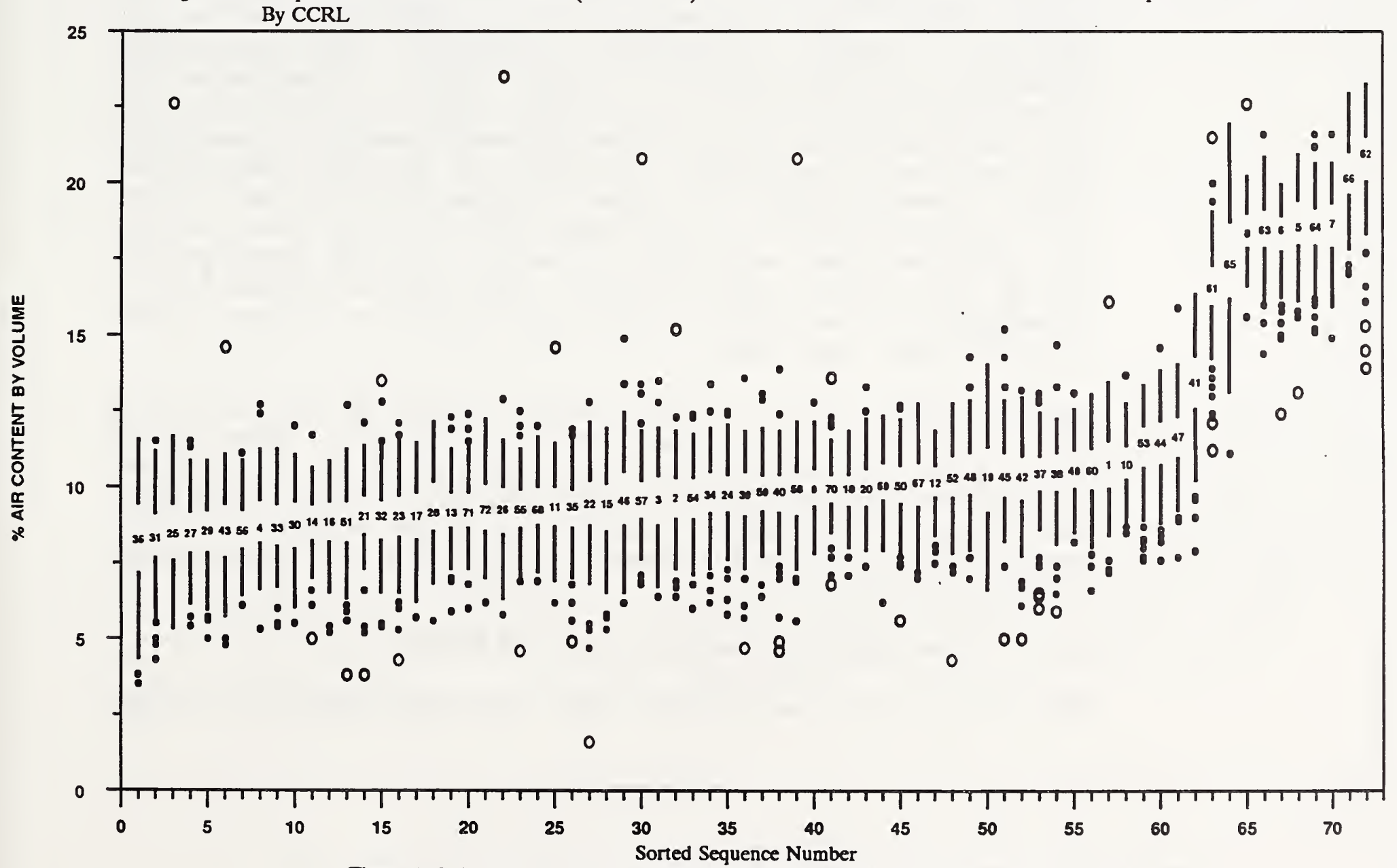

Figure 4.12 Box Plot of Air Content (ASTM C185) Test Results Sorted on Median Values 
b. Samples 17 through 60 (Type I cements) in Figure 4.11 seem to exhibit an oscillatory pattern.

c. Figure 4.12 shows the Type IA cements to the right, while the other cements are grouped at lower air content values. Cement types other than Type IA show a very gradual, almost linear, rise in the median values of air content. The available range in the data for Type I, II and III cements runs from 4 to 16 percent, and the available range in the air content data for Type IA cements from 13 to 23 percent. Typically, the IQ range fluctuates between 1 and 2 percent (excluding samples 19, 36 and 65$)$. New consolidation methods in C185-88 may affect future results. CCRL samples 95 and 96 are the first pair of samples effected by this new consolidation method.

4.6 Standard Test Method for Time of Setting of Hydraulic Cement By Vicat Needle (ASTM C191) [8.7]

\subsubsection{Discussion of Test Method}

The chemical changes involved in the setting of cements are distinguished by two points in time. "Initial set" is the time when a partial loss of plasticity occurs and "final set" is when the cement resists a specified load without penetration. ASTM C191, the current test method (ASTM C191) for determining the time of setting of hydraulic cement, specifies equipment and procedures developed in 1818 by L. J. Vicat. [8.12] Specimens are molded and cured according to ASTM Methods C191 and C511, and the penetration of a $1-\mathrm{mm}$ flat-end needle is measured initially at 30 minutes, and every 15 minutes thereafter until a penetration of $25 \mathrm{~mm}$ or less is obtained. When a $25 \mathrm{~mm}$ penetration is not obtained exactly, the results are interpolated, with the time of a $25 \mathrm{~mm}$ penetration being the initial time of set. The time of final set is recorded at the point where the needle no longer sinks visibly into the paste.

Bean and Dise [8.12] report that causes of variation in the C191 method may be poor condition of the vicat apparatus; use of oil on the vicat ring to facilitate removal of hardened paste; and failure to completely fill the Vicat ring with paste. Other causes may be contaminants in the mix water or from the surfaces of the mixer.

\subsubsection{Statistical Presentation of Data}

Figure 4.13 is a sequential box plot presentation of time 


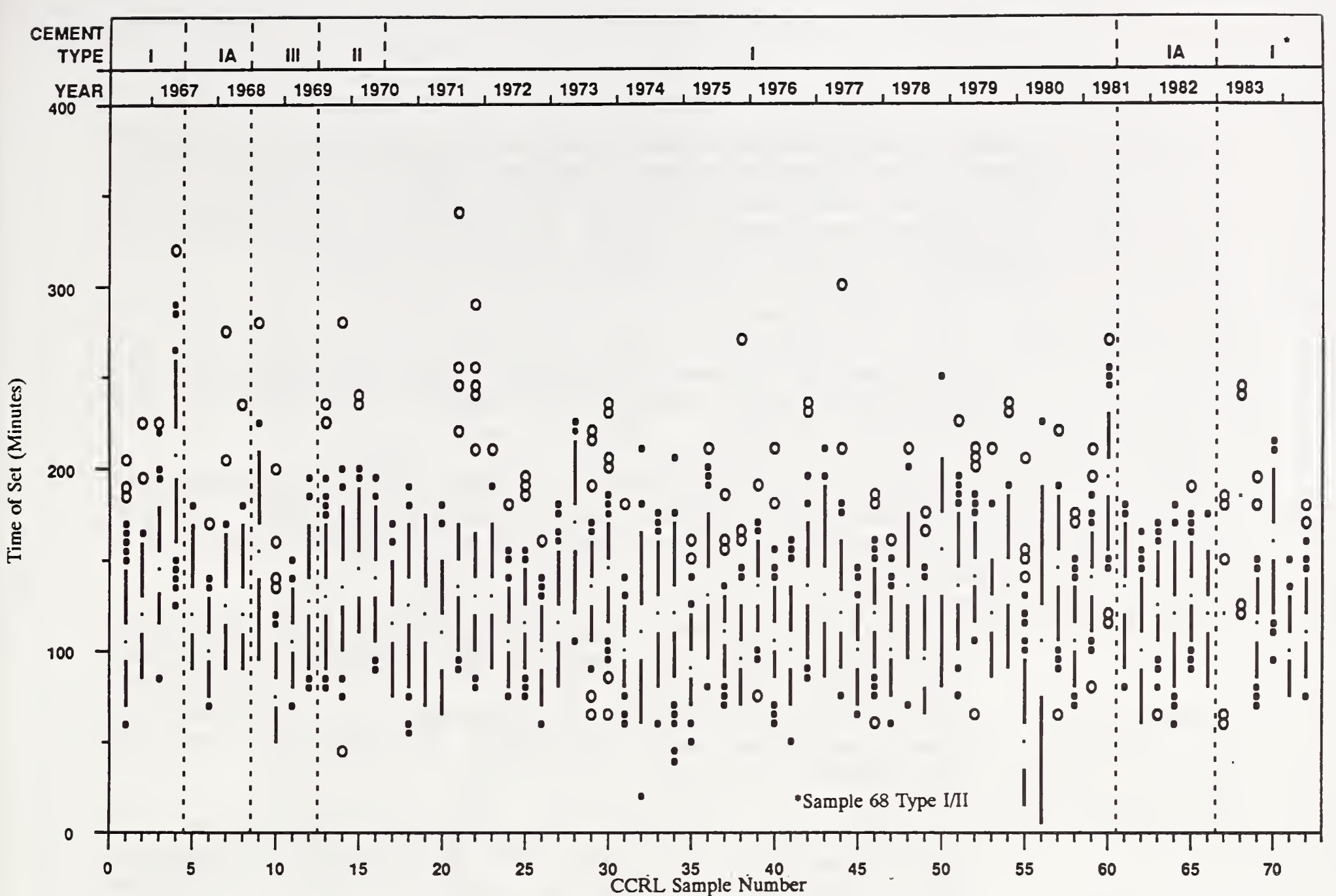

Figure 4.13 Sequential Box Plot of Initial Vicat Time of Set (ASTM C191) Test Results in the Order the Portland Cement Samples Were Distributed By CCRL

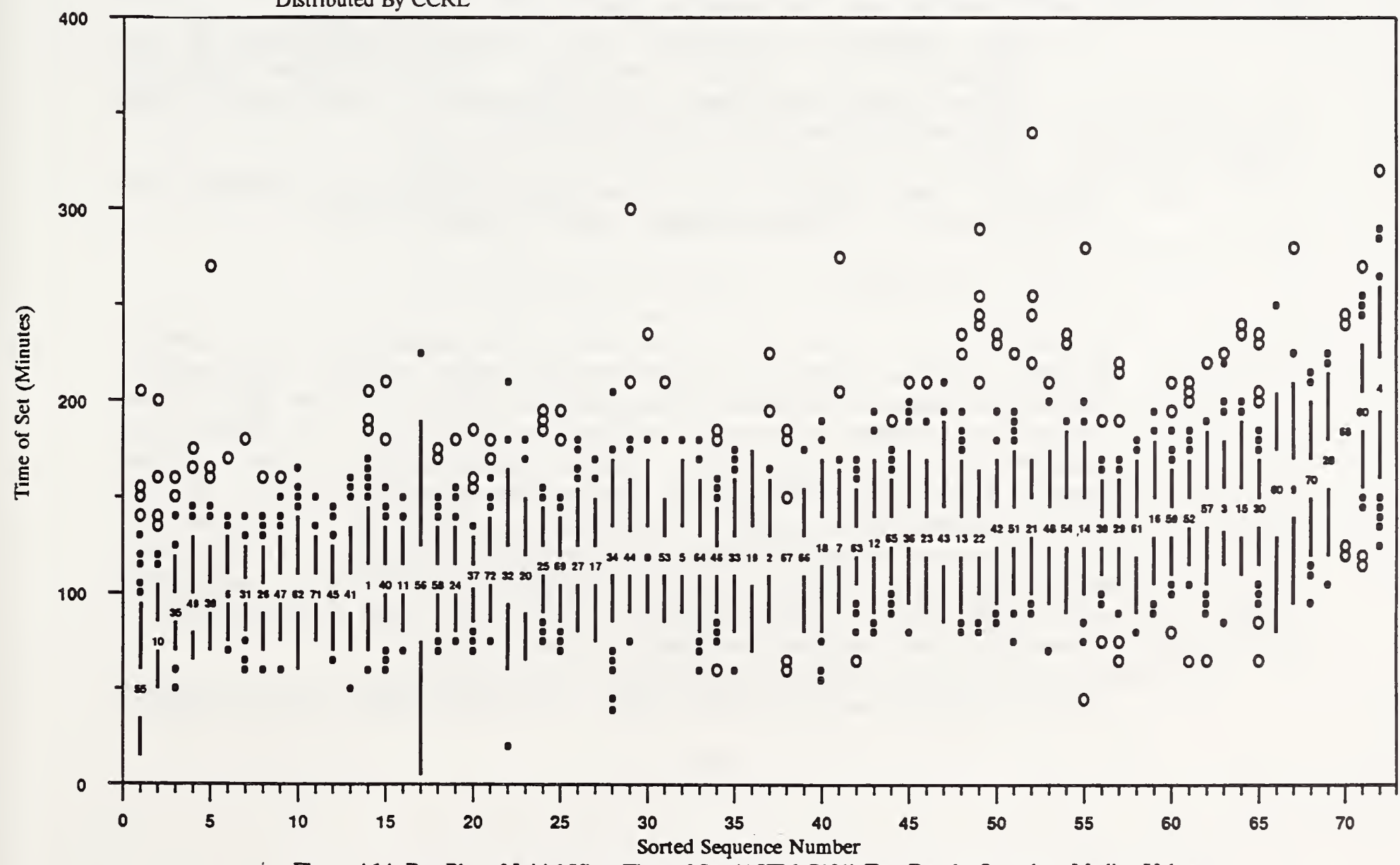

Figure 4.14 Bax Plot of Initial Vicat Time of Set (ASTM C191) Test Results Sorted on Median Values 
of set results for the first $72 \mathrm{CCRL}$ portland cement proficiency samples. The minutes required to attain the initial set are plotted by sample number. Figure 4.14 is a similar plot except that the initial set times are plotted by samples sorted on median values.

\section{6 .3 Observations}

a. Figure 4.13 shows no distinguishing trends for the different types of portland cements included in the study.

b. Figure 4.14 shows a definite stepping or plateauing, which is a discretization effect because Vicat values are reported to the nearest 5 minutes.

c. Figure 4.14 shows considerably more highliers than lowliers. The mix water may contain hydration inhibitors which may account for the highliers. The available range of data for initial time of sets is from approximately 10 minutes to 260 minutes.

d. Figure 4.14 shows a typical IQ range of approximately 15 minutes for the first 17 samples, and a typical IQ range of approximately 20 minutes for subsequent samples.

e. The unusual patterns for samples 67 and 68 in Figure 4.14 result because laboratories testing these specimens reported only seven different time of set values for each sample.

4.7 Standard Test Method for Fineness of Portland Cement by Air Permeability Apparatus (ASTM C204) [8.7]

\subsubsection{Discussion of Test Method}

Fineness, or specific surface, of cement is a major factor in the rate of reaction between cement and water. Fineness has a definite bearing on many of the qualities of cement paste, mortar and concrete. The fineness of cement in a concrete mix influences its water requirements, workability and ease of placement. [8.13] An increase in cement fineness results in increases in cohesiveness, strength (particularly early strength), workability, and impermeability (which improves resistance to freezing and thawing): and decreases in bleeding and autoclave expansion.

Blaine modified earlier work by Lea-Norse to develop a 
test which measures the permeability of a bed of cement by determining the time required for a known volume of air to pass through the compacted bed at a prescribed average pressure. [8.12] The air permeability apparatus consists of a permeability cell and a U-tube manometer filled to the midpoint with a suitable liquid. The test is accomplished by attaching the cell containing a carefully prepared bed of cement to the manometer and evacuating the air in the arm under the cell until the liquid rises to a point just beneath the cell. The liquid is then released, drawing the air through the bed of cement. The time required for the meniscus to fall through a distance of approximately $55 \mathrm{~mm}$ is measured. The specific surface is then calculated from this timeof-flow determination in an apparatus calibrated with NIST Standard Reference Material 114. [8.22] This method for determining the fineness of cement by the air permeability apparatus introduced by Blaine was adopted as ASTM C204 in 1946.

The air permeability fineness test method is economical to perform and can be used to determine the fineness of materials other than portland cement. The method is not suitable for determining the specific surfaces of materials finer than $7000 \mathrm{~cm}^{2} / \mathrm{g}$, or of porous materials such as fly ash.

The following causes of variations in test results for C204 have been identified by Bean and Dise [8.12] and others:

1. A laboratory may modify the standard procedure to compensate for factors particular to its conditions causing variation in results between laboratories.

2. Permeability cells may not conform to the specification requirements.

3. Stopcock lubricants may foul the upper part of the manometer.

4. An incorrect amount of fluid may be used in the manometer.

5. A manometer fluid may be used whose viscosity varies appreciably with changes in temperature.

6. Test procedure errors may include: errors in calibration of the apparatus; cement not at room temperature at time of test; not considering the difference between air temperature at time of test and time of calibration; variations in the volume of the test bed; errors in timing; leakage of air around the outside of the cell during test: variations in cement compaction pressures over time or between techniques; and calculation errors. 


\subsubsection{Statistical Presentation of Data}

Figure 4.15 is a sequentially ordered presentation of box plots of the air permeability fineness test for the first 72 CCRL proficiency samples. The surface area is expressed in $\mathrm{cm}^{2} / \mathrm{g}$ and is plotted by the sample number. In Figure 4.16 samples are sorted on median values of air permeability fineness.

\section{$4 \cdot 7.3$ Observations}

a. Figure 4.15 shows Type III cements (samples 9 through 12) having higher fineness than other cements in the study. This is expected since high early strength cements are ground finer. Also, sample 66 has high fineness values. Overall, there are a fair number of outliers, generally balanced, although with perhaps a slight preponderance of lowliers. There appears to be a gradual rise in fineness, consistent with the fact that cements have been ground finer over time. It should be noted that NIST standard Reference Material 114 (Portland Cement Fineness), which is used to calibrate the air permeability apparatus, has changed in fineness over time which may affect this trend in some small way.

b. Figure 4.16 shows that no funneling on the IQ ranges except for the Type III cements, which are represented by four of the last five samples.

c. Figure 4.16 shows the non-Type III cements present an available range of data from 2800 to $4400 \mathrm{~cm}^{2} / \mathrm{g}$. The available range of data for Type III cements is from 4200 to $6700 \mathrm{~cm}^{2} / \mathrm{g}$. The IQ ranges extend from 70 to $110 \mathrm{~cm}^{2} / \mathrm{g}$ for the non-Type III cements.

4.8 Standard Test Method for Fineness of Portland Cement by the Turbidimeter (ASTM C115) [8.7]

\subsubsection{Discussion of Test Method}

L. A. Wagner presented a method of test for fineness of portland cement by the turbidimeter in 1933 and the method was adopted as a standard ASTM test for cement in $1934 .[8.23]$

The Wagner Turbidimeter consists essentially of a source of light maintained at constant intensity and adjusted so that approximately parallel rays of light pass through a suspension of the cement to be tested and impinge upon the sensitive plate of a photoelectric cell. The current 


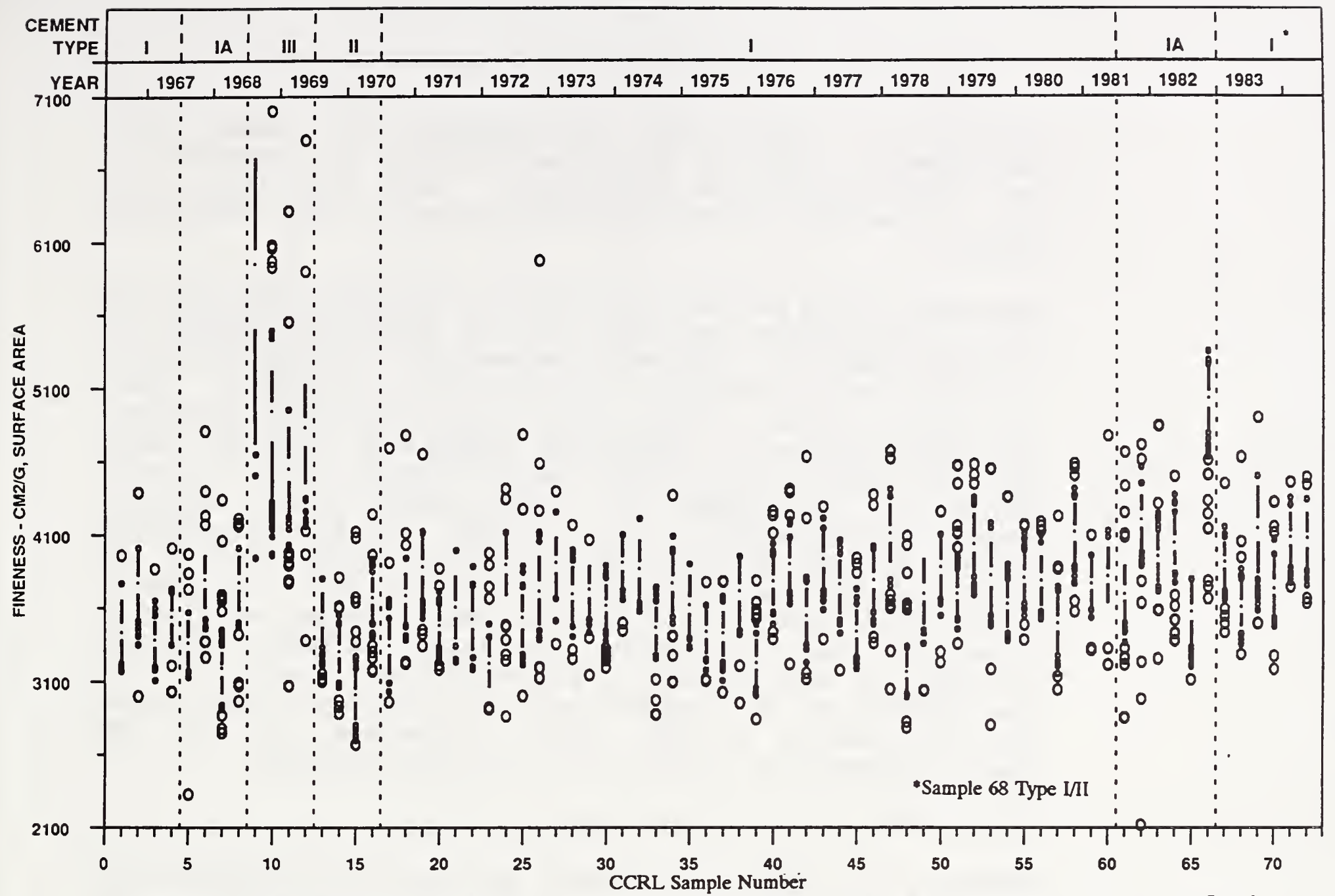

Figure 4.15 Sequential Box Plot of Fineness by Air Permeability (ASTM C204) Test Results in the Order the Portland Cement Samples Were Distributed By CCRL

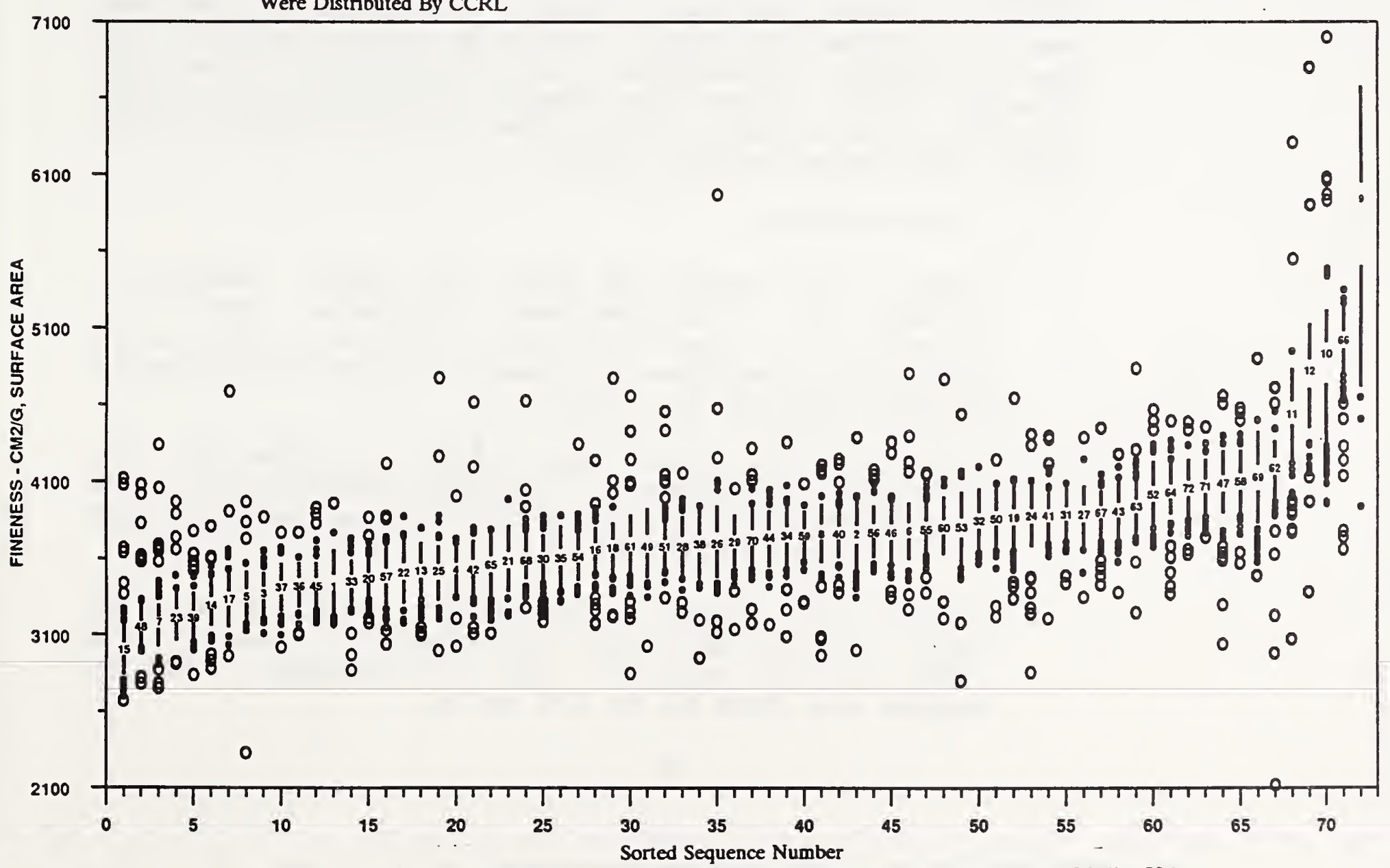

Figure 4.16 Box Plot of Fineness by Air Permeability (ASTM C204) Test Results Sorted on Median Values 
generated in the cell is measured by means of a microammeter and the indicated reading is a measure of the turbidity of the suspension. The turbidity is in turn a measure of the surface area of the suspended cement.

The test method provides a means for determining particle size distribution as well as the specific surface of portland cements. However, the method is quite dependent on satisfactory maintenance of the test equipment. Bean and Dise [8.12] point out the following possible apparatus problems: apparatus improperly mounted; water cell in poor condition; sedimentation tank in poor condition; reflection of light from bright surfaces inside turbidimeter case; trouble in the electrical system; trouble with the microammeter; variations in the character of the suspension; trouble with the timing buret; and problems with the wet sieving apparatus. Potential test procedure problems include improper cleaning of tank prior to starting test; variations in the agitation of suspensions; fouling of tank faces during handling of the tank; variations in the wet sieving operation; and errors in calculations.

\subsubsection{Statistical Presentation of Data}

Figure 4.17 is a sequential box plot of fineness as measured by the Wagner Turbidimeter for the first $72 \mathrm{CCRL}$ portland cement samples. Figure 4.18 depicts the same results plotted by samples sorted on median values. For the 72 samples, an average of 85 laboratories reporting fineness data using the wagner Turbidimeter (C115) compared to an average of 181 laboratories reporting data using the Blaine Method (C204).

\section{8 .3 Observations}

a. Figure 4.17 shows the Type III cement (samples 9 through 12) distributions displaced upward in comparison to the other cement types. This is as expected since Type III cements are ground finer to achieve high early strength.

b. Figure 4.17 shows that Type I cements have gradually increased in fineness over time. (See section 4.7 .3 where similar fineness results were noted using ASTM C204).

c. Figure 4.18 shows an available range of data of 1500 to $2500 \mathrm{~cm}^{2} / \mathrm{g}$ for non-Type III cements, and 2250 to $3100 \mathrm{~cm}^{2} / \mathrm{g}$ for Type III cements. The IQ ranges are from 80 to $130 \mathrm{~cm}^{2} / \mathrm{g}$. 


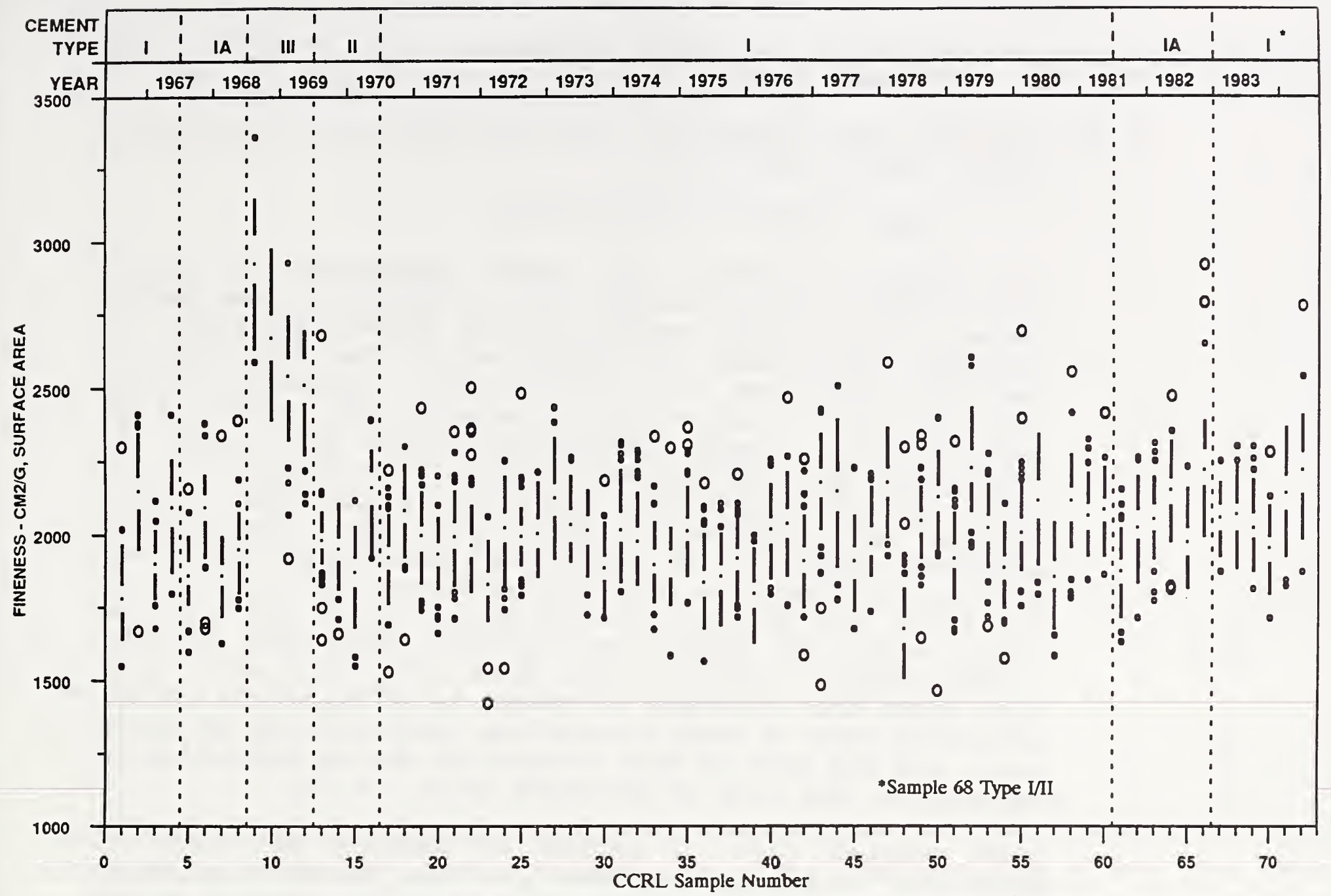

Figure 4.17 Sequential Box Plot of Fineness by Turbidimeter (ASTM C115) Test Results in the Order the Portland Cement Samples Were

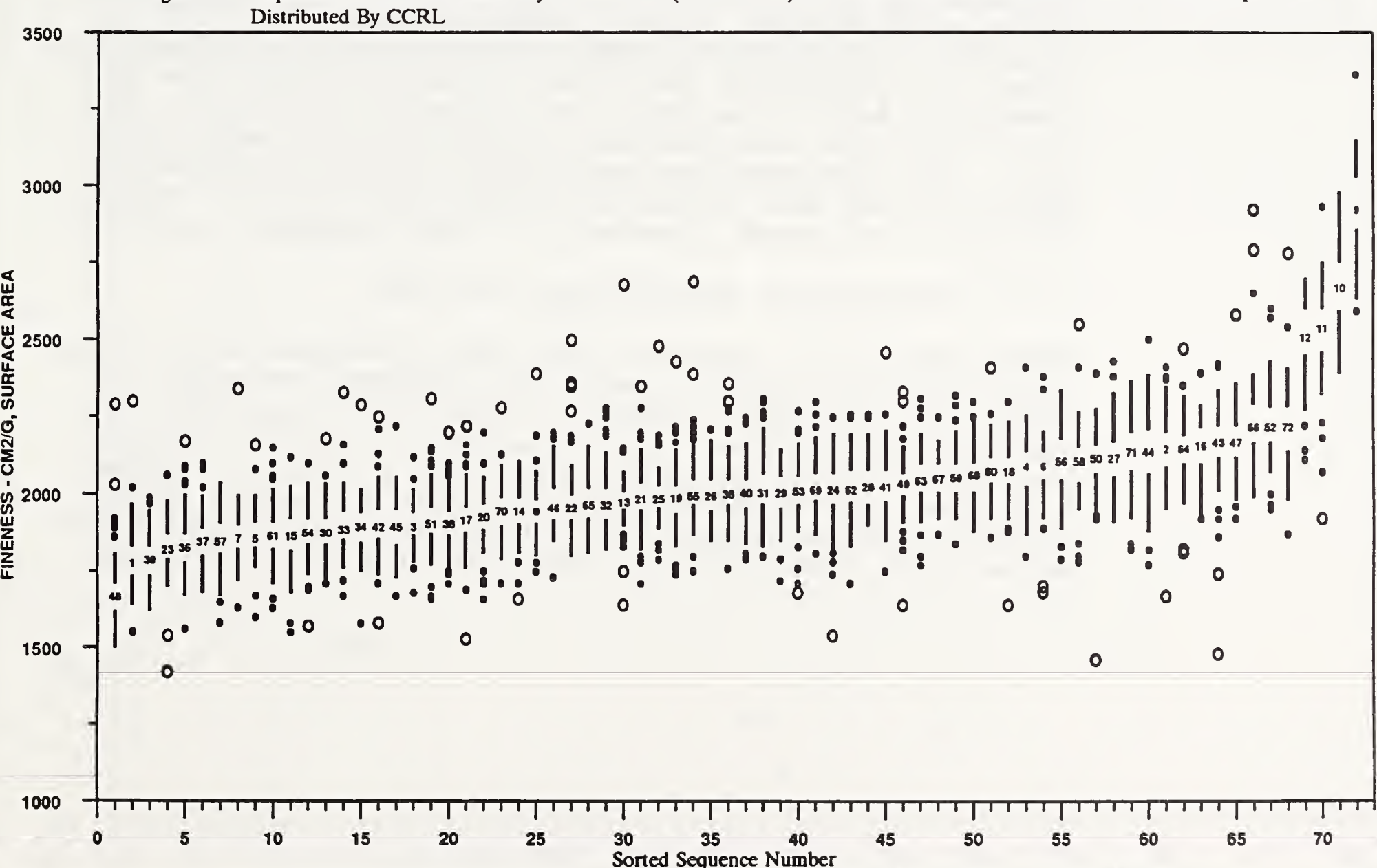

Figure 4.18 Box Plot of Turbidimeter Fineness (ASTM C115) Test Results Sorted on Median Values 
d. Figure 4.18 shows funneling for samples with fineness greater than $2000 \mathrm{~cm}^{2} / \mathrm{g}$.

4.9 Standard Test Method for Heat of Hydration of Hydraulic Cement (ASTM C186) [8.7]

\subsubsection{Discussion of Test Method}

The reactions between the cement compounds and water, which result in the setting and hardening of the paste, cause a considerable amount of heat to be liberated. In concrete structures of large mass, the low thermal conductivity of the concrete prevents dissipation of the heat and the mass of the concrete may attain high temperatures. These temperature rises may result in cracking of the concrete when cooling takes place. [8.24] The principle compounds (phases) in portland cement hydrate at different rates yielding considerably different amounts of heat per unit mass hydrated; tricalcium aluminate $\left(C_{3} A\right)$ releases most of its heat in the first day or so, tricalcium silicate $\left(C_{3} S\right)$ in the first week, and dicalcium silicate $\left(C_{2} S\right)$ and calcium aluminoferrite $\left(C_{4} A F\right)$ hydrate more slowly. [8.24] It is also known that fineness of cement is an important factor affecting rate of heat liberation, particularly at early ages, and the rate of heat liberation during hydration is related to the rate of strength gain. [8.13]

ASTM adopted C186, a method of testing for heat of hydration of portland cement, in 1944 based on studies conducted by L. Shartsis and E. S. Newman of the National Bureau of standards. [8.12, 8.25] The current C186-92, is used to determine the heat of hydration of a hydraulic cement by measuring the heat of solution of the dry cement and heat of solution of a separate portion of the cement that has been partially hydrated for 7 and for 28 days. The difference between these values is the heat of hydration for the respective hydrating period. Bogue provides a thorough discussion of this method. [8.24]

\subsubsection{Statistical Presentation of Data}

Figure 4.19 is a sequential box plot presentation of the 7-day heat of solution results for samples 19 through 72 . Heat of solution results were not reported by laboratories for the first 18 samples. Heat of solution results in cal/g are plotted by sample number. Figure 4.20 plots the 7-day heat of solution by sample number sorted on median values. The number of laboratories that tested CCRL samples using C186 was generally less than 30 . 


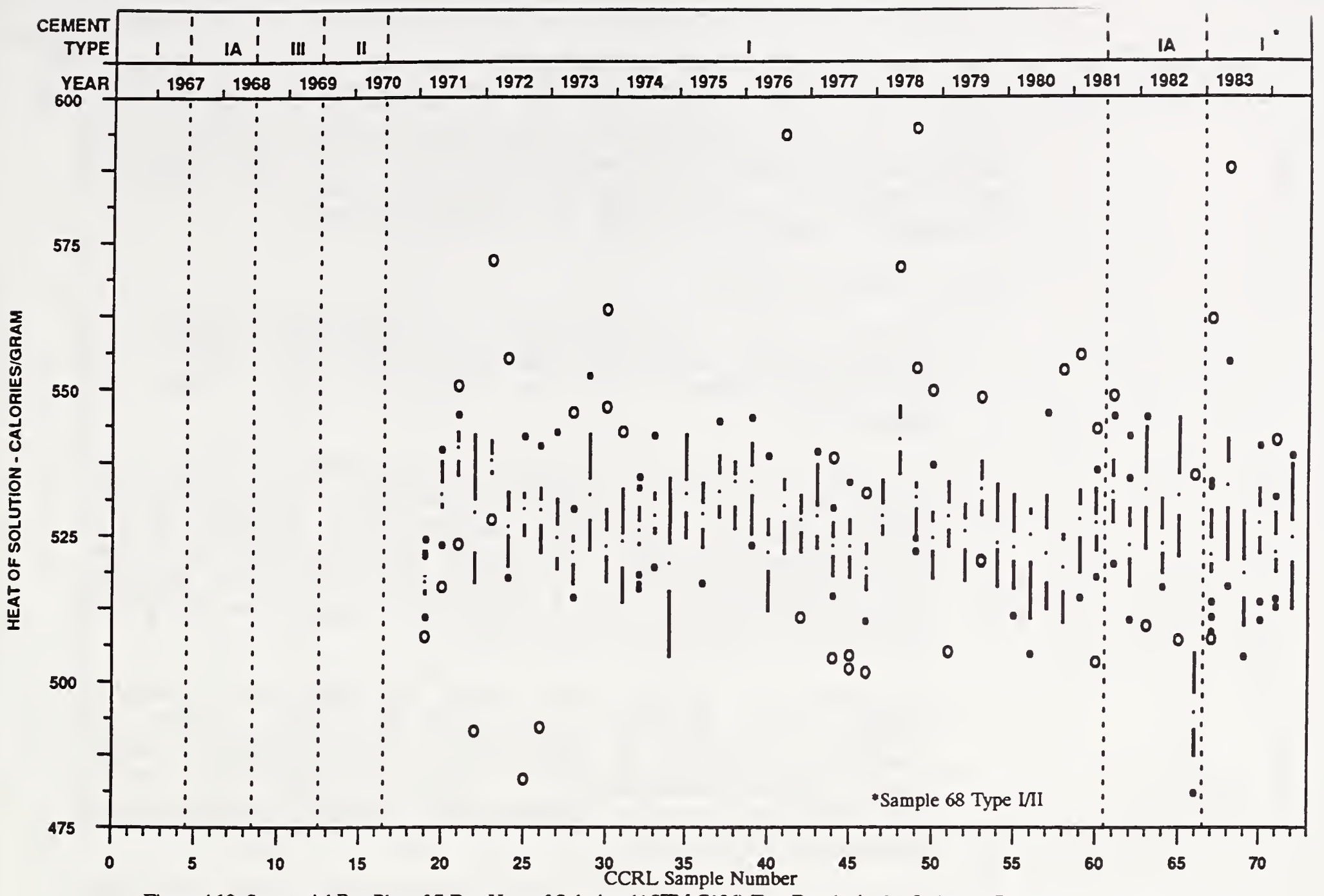

Figure 4.19 Sequential Box Plot of 7-Day Heat of Solution (ASTM C186) Test Results in the Order the Portland Cement Samples Were Distributed By CCRL

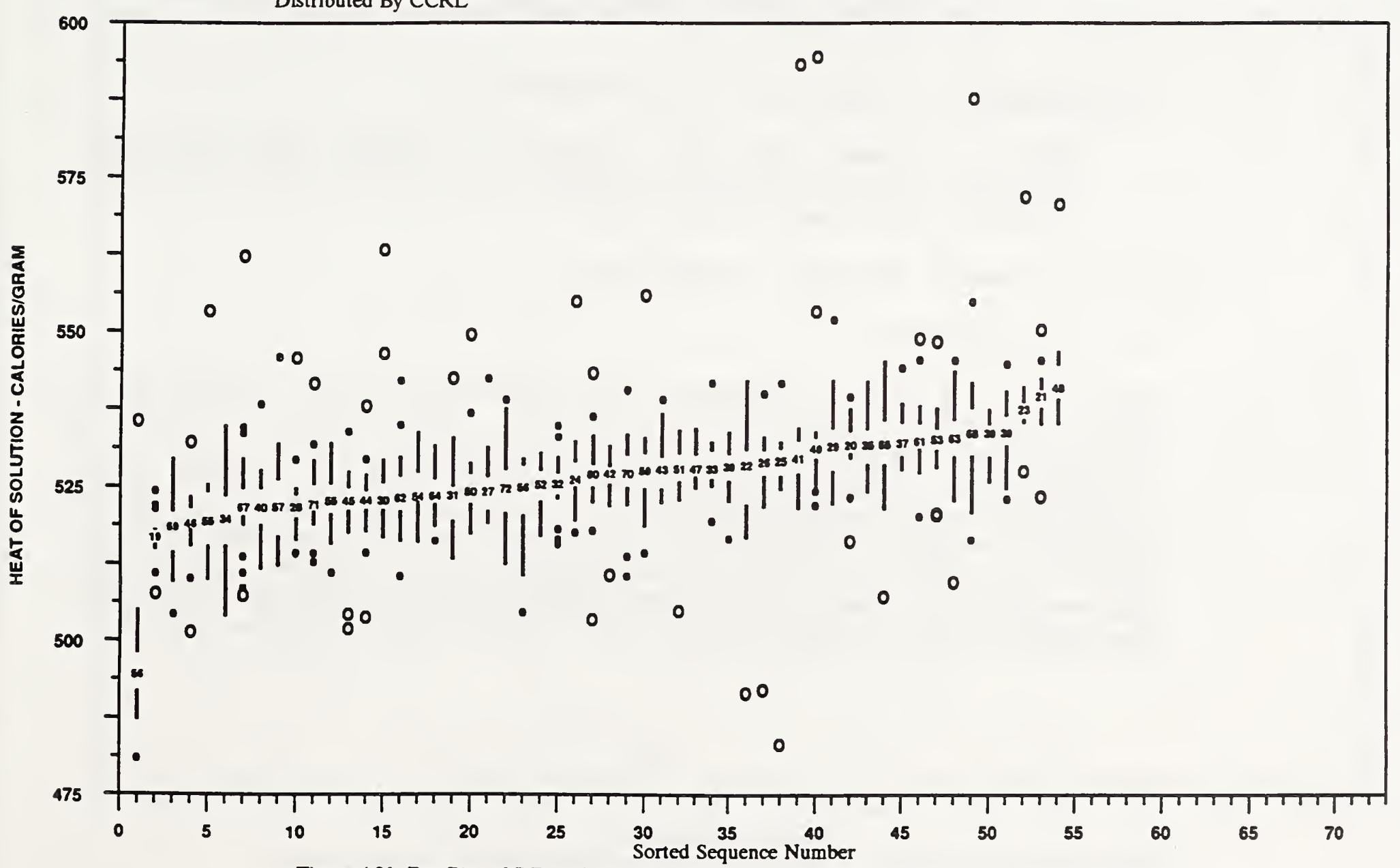

Figure 4.20 Box Plot of 7-Day Heat of Solution (ASTM C186) Test Results Sorted on Median Values 
Figure 4.21 is a sequential box plot presentation of the 7-day heat of hydration results in cal/g for the first 72 CCRL samples. Figure 4.22 depicts the same results plotted by samples sorted on median values.

\subsubsection{Observations}

a. Figure 4.19 (7-day heat of solution) shows no discernible pattern regarding cement types. A downward trend in the results over time is apparent.

b. Figure 4.20 shows a pattern of broken rising line segments, with no visible funneling in the spread. The range of observed values for sample 66 is significantly lower than that of the other samples. The available range of data is from 505 to 550 cal/g when sample 66 is ignored, and the IQ range is from 3 to $9 \mathrm{cal} / \mathrm{g}$.

c. Figure 4.22 shows 7-day heat of hydration results displaying modulation in the IQ range. Type III cements (samples 9 through 12) have higher values than the other samples. The outliers tend to be distributed evenly above and below the principal range of the data.

d. Figure 4.22 shows that the available range of data is from 62 to $96 \mathrm{cal} / \mathrm{g}$, and the IQ range from 2.5 to $7.0 \mathrm{cal} / \mathrm{g}$.

\subsection{Summary of Physical Test Properties}

Table 3 summarizes the spreads of median and IQ range results for the physical properties of the CCRL Portland Cement Proficiency samples.

5. Portland Cement Chemical Components

\subsection{Introduction}

Typically, portland cements are considered to be made up of the compounds tricalcium silicate $\left(3 \mathrm{CaO}-\mathrm{SiO}_{2}\right)$, dicalcium silicate $\left(2 \mathrm{CaO}-\mathrm{SiO}_{2}\right)$, tricalcium aluminate $\left(3 \mathrm{CaO}-\mathrm{Al}_{2} \mathrm{O}_{3}\right)$ and tetracalcium aluminoferrite $\left(4 \mathrm{CaO}-\mathrm{Al}_{2} \mathrm{O}_{3}-\mathrm{Fe}_{2} \mathrm{O}_{3}\right)$. These four compounds are considered to make up 90 percent of the mass of portland cement. These entities may contain some impurities and vary in crystalline structure. These chemical representations are just "working" chemical formulae which can be abbreviated further as $C_{3}$ s for tricalcium silicate, $c_{2}$ s for 


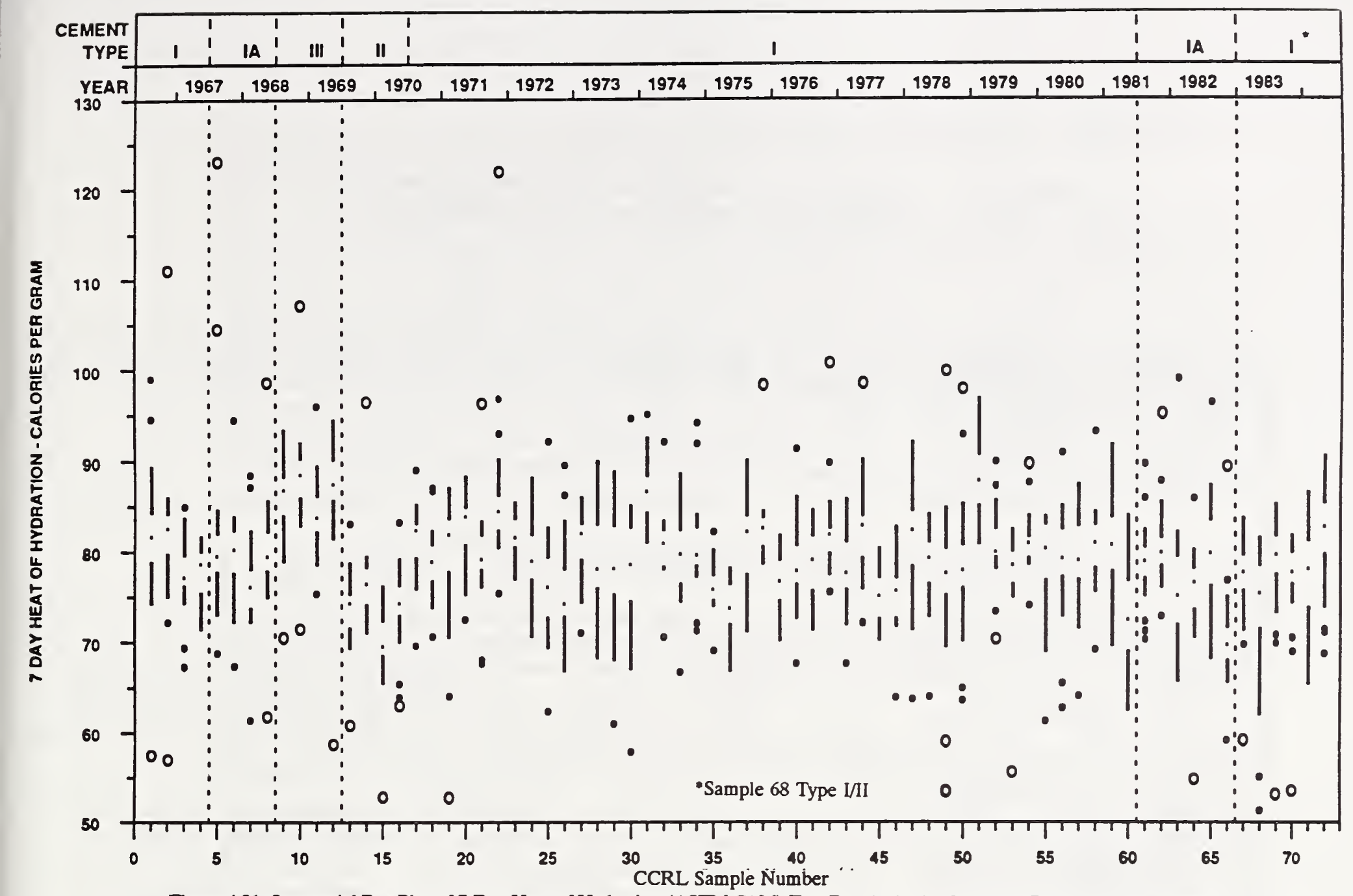

Figure 4.21 Sequential Box Plot of 7-Day Heat of Hydration (ASTM C186) Test Results in the Order the Portland Cement Samples Were Distributed by CCRL

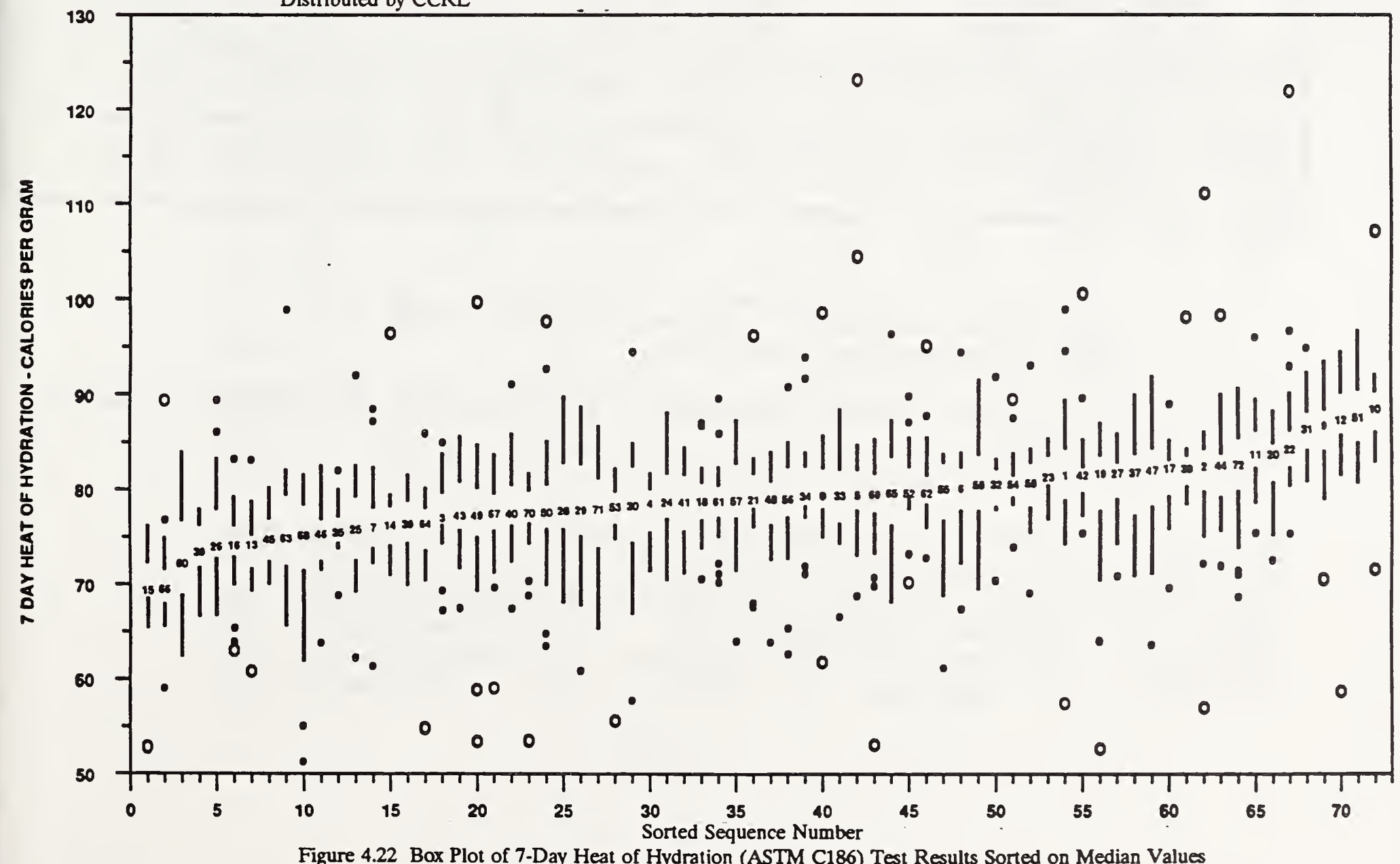

Figure 4.22 Box Plot of 7-Day Heat of Hydration (ASTM C186) Test Results Sorted on Median Values 
Table 3 - Spread of Medians and Interquartile (IQ) Range for Physical Test Results*

\begin{tabular}{|c|c|c|}
\hline Physical Tests & Medians & IQ Ranges \\
\hline $\begin{array}{c}\text { Normal Consistency } \\
\qquad\left(\% \mathrm{H}_{2} \mathrm{O}\right)\end{array}$ & $22.4-29.0$ & $0.3-1.15(1.8)$ \\
\hline $\begin{array}{c}\text { Autoclave Expansion } \\
(\%)\end{array}$ & $-0.02-0.66$ & $0.01-0.08(0.11)$ \\
\hline $\begin{array}{c}3 \text { - day Compress Str } \\
(\mathrm{MPa})\end{array}$ & $14.2-26.5(27.7)$ & $1.4-3.6$ \\
\hline 7 - day Compress Str & $(18.8) 21.9-34.8$ & $1.9-3.5$ \\
\hline Air content $(\%)$ & $\begin{array}{c}* * 8.3-10.8 \\
11.5-21.0\end{array}$ & $\begin{array}{c}* * 1.0-1.8(2.1,2.3) \\
1.2-2.5(3.1,8.3,8.4)\end{array}$ \\
\hline $\begin{array}{l}\text { Vicat Initial } \\
\text { Time of Set (Min.) }\end{array}$ & $50-207$ & $5-30(45,50)$ \\
\hline $\begin{array}{l}\text { Air Permeability } \\
\text { Fineness }\left(\mathrm{cm}^{2} / \mathrm{g}\right)\end{array}$ & $\begin{array}{c}* *(2825) 3010- \\
42004550-5950\end{array}$ & $\begin{array}{c}* * 70-190(220) \\
120-910\end{array}$ \\
\hline $\begin{array}{l}\text { Turbidimeter } \\
\text { Fineness }\left(\mathrm{cm}^{2} / \mathrm{g}\right)\end{array}$ & $\begin{aligned} * \star 1670 & -2220 \\
2510 & -2925\end{aligned}$ & $\begin{array}{l}(50) 70-140 \\
155-163\end{array}$ \\
\hline $\begin{array}{l}\text { Heat of Solution } \\
(\mathrm{cal} / \mathrm{g})\end{array}$ & $495-541$ & $2.7-9.6$ \\
\hline $\begin{array}{l}\text { Heat of Hydration } \\
(\mathrm{cal} / \mathrm{g})\end{array}$ & $69.5-88.5$ & $2.4-7.7(8.1)$ \\
\hline
\end{tabular}

* Values in brackets are those separated from the principal spread of the data.

** Two distinct levels due mainly to variation in types of cement 
dicalcium silicate, $C_{3} A$ for tricalcium aluminate, and $C_{4} A F$ for tetracalcium aluminoferrite.

The main compound, $C_{3}$ s exists in clinker in the impure form alite which may take on 6 or 7 crystal forms and contain the elements sulfur, sodium, potassium, iron, magnesium and fluorine in addition to trace elements. [8.13] The $\mathrm{C}_{2} \mathrm{~S}$ exists as belite which has at least five crystalline forms which, unlike alite, differ greatly in performance. Both $C_{3} A$ and the ferrite phase, $\mathrm{C}_{4} \mathrm{AF}$, also exist in several different crystalline forms with some variation in properties. The ferrites are of less importance than $C_{3} A$ in cements because of slower hydration. $C_{3} S, C_{2} S$ and $C_{3} A$ are the principal strengthproducing components in portland cement $[8.17,8.26]$.

A procedure for calculating the potential compound compositions of cement from the basic chemical assay was developed by Bogue [8.24] and is given in ASTM C150. It uses simplified assumptions and only approximates the percentages actually present. The procedure assumes that chemical equilibrium is attained in the burning zone of the kiln, whereas in fact equilibrium is not quite reached. Also, small but significant quantities of other elements such as sodium, potassium, magnesium, phosphorus and titanium are usually present in cements and may substitute for the various principal elements or form other compounds and solid solutions. The ACI Committee 225 "Guide to the Selection and Use of Hydraulic Cements" provides an excellent summary of cement chemistry. [8.13]

Chemically, the make-up of portland cement is determined as oxides of the elements calcium, silicon, iron, magnesium, manganese, sulfur, aluminum, zinc, phosphorous, sodium, potassium and titanium. The oxides of manganese, zinc, phosphorous and titanium are not reported in the general CCRL portland cement proficiency sample program and are not included in this chapter. Three other components are included; loss on ignition, insoluble residue, and free lime. In the loss on ignition determination, carbon dioxide and moisture are driven off on ignition and the loss is determined. In the insoluble residue test, the material remaining after dissolution with hydrochloric acid and sodium hydroxide is weighed and determined as a percentage of the mass of cement. These components and the compounds included in the CCRL program are discussed in detail beginning in 5.2 .

ASTM Method C114, Standard Test Method for Chemical Analysis of Hydraulic Cement [8.7] provides two types of methods for the chemical analysis of hydraulic cements: reference methods and alternate methods. The "reference methods" are longaccepted wet chemistry test methods which provide a reasonably well-integrated basic scheme of analysis for hydraulic 
cements. The "alternate methods" generally provide determinations of specific components. ASTM Method C114 allows the use of any test method of demonstrated acceptable precision and bias. Methods are qualified by analysis of an NIST Portland Cement Chemical standard Reference Material [8.22] for each constituent of concern, and comparison of laboratory results to maximum permissible ranges given in Table 1 of C114. If agreement is not within the permissible range, the determination is repeated following identification and correction of problems. Methods qualified in this manner may be used for acceptance testing in those cases where conformance to chemical specification requirements are questioned.

Chemical determinations using wet chemistry "reference methods" depend on a sequence of tests and the results of any given test can be adversely affected by an error in an earlier step. Figure 5.1 summarizes the steps in the wet chemical analysis of hydraulic cement. The compounds and components are shown in the order listed in ASTM Method C114. The determination of compounds and components proceeds sequentially with either solutions or results from previous determinations used in subsequent determinations. Unless all testing is done with care the precision of the test results further along in the sequence may be adversely affected by prior errors.

Recognizing the shift away from classical analytical chemistry to instrumental methods of analysis, a major effort was made by ASTM Committee $\mathrm{Cl}$ to allow the use of rapid methods of analysis of cements which are in some cases more convenient to perform than the reference methods. [8.27] C114 allows the use of rapid methods which are qualified as outlined above including atomic absorption methods, $x$-ray spectrochemical methods, spectrophotometric/EDTA methods, free lime rapid methods, and rapid analysis of sulfur.

The CCRL Portland Cement proficiency samples included in this study may have been tested using any of the methods allowed in c114. It is likely that predominantly wet-chemistry methods were used for the earlier samples in the study, with most laboratories now using rapid instrumental methods for cement analysis. [8.27] since a full analysis by wet methods requires about a week, cement plants rely on rapid methods to control cement composition during production. Because the exact method used is not identified in the portland cement chemical data in this study, it is not possible to draw any quantitative conclusions concerning the types of c114 test methods used. 

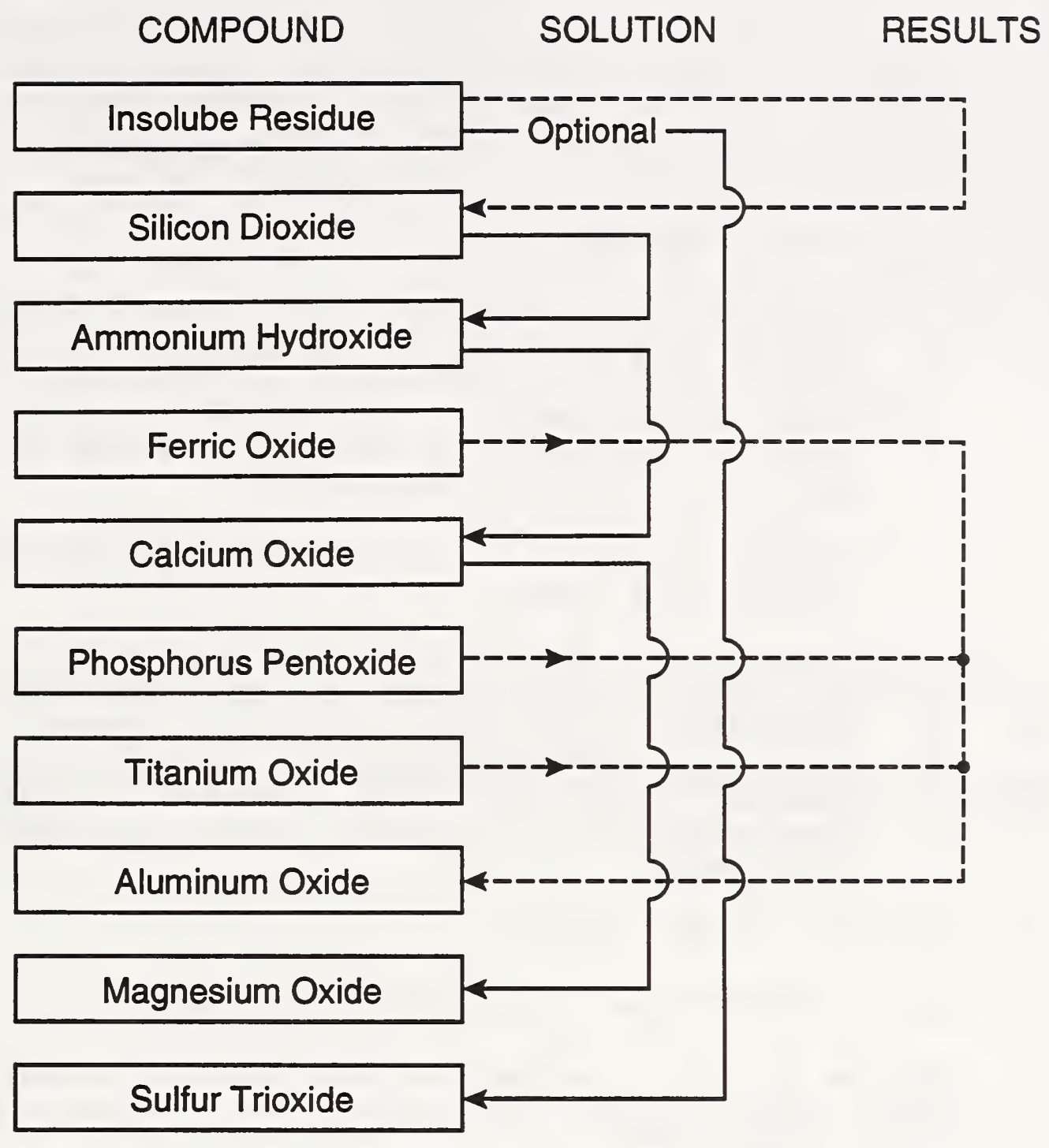

Sodium Oxide

Potassium Oxide

Loss of Ignition

Free Lime

Figure 5.1 Flow Chart of Reference Methods for Chemical Analysis of Portland Cement Using ASTM C114 
5.2 Silicon Dioxide $\left(\mathrm{SiO}_{2}\right)$

5.2.1 Statistical Presentation of Data

$\mathrm{SiO}_{2}$ is a determinate factor along with $\mathrm{CaO}$ in establishing the amounts of $\mathrm{C}_{3} \mathrm{~S}$ and $\mathrm{C}_{2} \mathrm{~S}$ which are considered strength components for cement. [8.13]

Figure 5.2 is a sequentially ordered presentation of box plots of silicon dioxide $\left(\mathrm{SiO}_{2}\right)$ test results for the first 72 CCRL portland cement samples. Figure 5.3 is a similar plot except that silicon dioxide content is plotted by samples sorted on median values.

\section{2 .2 Observations}

a. Figure 5.2 shows that Type II cements tend to be higher in $\mathrm{SiO}_{2}$ (samples 13 through 16) compared to other samples in the study, while Type III cements tend to be lower in $\mathrm{SiO}_{2}$ (samples 9 through 12). $\mathrm{SiO}_{2}$ is limited to 20 percent minimum for Type II and IIa cements in ASTM C150.

b. Figure 5.2 exhibits an oscillatory pattern in $\mathrm{SiO}_{2}$ levels over time.

c. Figure 5.3 shows line segments in median values ascending, with breaks at the ends of the line segments. The total available range of data is from 18.5 to 22.8 percent. The IQ range varies between 0.19 and 0.29 percent. There is a preponderance of lowliers above the 20.2 percent $\mathrm{SiO}_{2}$ level.

5.3 Aluminum Oxide $\left(\mathrm{Al}_{2} \mathrm{O}_{3}\right)$

5.3.1 Statistical Presentation of Data

Figure 5.4 is a sequential box plot of aluminum oxide $\left(\mathrm{AL}_{2} \mathrm{O}_{3}\right)$ test results, and Figure 5.5 is a sorted box plot of the same data.

\section{3 .2 Observations}

a. Figure 5.4 shows Type II cements (samples 13 through 16) tend to be low in $\mathrm{Al}_{2} \mathrm{O}_{3}$ content. $\mathrm{Al}_{2} \mathrm{O}_{3}$ is limited to 6.0 percent for Type II and IIa cements in ASTM C150 to achieve moderate heat of hydration and moderate sulfate resistance.

b. Figure 5.4 shows a general oscillatory pattern in $\mathrm{Al}_{2} \mathrm{O}_{3}$ content through the years. Samples 55 through 72 display a lower numbers of outliers compared to previous samples. 


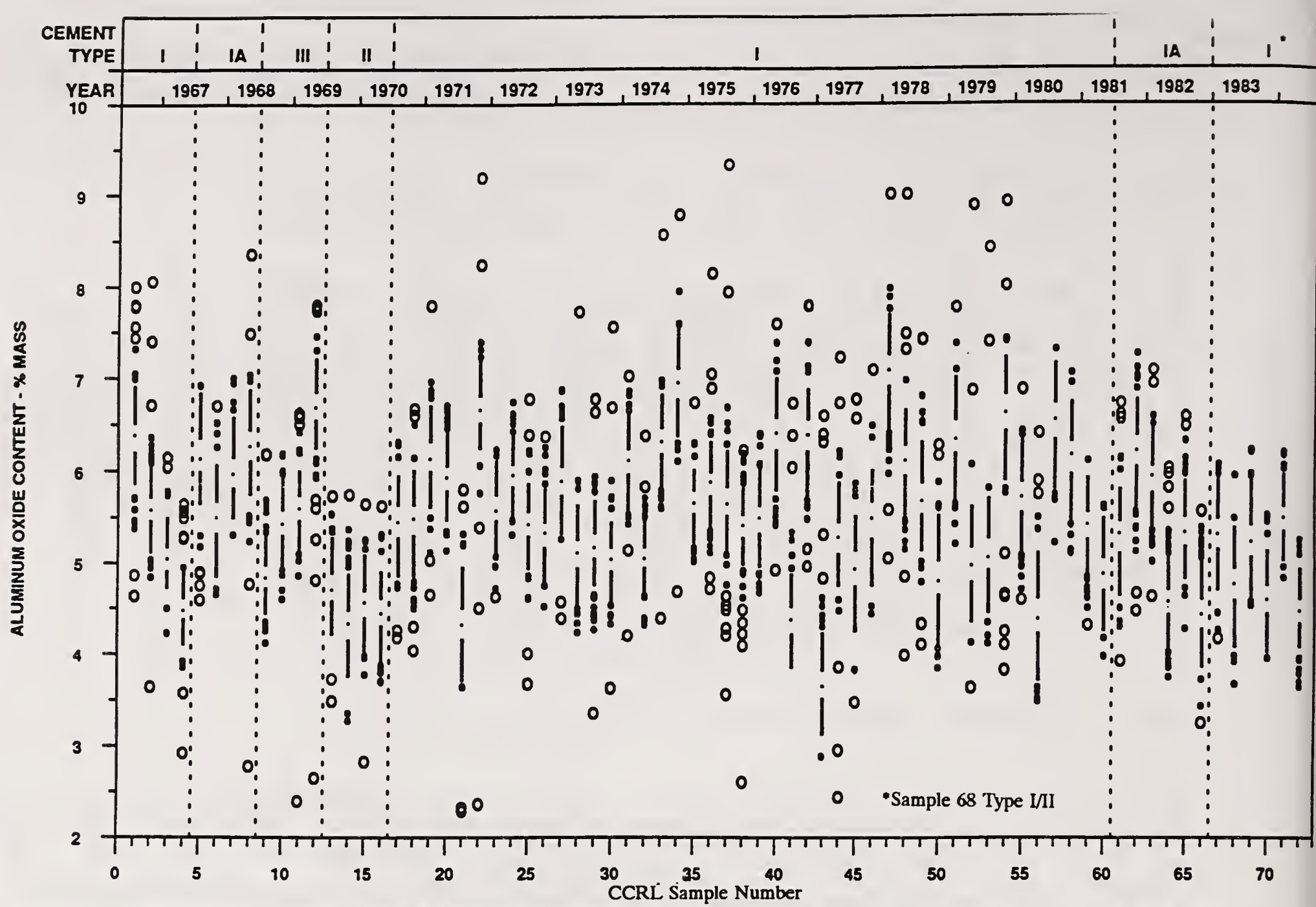

Figure 5.4 Sequential Box Plot of Aluminum Oxide (ASTM C114) Test Results in the Order the Portland Cement Samples Were Distributed Bv CCRL.

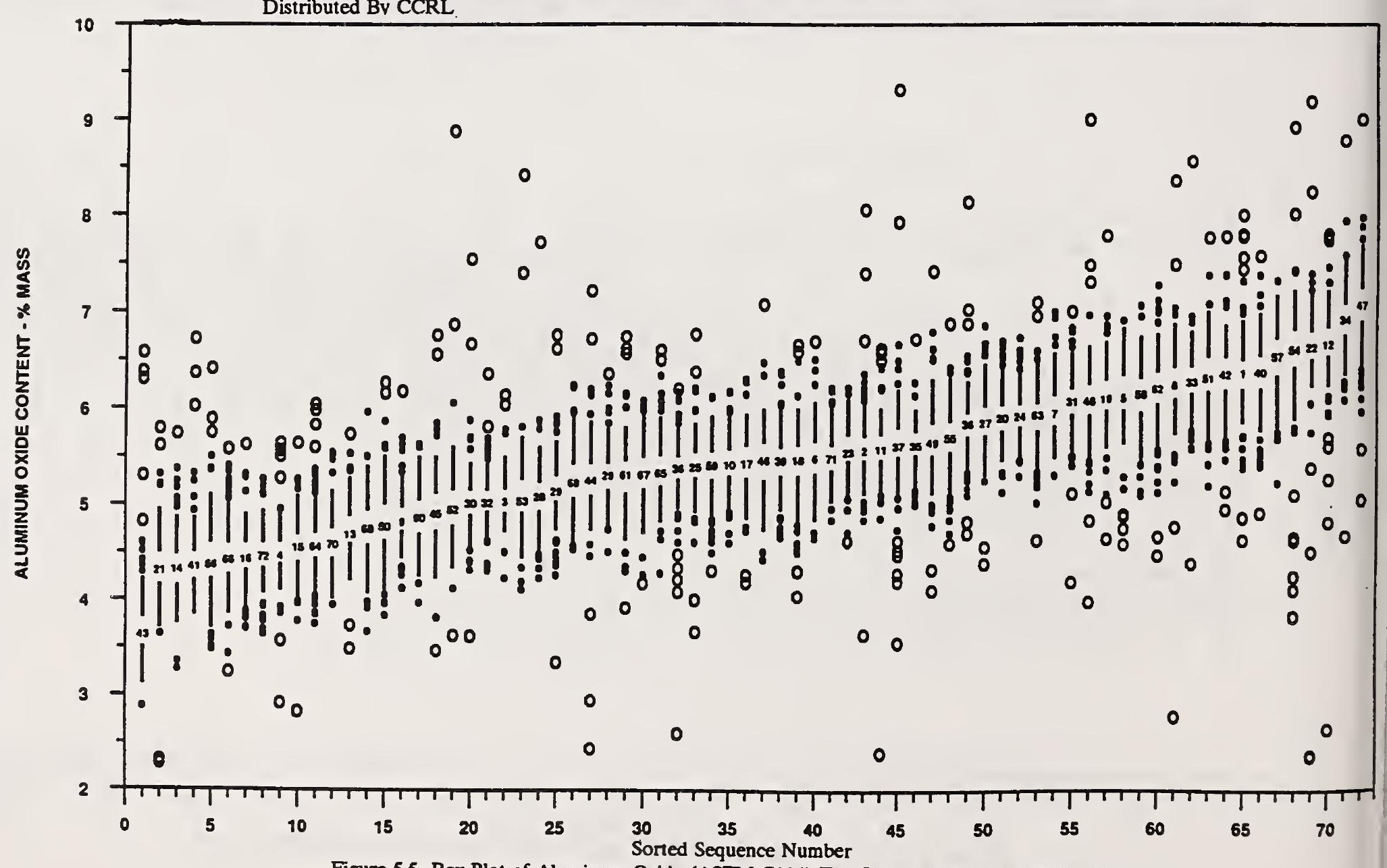

Figure 5.5 Box Plot of Aluminum Oxide (ASTM C114) Test Results Sorted on Median Values 
c. Figure 5.5 shows line segments ascending in median values with breaks at the ends of the line segments.

d. Figure 5.5 shows that the IQ range fluctuates from 0.2 to 0.35 percent. The available range of data is from 3.1 to 7.5 percent. There is a hint of amplitude modulation.

5.4 Ferric Oxide $\left(\mathrm{Fe}_{2} \mathrm{O}_{3}\right)$

\subsubsection{Statistical Presentation of Data}

$\mathrm{Fe}_{2} \mathrm{O}_{3}$ plays a role in the strength of portland cement. [8.13] The iron compound is also a factor in determining the color of the cement, with white cement containing little $\mathrm{Fe}_{2} \mathrm{O}_{3}$.

Figure 5.6 is a sequential box plot of ferric oxide $\left(\mathrm{Fe}_{2} \mathrm{O}_{3}\right)$ test results, and Figure 5.7 is a sorted box plot of the same data. Figure 5.8 is a plot of skewness described in $4.4 .3 .2(d)$.

\section{4 .2 Observations}

a. Figure 5.6 shows three of the four Type II cement samples $(13,14$ and 15$)$ to be higher in $\mathrm{Fe}_{2} \mathrm{O}_{3}$ content than the other samples in the study.

b. Figure 5.7 shows the test method to be a highprecision test with tight patterns in the IQ ranges.

C. Figure 5.7 shows the highliers to be more extreme and more numerous than the lowliers. The last eleven samples indicate an appreciably higher $\mathrm{Fe}_{2} \mathrm{O}_{3}$ content, which might relate to the geographic sources of the materials used in manufacturing the cements.

d. Figure 5.7 shows the available range of data varies from 1.8 to 4.6 percent. The IQ range varies between 0.06 and 0.09 percent with intermediate values of 0.07 and 0.08 percent. This limited set of values is due to the requirement in ASTM C114 that $\mathrm{Fe}_{2} \mathrm{O}_{3}$ contents be reported to the nearest 0.01 percent.

e. Figure 5.8 shows a skewness to the low side. 


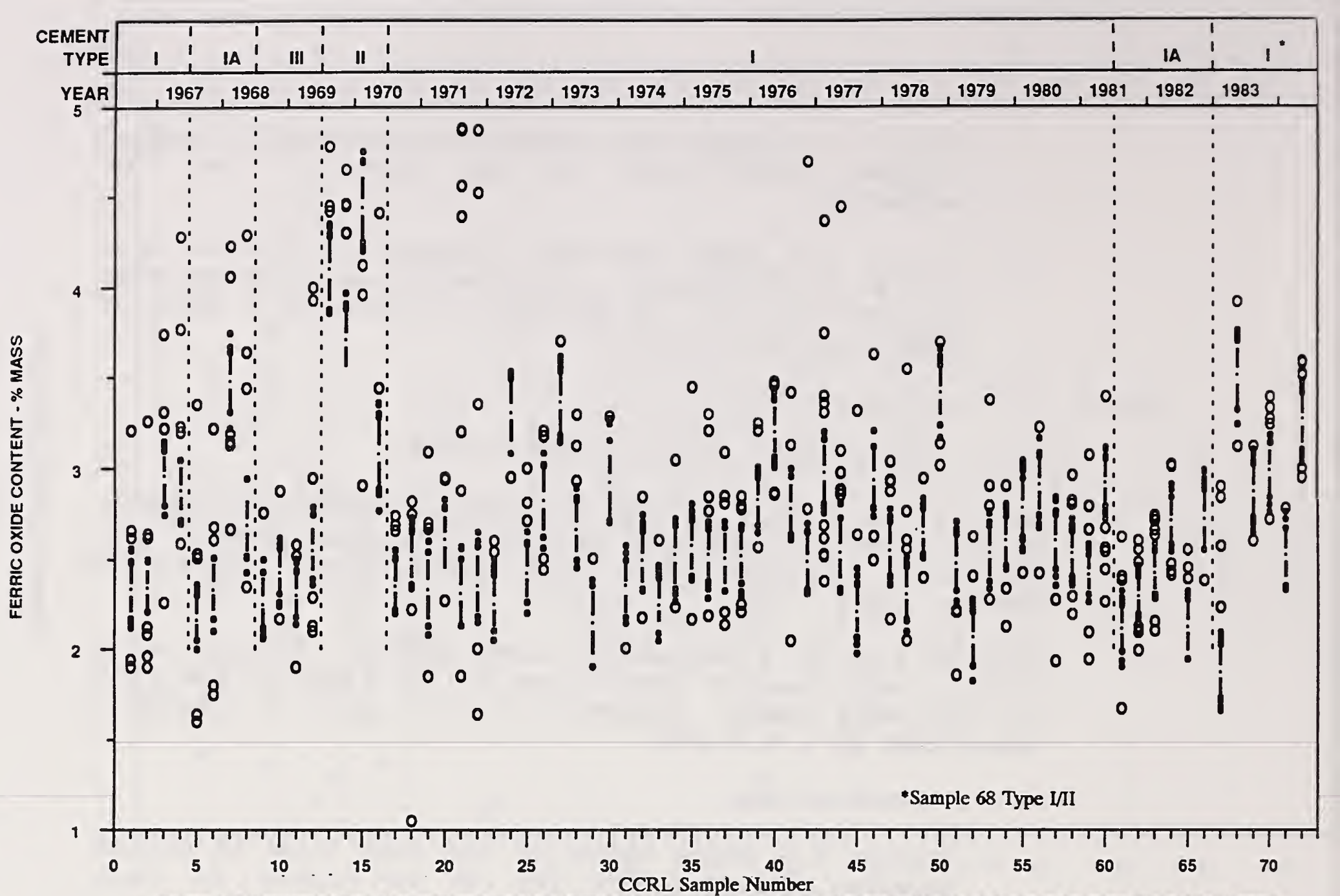

Figure 5.6 Sequential Box Plot of Ferric Oxide (ASTM C114) Test Results in the Order the Portland Cement Samples Were Distributed

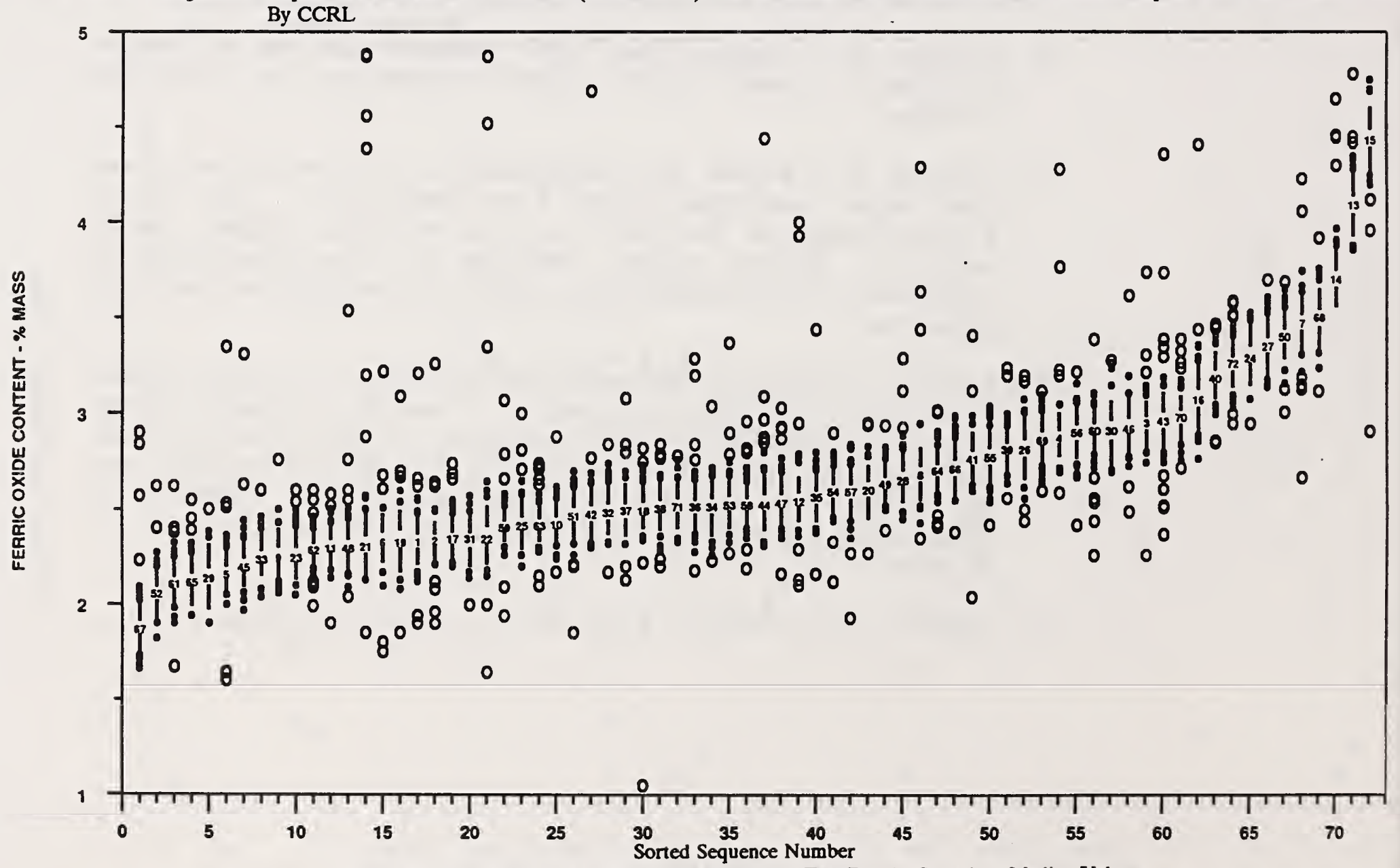

Figure 5.7 Box Plot of Ferric Oxide (ASTM C114) Test Results Sorted on Median Values 


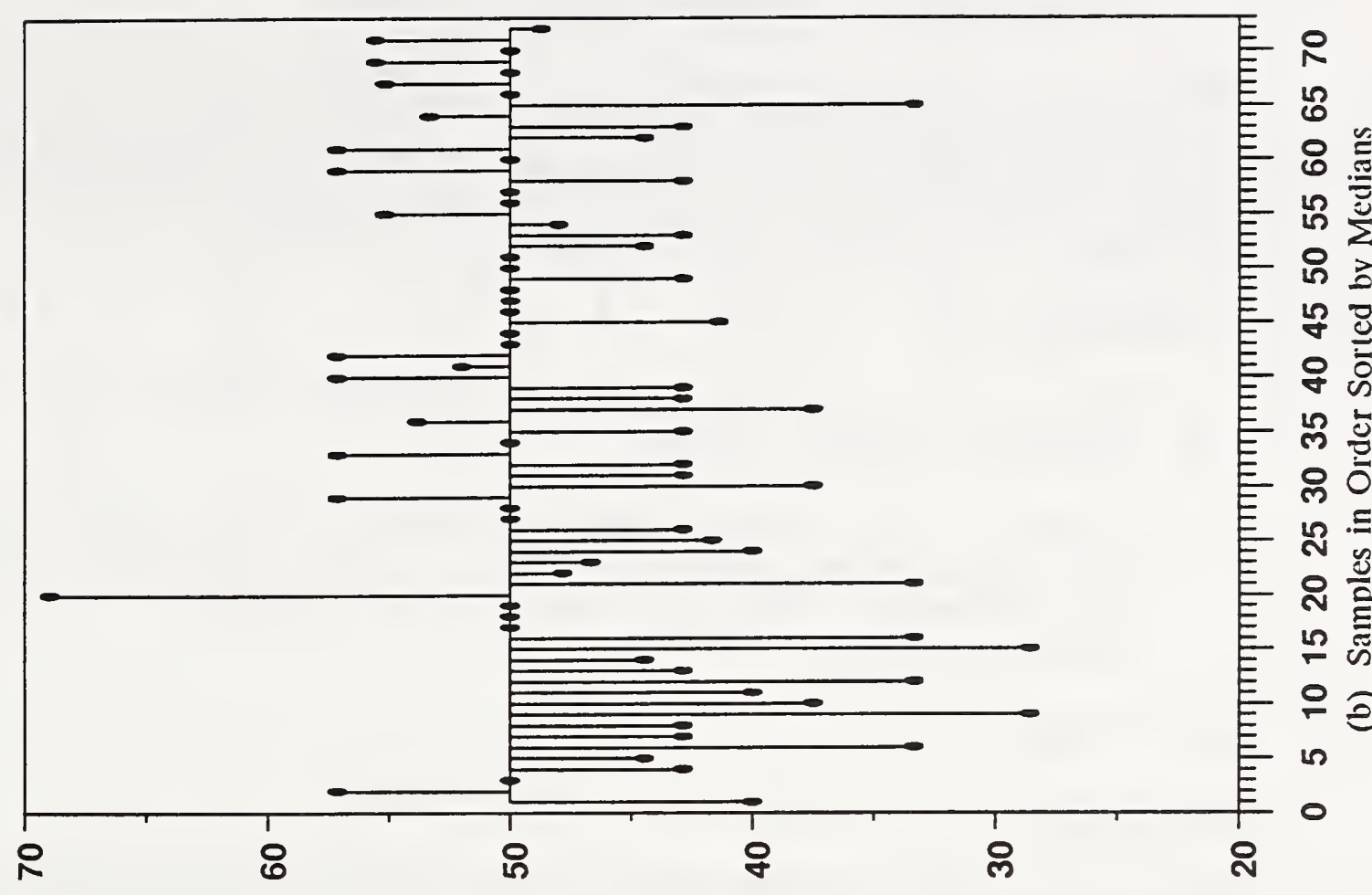

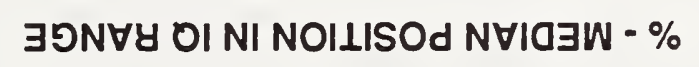

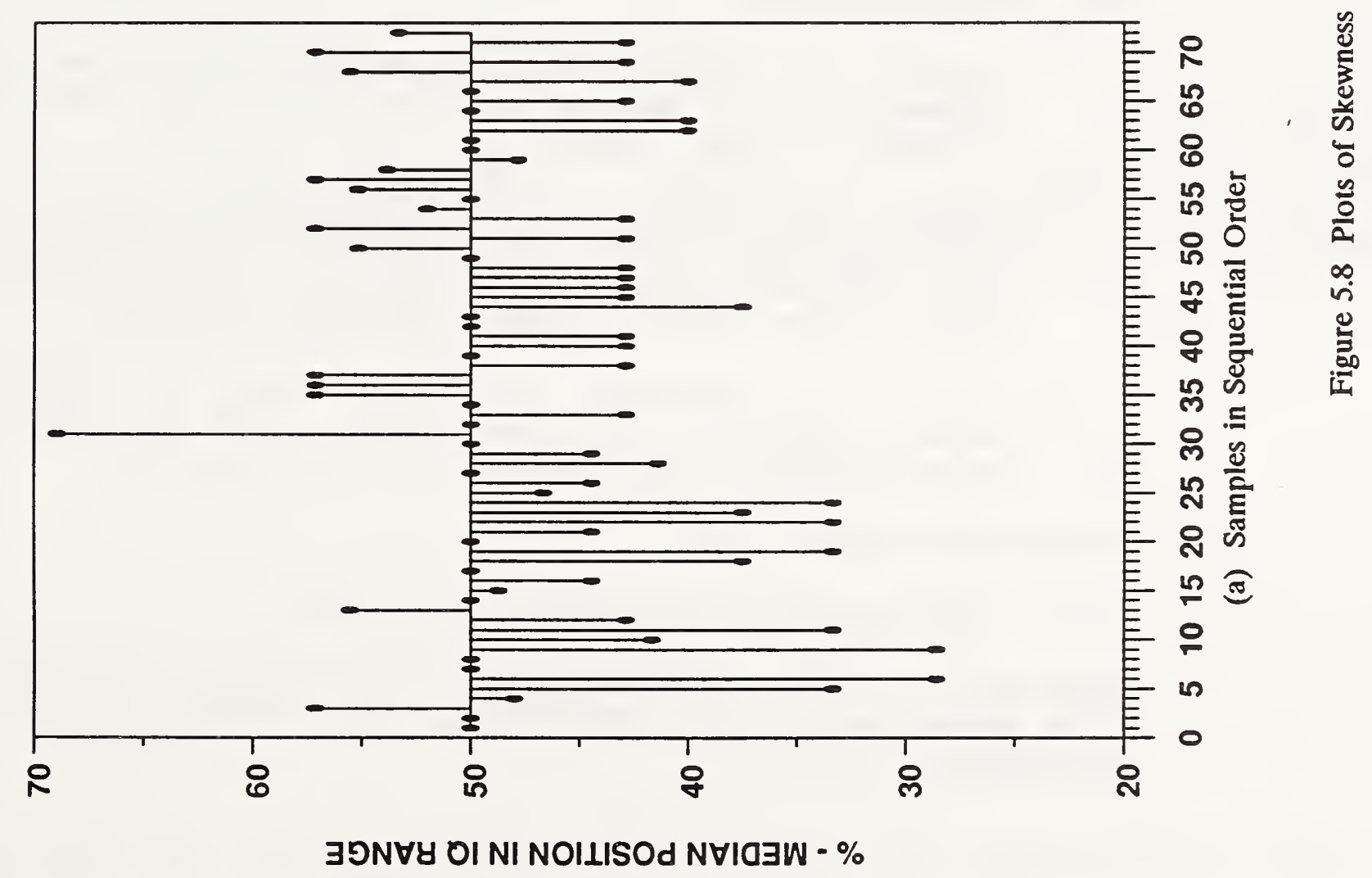


5.5 Calcium oxide ( $\mathrm{CaO})$

5.5.1 Statistical Presentation of Data

Figure 5.9 is a sequential box plot of calcium oxide (CaO) test results, and Figure 5.10 is a sorted box plot of the same data. CaO is a major constituent of portland cement which is closely controlled in the production process.

\section{5 .2 Observations}

a. Figure 5.9 does not show an obvious pattern for the various cement types.

b. Figure 5.10 shows more lowliers than highliers. The available range of data of $\mathrm{CaO}$ is about 60 to 66 percent. The IQ range varies between 0.29 and 0.43 percent.

5.6 Free Lime

5.6.1 Statistical Presentation of Data

Figure 5.11 is a sequential box plot of free lime test results for CCRL Portland Cement proficiency samples 35 through 72 which were Type I cements. Free lime was not determined in samples 1 through 34 . Figure 5.12 is a sorted box plot of the same data.

\section{6 .2 Observations}

a. Figure 5.11 gives the impression of a relatively imprecise test method compared to other chemical properties (e.g. $\mathrm{Fe}_{2} \mathrm{O}_{3}$ ).

b. Figure 5.12 shows a preponderance of highliers. There are also small plateaus and upward runs of about 4 sample duration. There is funneling and a hint of modulation in the IQ range as well.

c. Figure 5.12 shows an available range of data of 0 to 2.3 percent for free lime. The IQ range is approximately 0.19 percent to 0.35 percent.

\subsection{Magnesium oxide (MgO)}

\subsubsection{Statistical Presentation of Data}

Magnesium oxide, present in portland cement because of its presence in raw materials, has little effect on strength. [8.13] 


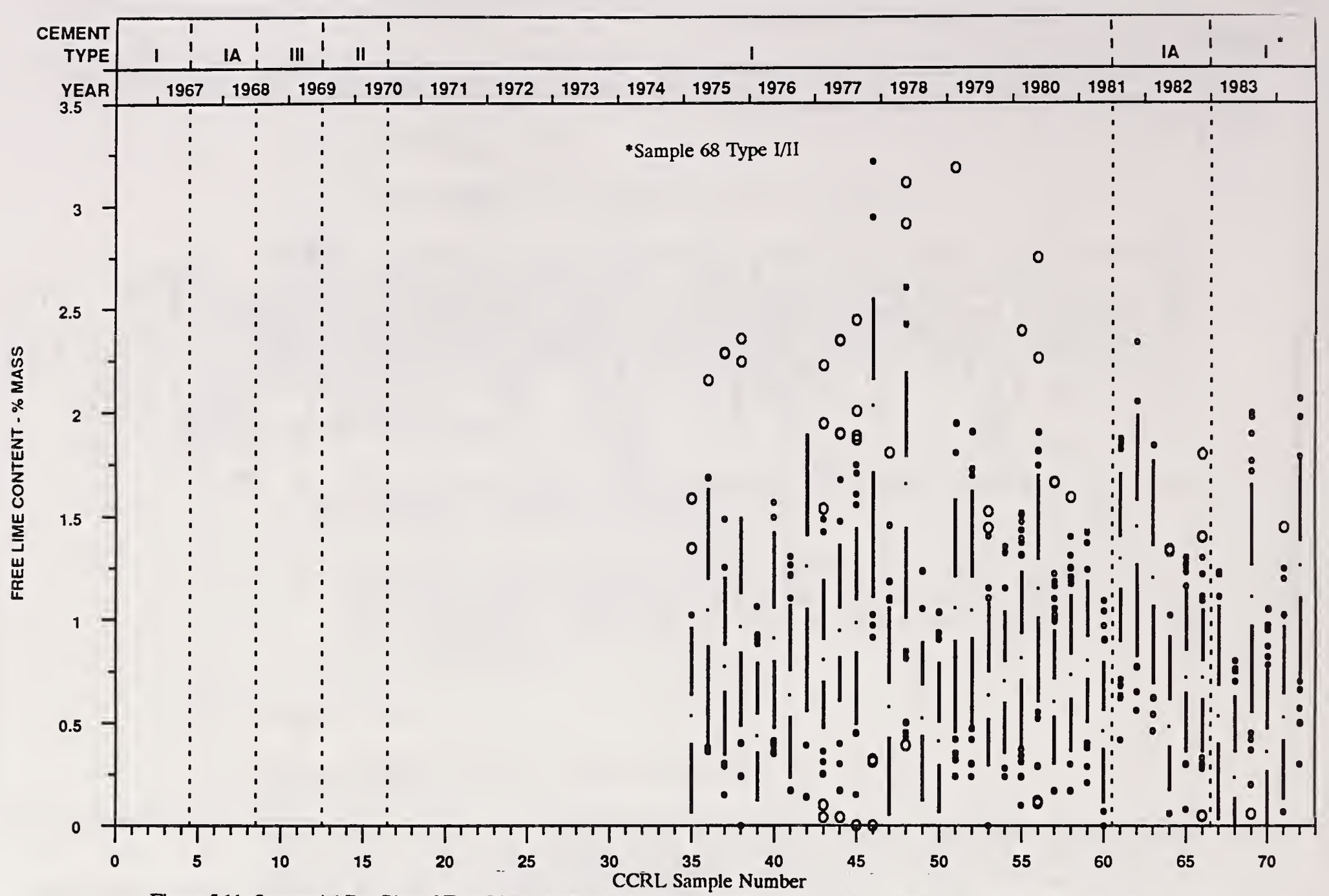

Figure 5.11 Sequential Box Plot of Free Lime (ASTM C114) Test Results in the Order the Portland Cement Samples Were Distributed

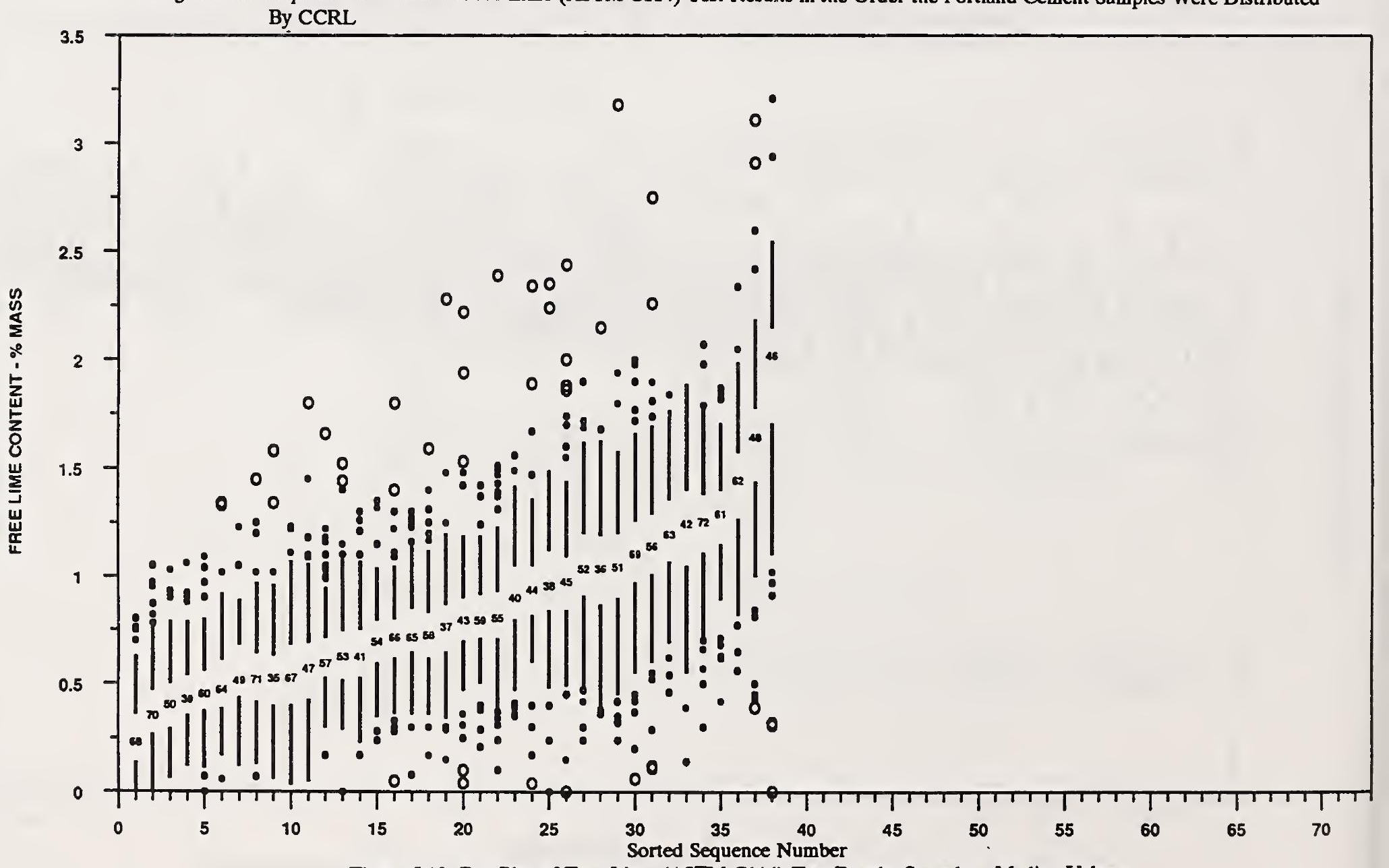

Figure 5.12 Bax Plot of Free Lime (ASTM C114) Test Results Sorted on Median Values 


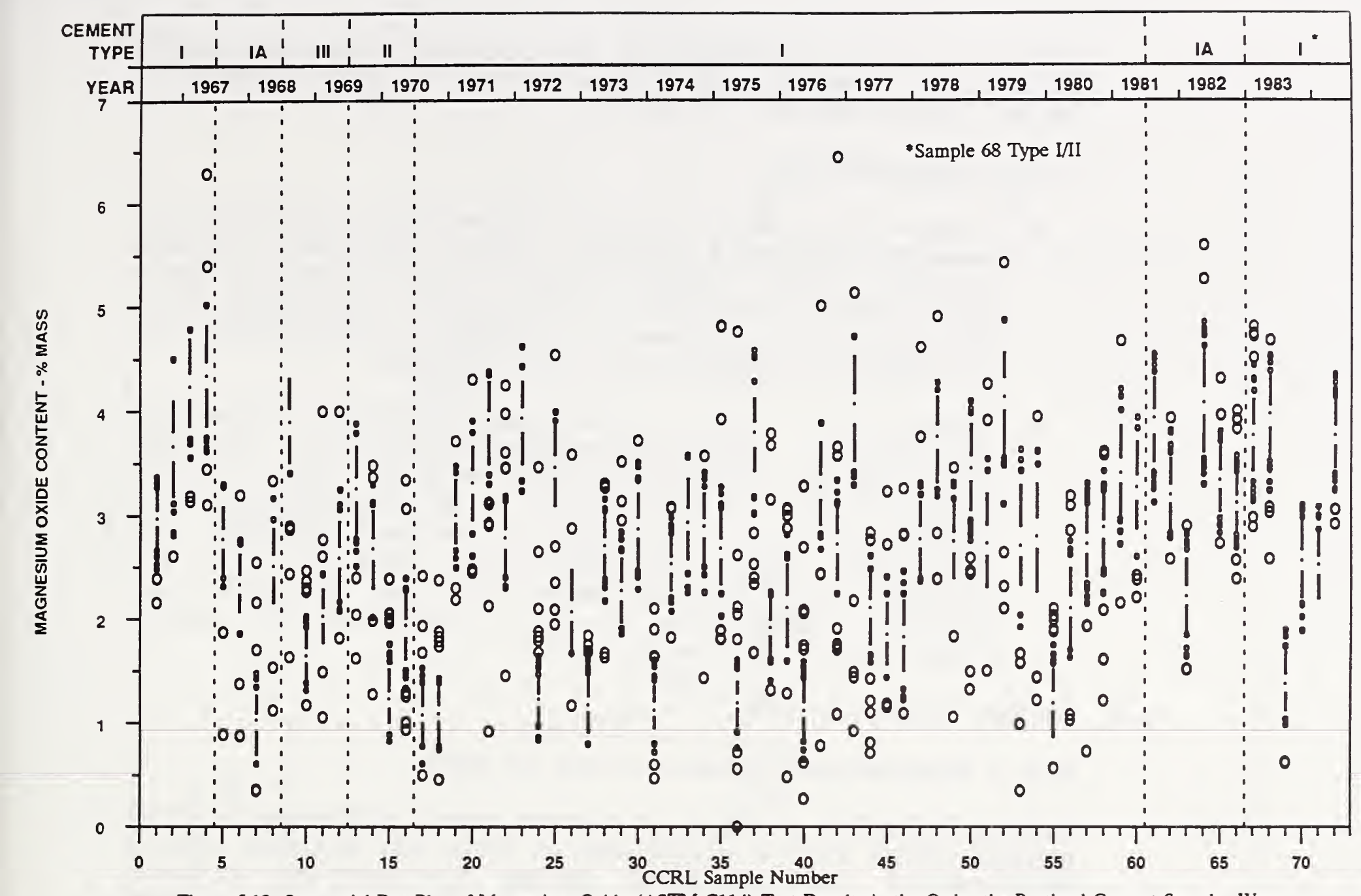

Figure 5.13 Sequential Box Plot of Magnesium Oxide (ASTM C114) Test Results in the Order the Portland Cement Samples Were Distributed By CCRL

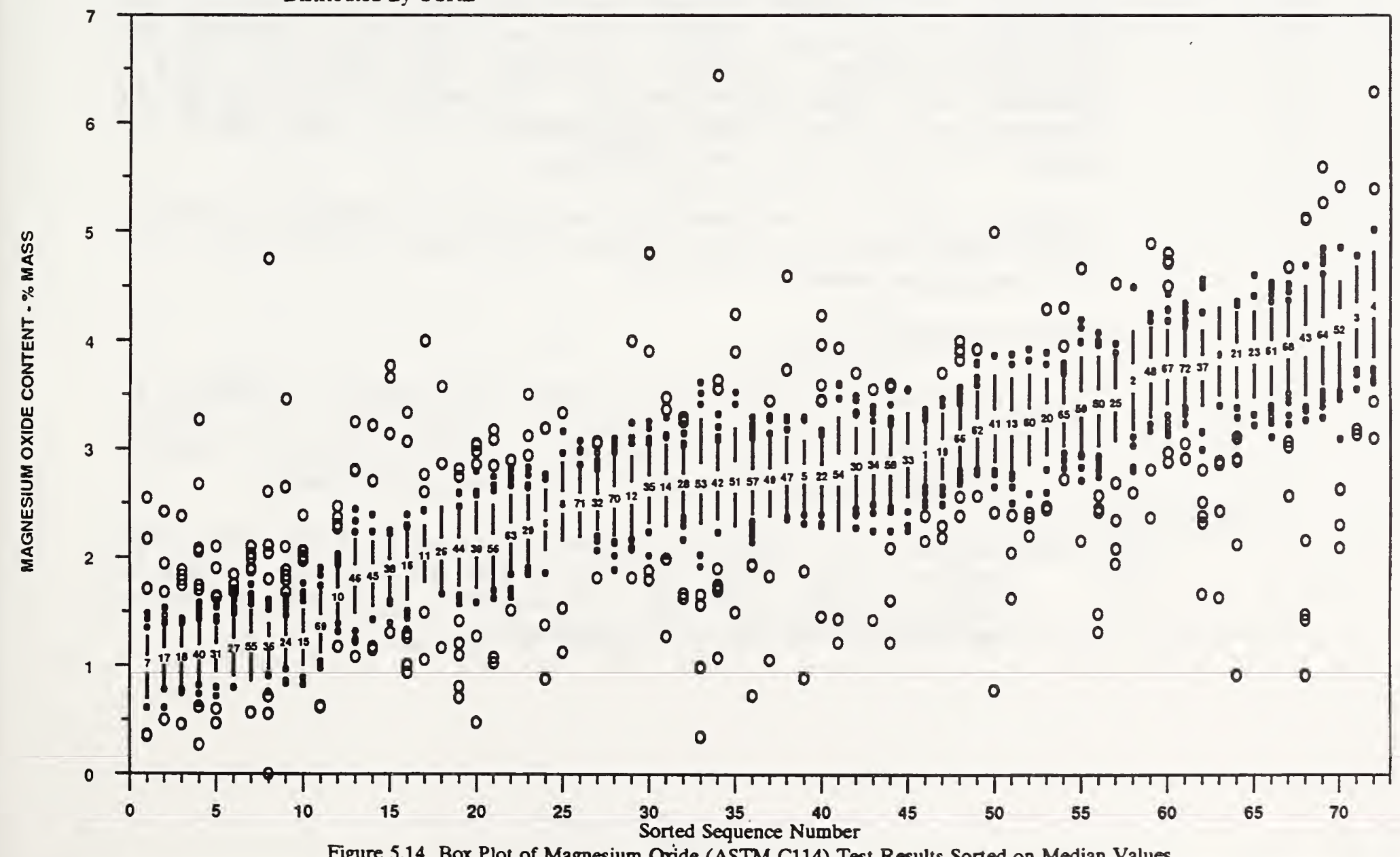

Figure 5.14 Box Plot of Magnesium Oxide (ASTM C114) Test Results Sorted on Median Values 
Figure 5.13 is a sequential box plot of magnesium oxide (MgO) test results, and Figure 5.14 is a sorted box plot of the same data.

\section{7 .2 Observations}

a. Figure 5.13 shows varied compositions for Type IA cement; samples 5 through 8 show lower than average results, while samples 61 through 66 show higher than average results. ASTM C150 limits Mg0 to a maximum of 6.0 percent to decrease the possibility of excessive expansion (unsoundness).

b. Figure 5.14 shows an obvious pattern of obvious plateauing. There is a preponderance of lowliers compared to highliers for samples with median values above 3 percent, and a preponderance of highliers in the 1.0 to 1.4 percent range. The available range of data runs from 0.7 to 4.9 percent, and the IQ range is from 0.13 to 0.27 percent. There is a steady funneling in the IQ range shown in Figure 5.15 .

\subsection{Sulfur Trioxide $\left(\mathrm{SO}_{3}\right)$}

\subsubsection{Statistical Presentation of Data}

Sulfur Trioxide present in cement comes principally from gypsum added during grinding, or from the clinker when a high-sulfur fuel is used during the burning process [8.13]. The gypsum is interground with the cement clinker to prevent flash setting and to control the hardening process. ASTM C150 establishes maximum $\mathrm{SO}_{3}$ contents ranging from 2.3 percent for Type IV to 4.5 percent for Type III cements. $\mathrm{SO}_{3}$ content is carefully controlled since it may react with $C_{3} A$ at later ages and result in long-term expansion.

Figure 5.16 is a sequential box plot of sulfur trioxide $\left(\mathrm{SO}_{3}\right)$ test results, and Figure 5.17 is a sorted box plot of the same data.

\section{8 .2 Observations}

a. Figure 5.16 shows that Type III cements (samples 912) tend to be generally higher in $\mathrm{SO}_{3}$ content compared to Type I cements, whereas Type II cements (samples 13-16) tend to be somewhat lower.

b. Figure 5.17 shows a number of lowliers at the upper end of the range of $\mathrm{SO}_{3}$. The available range of data is from 1.9 to 4.0 percent, and the IQ range is from 0.06 to 0.11 percent. 
Interquartile Range (\%)

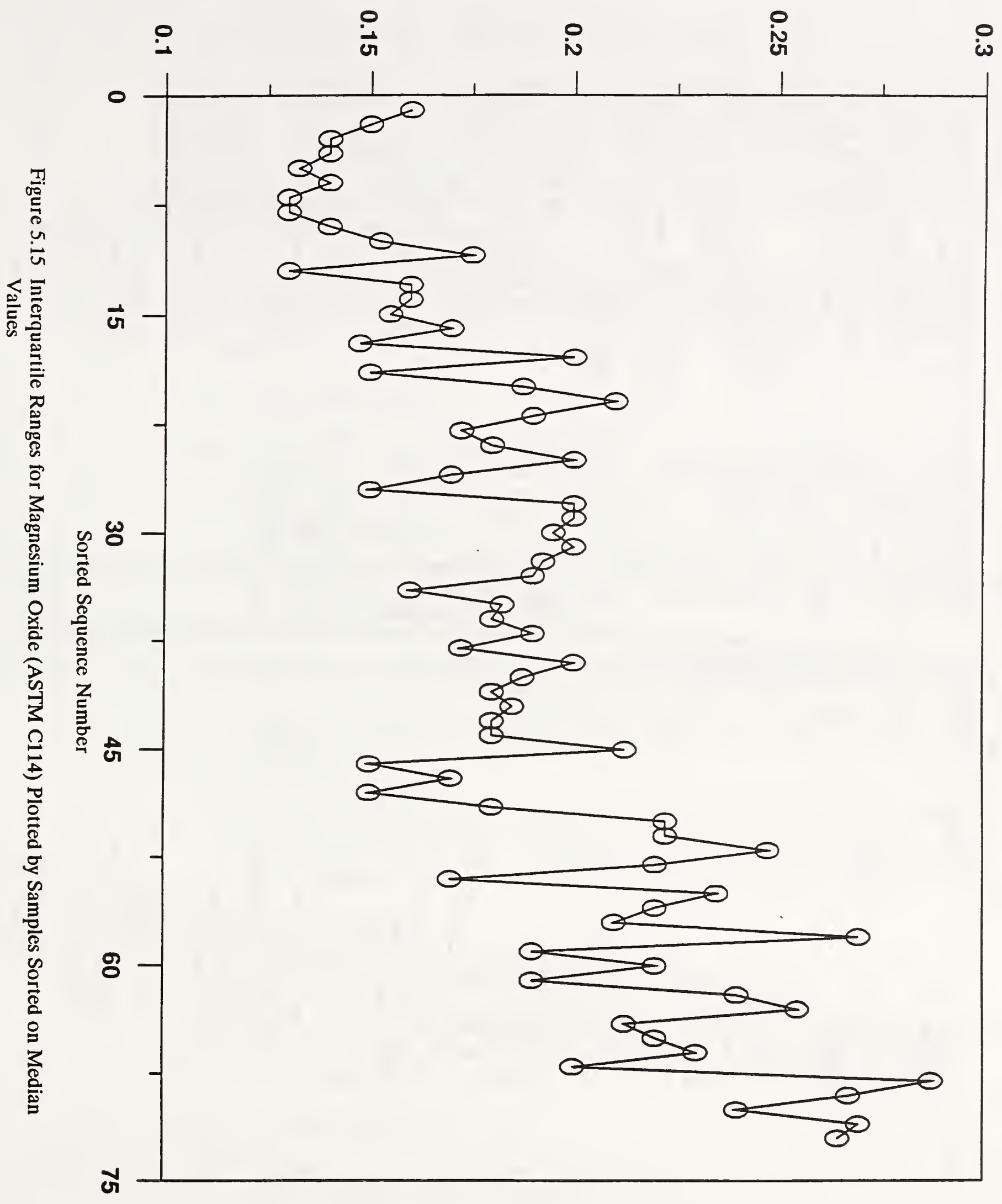




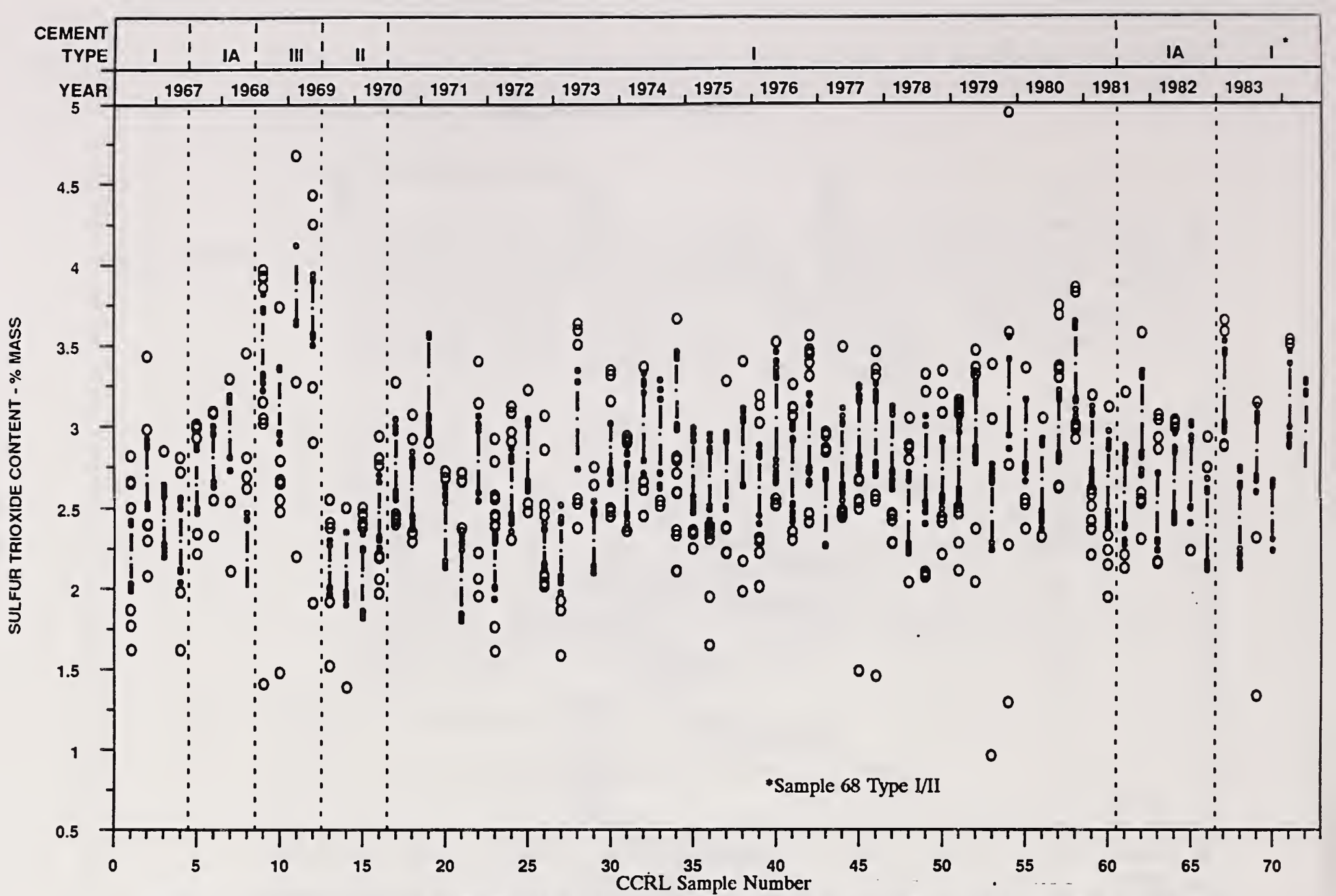

Figure 5.16 Sequential Box Plot of Sulfur Trioxide (ASTM C114) Test Results in the Order the Portland Cement Samples Were Distributed By CCRL

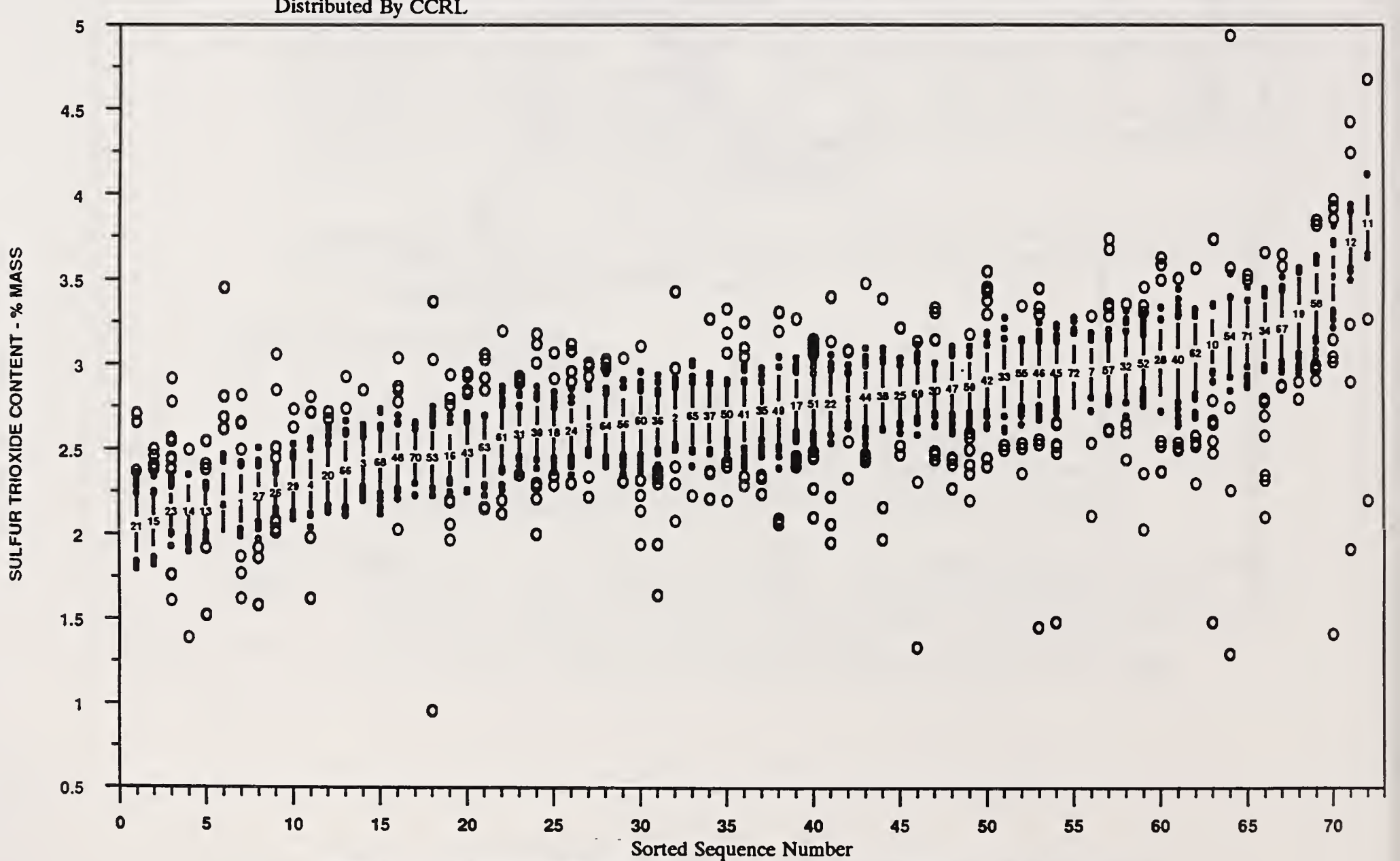

Figure 5.17 Box Plot of Sulfur Trioxide (ASTM C114) Test Results Sorted on Median Values 
5.9 Loss on Ignition

5.9.1 Statistical Presentation of Data

Loss of ignition of a cement is generally an indication of the amount of water or carbon dioxide, or both, loosely bonded or chemically combined with the cement. [8.13] The bending of clinker stored outside exposed to the weather with new clinker results in cements with higher loss on ignition. Strengths tend to decrease with increasing ignition loss.

Figure 5.18 is a sequential box plot of loss on ignition test results, and Figure 5.19 is a sorted box plot of the same data. Figure 5.20 is a plot of skewness described in $4.4 \cdot 3 \cdot 2(d)$.

\section{9 .2 Observations}

a. Figure 5.18 shows that the Loss on Ignition test exhibits large variability. Sample 66 shows a very high percent loss on ignition. Outliers generally exhibit a consistent pattern of regularly occurring lowliers and highliers except for samples 4 and 5 which have exceptionally high outliers. High loss on ignition would typically indicate high moisture and/or carbonate content.

b. Figure 5.19 shows an available range of data from 0.30 to 2.40 percent; and the IQ range is 0.08 to 0.10 percent. (Samples 17 and 71 have low IQ ranges, while samples 29 and 70 have high IQ ranges.)

c. Figure 5.20 shows a skewness to the low side. This may be due to the tendency of some laboratories to not take the test to completion by not reigniting the samples until constant weight is achieved.

\subsection{Insoluble Residue}

\subsubsection{Statistical Presentation of Data}

Figure 5.21 is a sequential box plot of percent of insoluble residue, and Figure 5.22 is a sorted box plot of the same data. Figure 5.23 is a plot of skewness.

\subsection{0 .2 Observations}

a. Figure 5.21 shows no obvious pattern except for a fair number of highliers. 


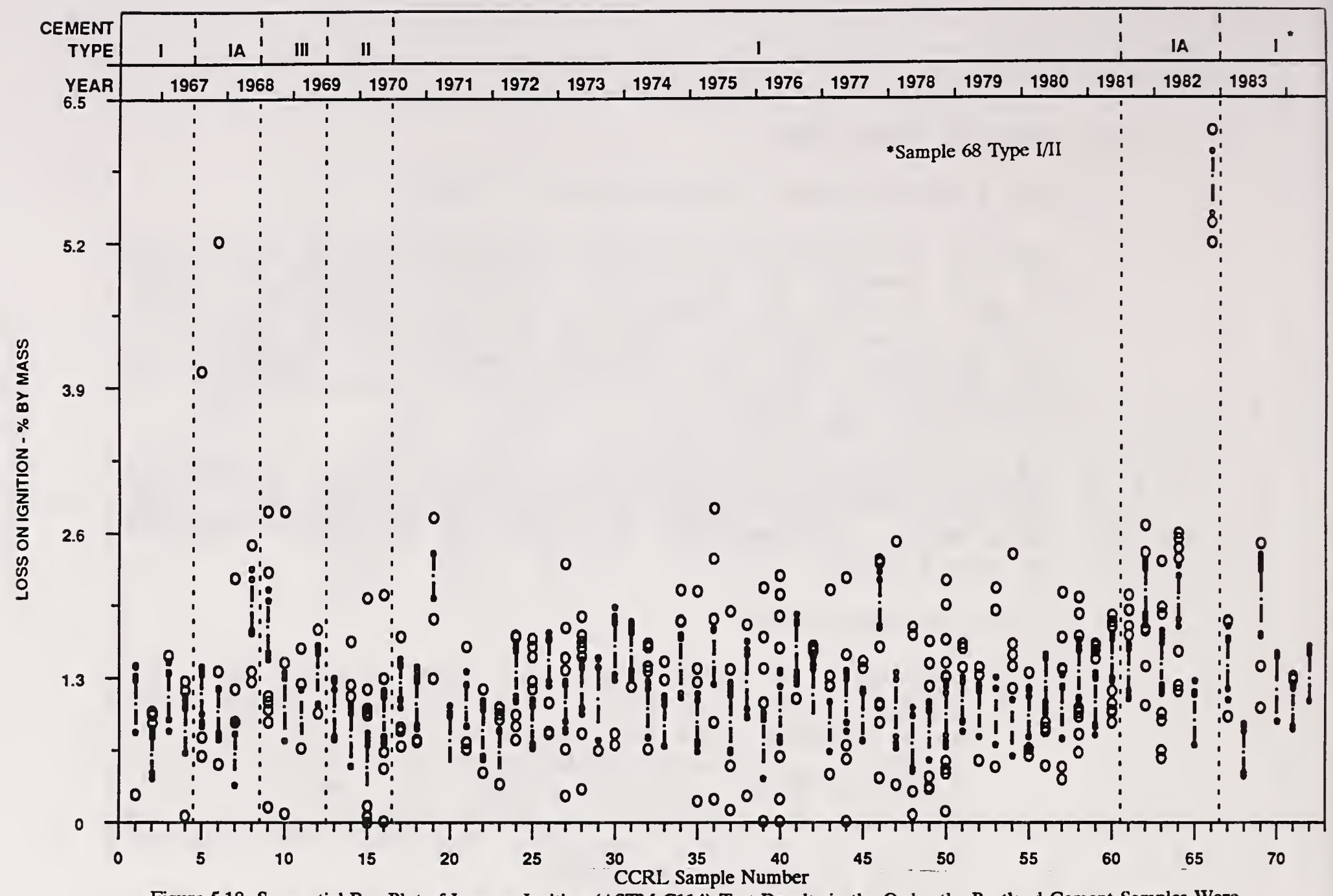

Figure 5.18 Sequential Box Plot of Loss on Ignition (ASTM C114) Test Results in the Order the Portland Cement Samples Were Distributed By CCRL

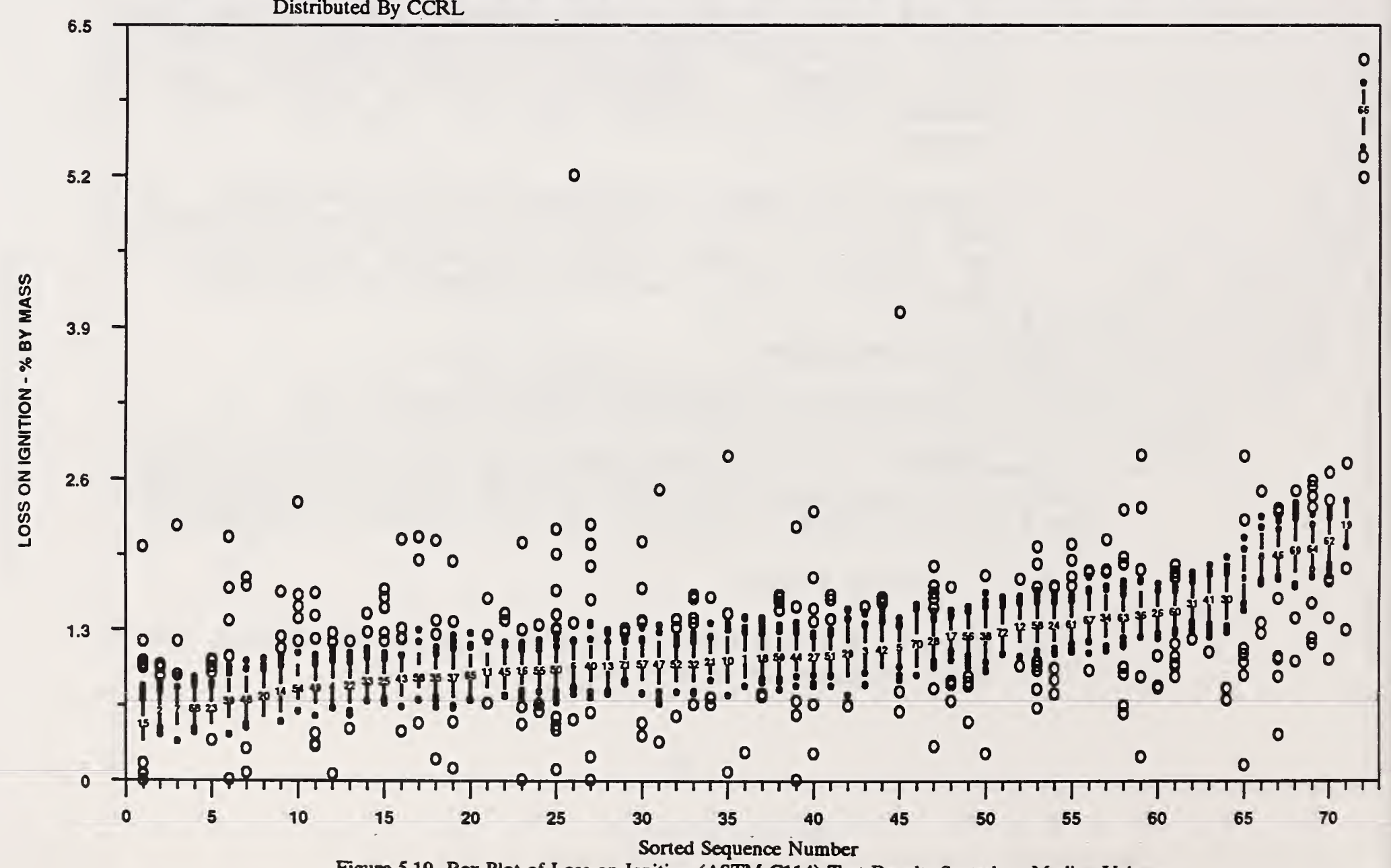

Figure 5.19 Bax Plot of Loss on Ignition (ASTM C114) Test Results Sorted on Median Values 


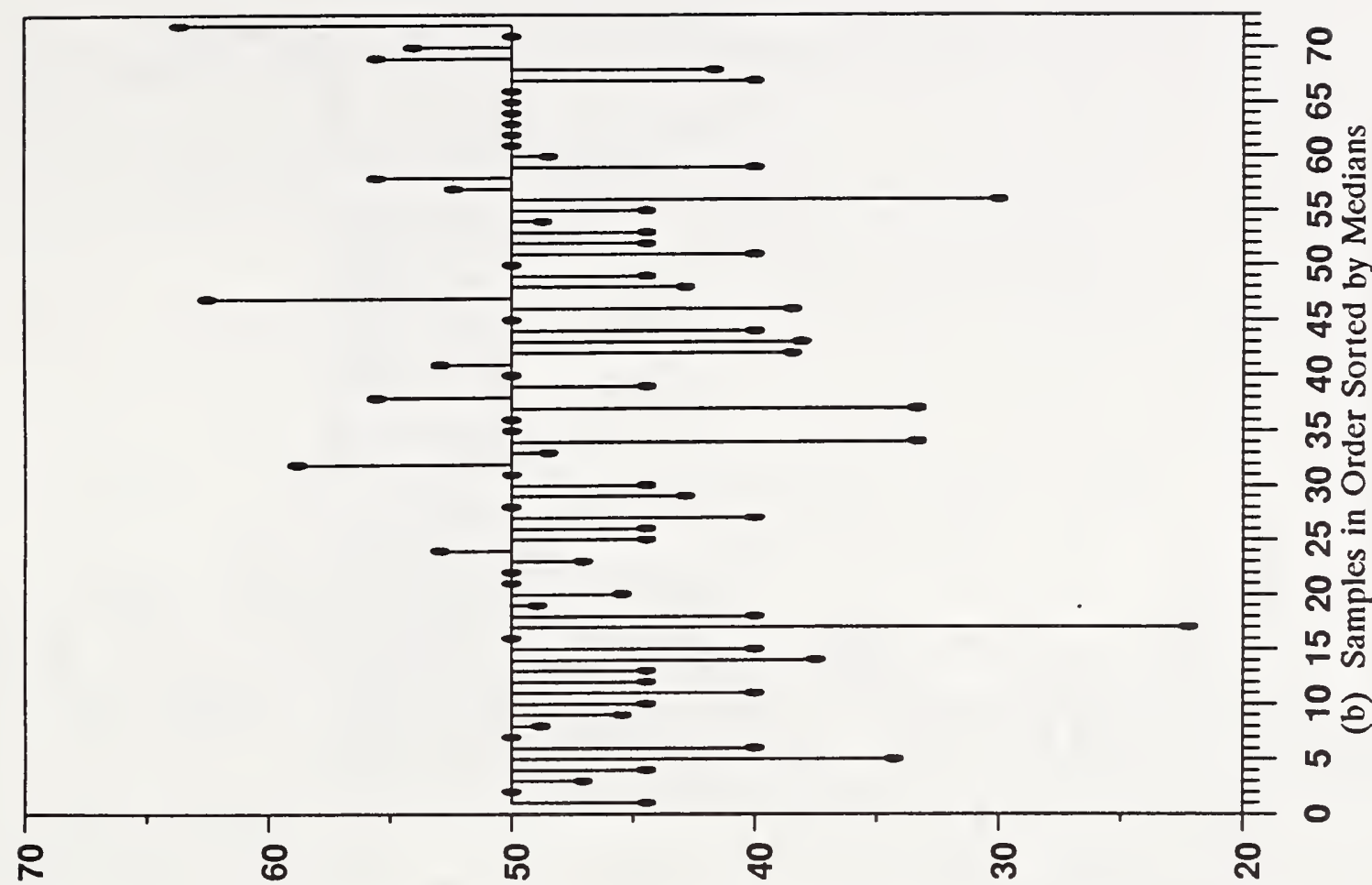

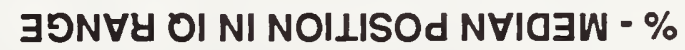

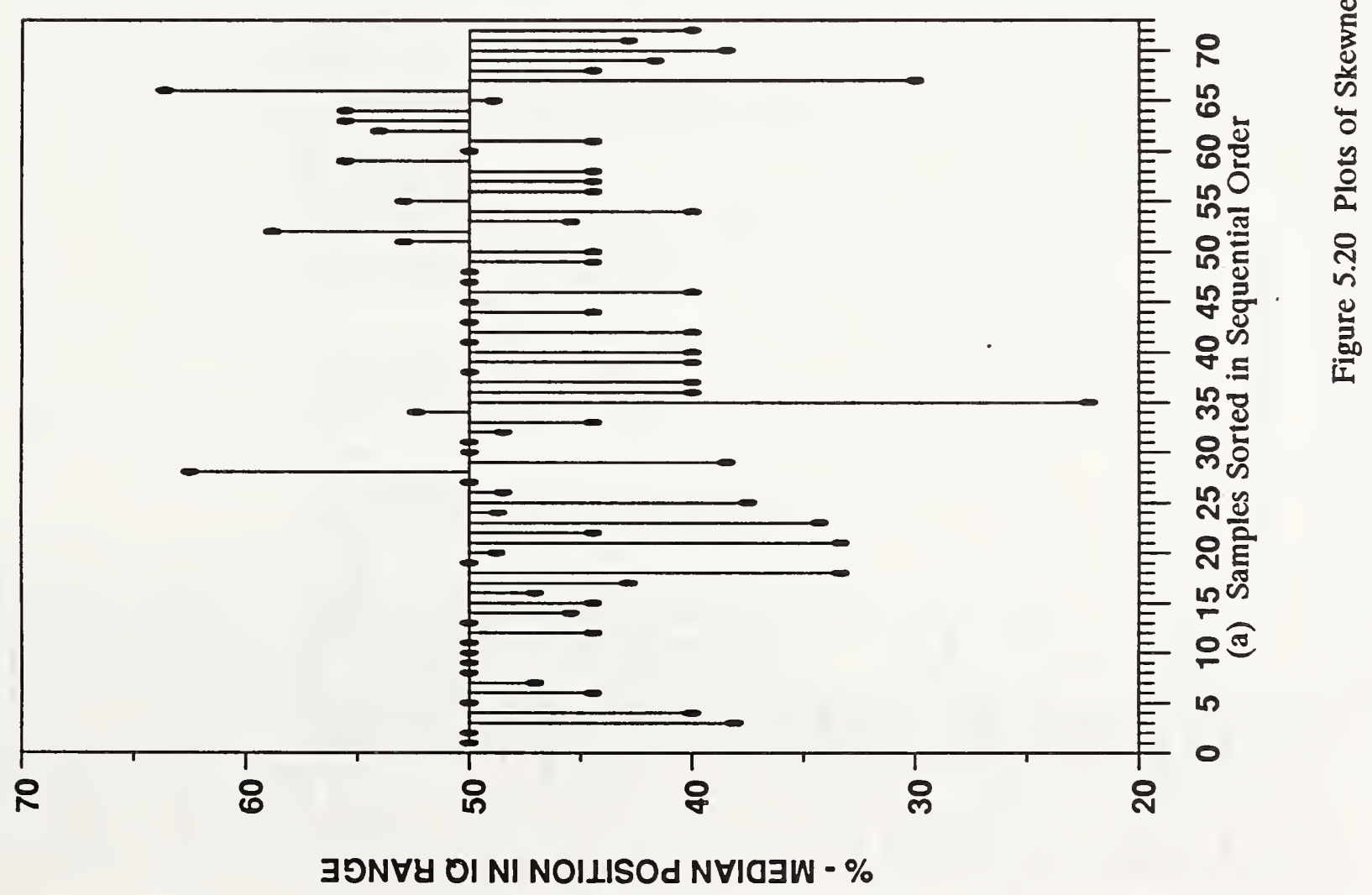



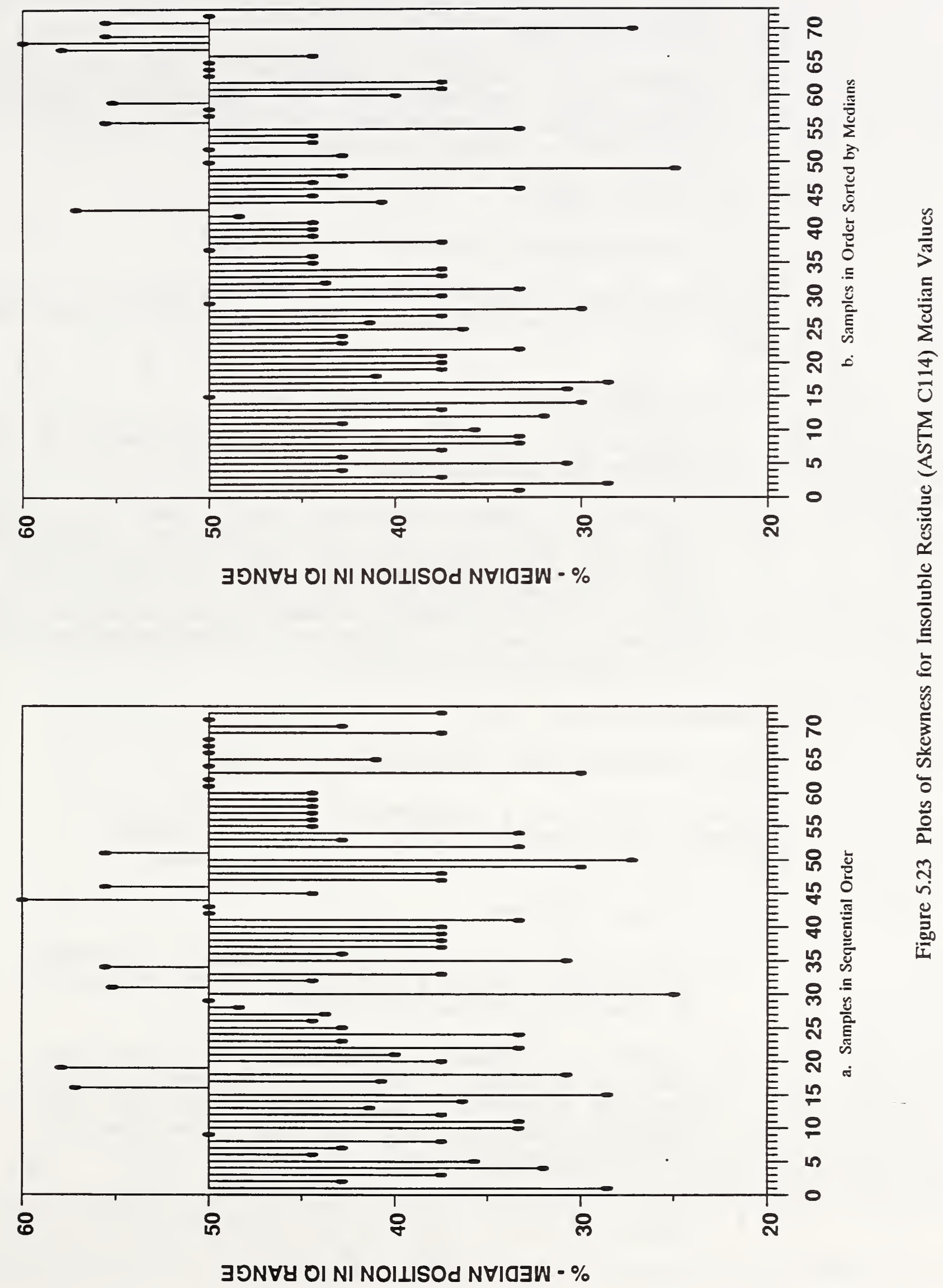
b. Figure 5.22 shows an available range of data from 0 to 0.65 percent (excluding sample 66). The IQ range is from 0.06 to 0.11 percent with some funneling apparent.

c. Figure 5.23 shows a skewness to the low side. While many laboratories are achieving complete dissolution as described in the test method, an appreciable number are not.

5.11 Sodium Oxide $\left(\mathrm{Na}_{2} \mathrm{O}\right)$

5.11.1 Statistical Presentation of Data

Figure 5.24 is a sequential box plot of percent of sodium oxide, and Figure 5.25 is a sorted box plot of the same data.

\subsection{1 .2 Observations}

a. Figure 5.24 yields no specific observations with respect to type of cement.

b. Figure 5.25 shows lowliers which tend to hug the body of data of the distributions, while the highliers are further away. The available range of data is from 0 to 0.56 percent (excluding sample 15). The IQ range extends from 0.03 to 0.06 percent. There is funneling in the IQ range above 0.25 percent $\mathrm{Na}_{2} \mathrm{O}$ content.

\subsection{Potassium Oxide $\left(\mathrm{K}_{2} \mathrm{O}\right)$}

\subsubsection{Statistical Presentation of Data}

Figure 5.26 is a sequential box plot of percent of potassium oxide results. Figure 5.27 is a sorted box plot of the same data.

\subsection{2 .2 Observations}

a. Figure 5.26 shows the Type II cements (samples 13-16) tend to be a bit lower in $\mathrm{K}_{2} \mathrm{O}$ compared to the other types of cement.

b. Figure 5.27 shows a preponderance of lowliers for all samples. The available range of data is from 0.08 to 1.25 percent. The IQ range extends from 0.03 to 0.1 percent, and there is clear funneling in the IQ range. 


\subsection{Summary of Chemical Component Test Data}

Table 4 summarizes the spreads of the medians and interquartile (IQ) ranges over all 72 samples for the chemical components of the CCRL Portland Cement Proficiency Samples.

\subsection{Relationships Between Properties of Portland Cements}

\subsection{Introduction}

The information on portland cement in chapters 4. and 5. provides opportunities to study interactions between various physical properties and chemical components. The purpose of this chapter is to give examples of such interactions which may be extended by the reader to other relationships. The treatment here is not exhaustive.

\subsection{Assemblage of Sorted Box Plots}

The sorted box plots in Chapters 4. and 5. are assembled on single sheets so that the characteristics of the tests may be visually compared and interpreted by those knowledgeable in the test methods. Characteristics of the test methods including relative test precision may be determined. Even though the box plots generally have different scales or units, characteristics of the method may be determined by observing lengths of the lines in relation to the available range of data, and the number and location of outliers. Recall that each box in a box plot is a schematic of a histogram with the interquartile range representing the body of the distribution and the outliers representing the tail of the distribution.

\subsubsection{Box Plots of Physical Properties}

Figures $6.1 \mathrm{a}$ and $6.1 \mathrm{~b}$ are assemblages of sequential box plots for the physical properties of portland cement presented in chapter 4. It should be noted that the properties shown on the vertical scale generally have different units and scales, while the sample sequences on the horizontal scale are the same. In this presentation it is possible to evaluate a given sample or group of samples for various properties.

Figures $6.2 \mathrm{a}$ and $6.2 \mathrm{~b}$ are assemblages of sorted box plots for the physical properties. The vertical axes generally have different units, and the sample sequence numbers on the horizontal scale differ from box plot to box plot.

The following observations may be made from Figures $6.2 \mathrm{a}$ and $6.2 \mathrm{~b}$ : 
Table 4 - Spread of Medians and Interquartile (IQ) Range for Chemical Test Results*

\begin{tabular}{||c|c|c|}
\hline \multicolumn{1}{|c|}{ Chemical Test } & Medians & IQ Ranges \\
\hline $\mathrm{SiO}_{2}(\%)$ & $19.20-22.41$ & $0.19-0.29(0.37)$ \\
\hline $\mathrm{Al}_{2} \mathrm{O}_{3}(\%)$ & $3.64-7.07$ & $0.21-0.38(0.49,0.74$, \\
\hline $\mathrm{Fe}_{2} \mathrm{O}_{3}(\%)$ & $1.87-4.44$ & $0.05-0.10(0.22,0.29)$ \\
\hline $\mathrm{CaO}(\%)$ & $60.29-65.73$ & $0.29-0.46$ \\
\hline $\mathrm{Free} \mathrm{Lime} \mathrm{( \% )}$ & $0.23-2.02$ & $0.17-0.35(0.45)$ \\
\hline $\mathrm{MgO}(\%)$ & $1.03-4.34$ & $0.13-0.29$ \\
\hline $\mathrm{SO} \mathrm{O}_{3}(\%)$ & $2.05-3.84$ & $0.06-0.12$ \\
\hline $\begin{array}{l}\text { Loss on Ignition } \\
(\%)\end{array}$ & $0.50-2.22(5.78)$ & $0.07-0.13$ \\
\hline $\begin{array}{l}\text { Insoluble Residue } \\
(\%)\end{array}$ & $0.10-0.43(1.45)$ & $0.06-0.11(0.14)$ \\
\hline $\mathrm{Na}_{2} \mathrm{O}(\%)$ & $0.04-0.43(0.66)$ & $0.02-0.13$ \\
\hline $\mathrm{K}_{2} \mathrm{O}(\%)$ & $0.14-1.06$ & $0.02-0.12$ \\
\hline
\end{tabular}

* Values in brackets are those separated from the principal range of the data. 

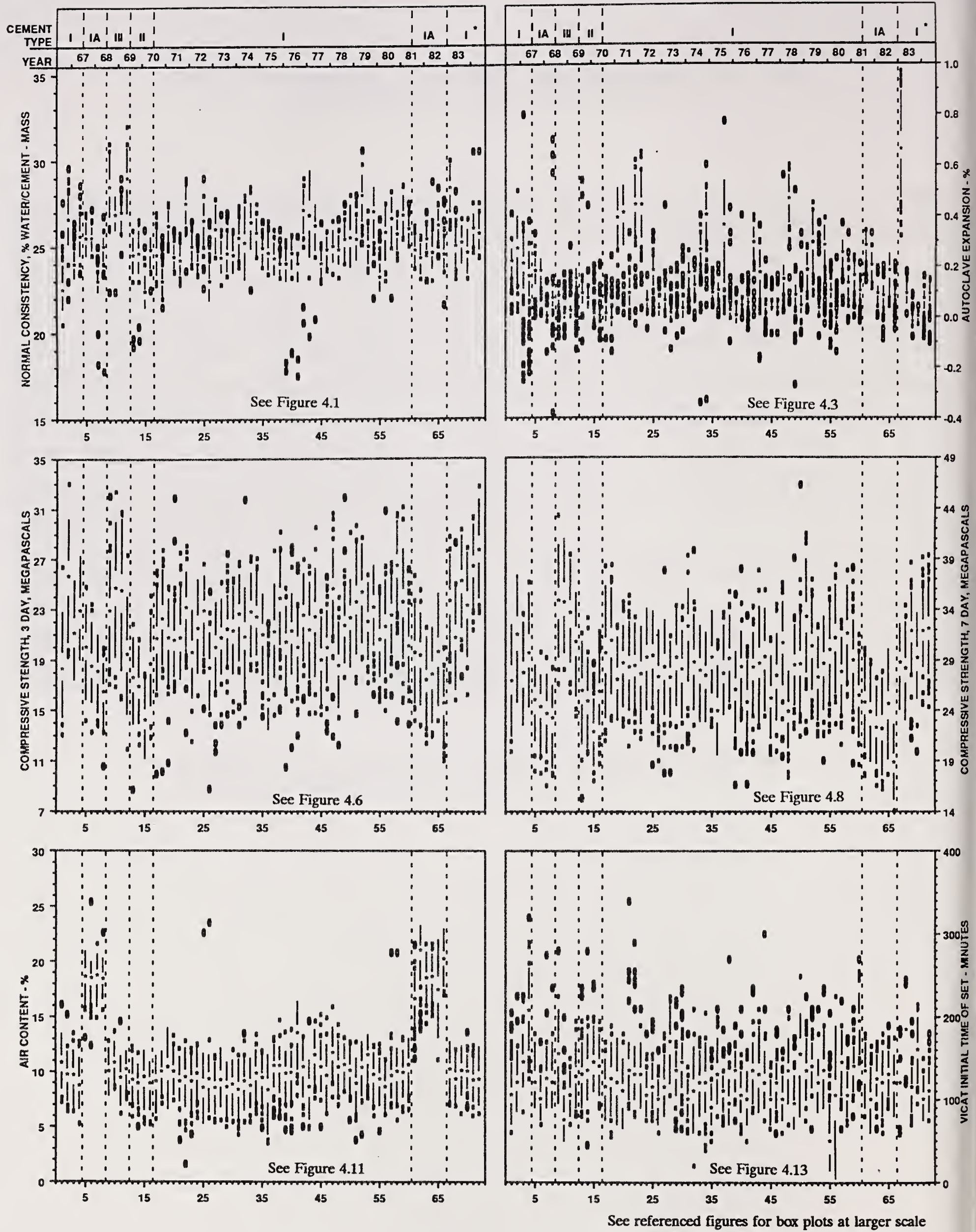

*Sample 68 Type I/II

Figure 6.1a Assemblage of Sequential Box Plots for Physical Properties of CCRL Portland Cement Samples 1-72 

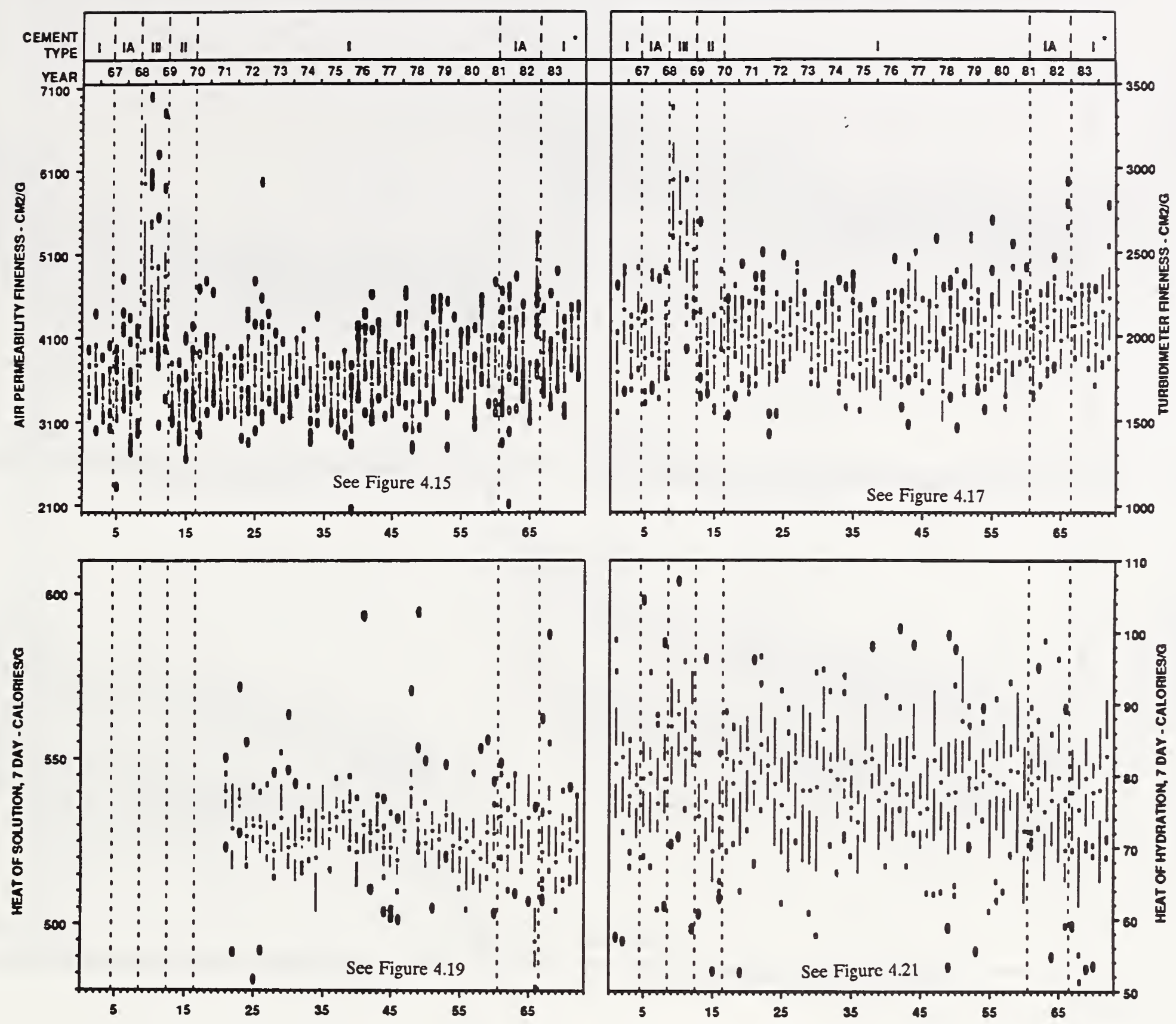

See referenced figures for box plots at larger scale

-Sample 68 Type I/II

Figure 6.1b Assemblage of Sequential Box Plots for Physical Properties of CCRL Portland Cement Samples 1-72 


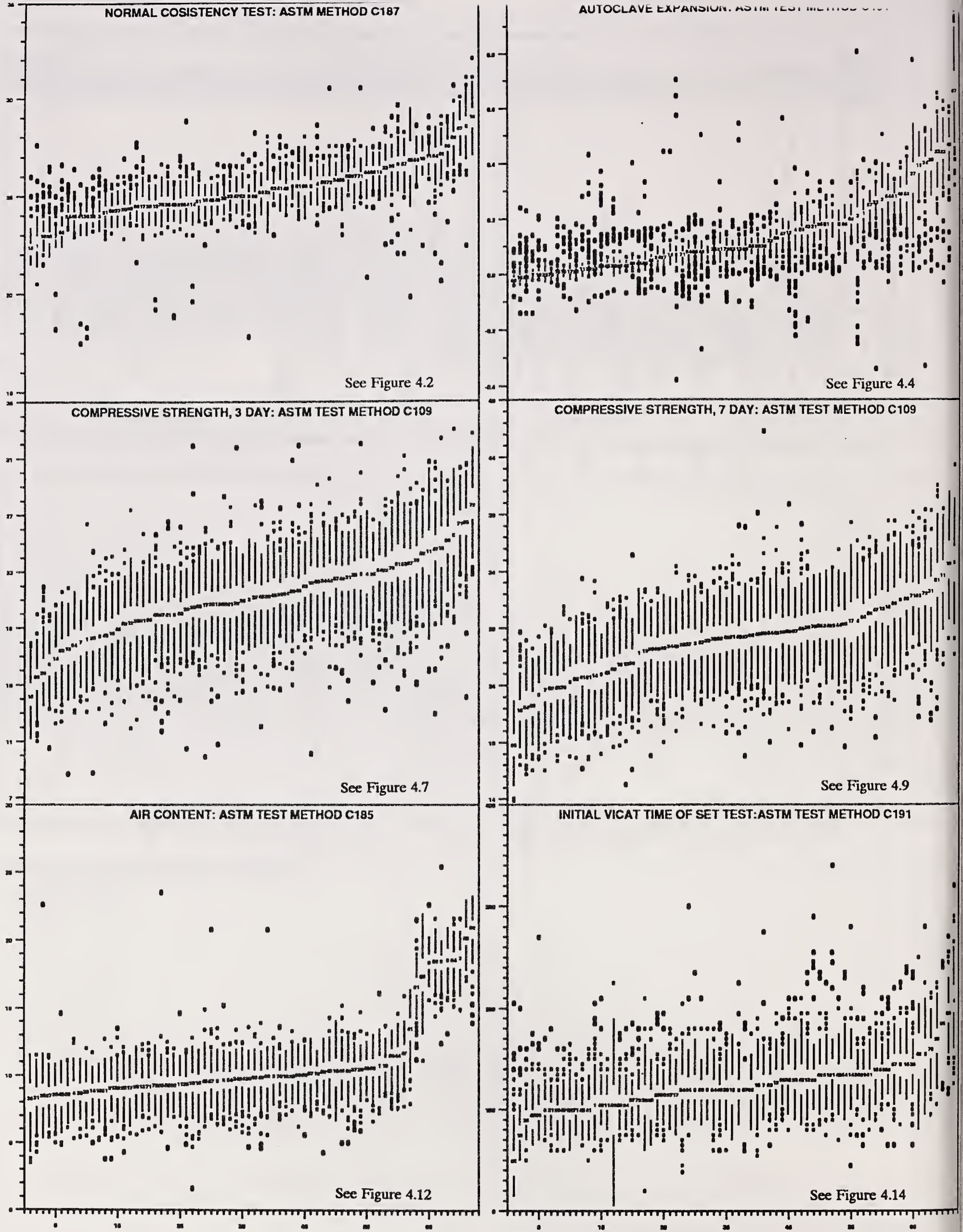

See referenced figures for box plots at larger scale 


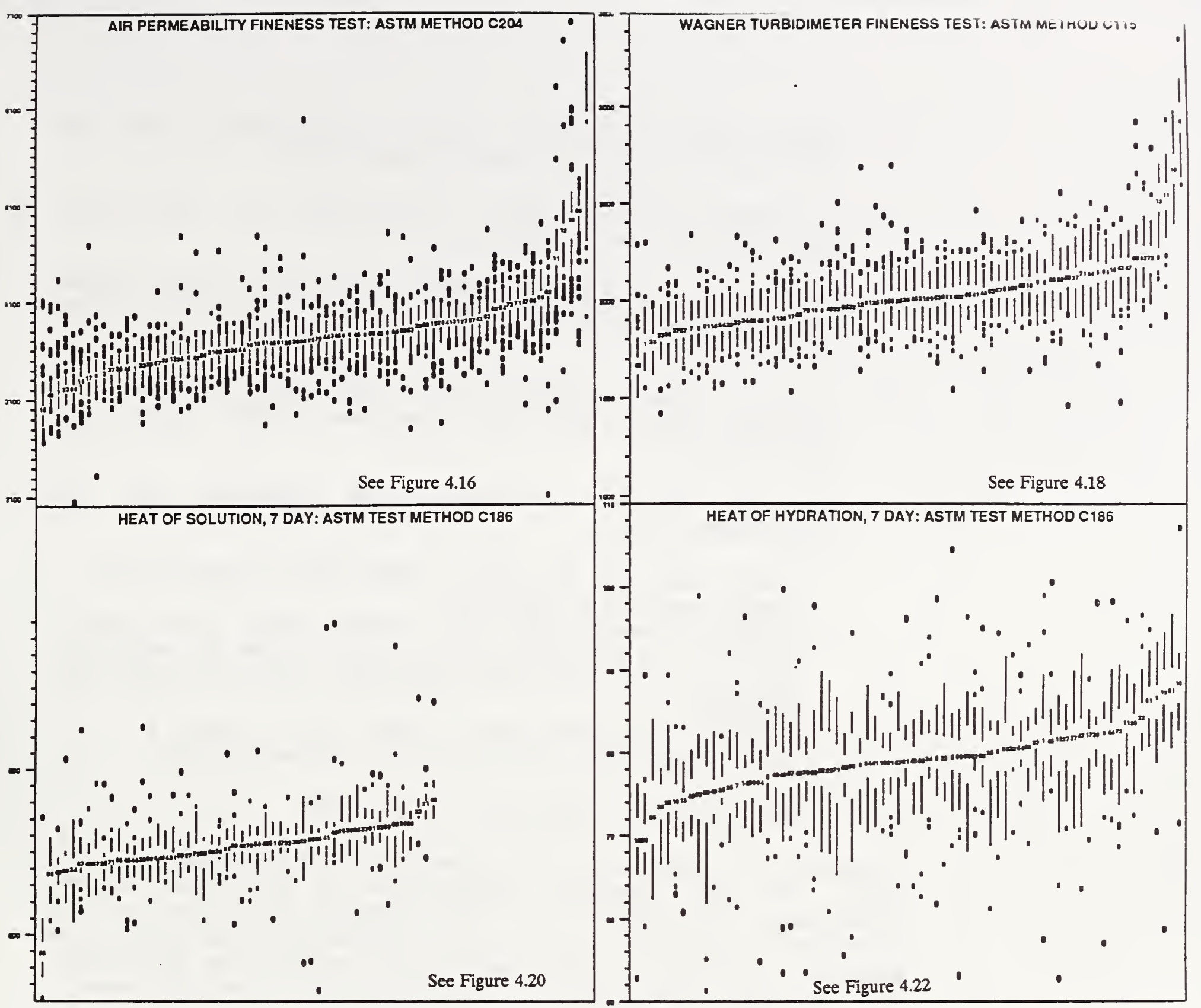

See referenced figures for bax plots at larger scale

Figure 6.2b Assemblage of Sorted Box Plots for Physical Properties of CCRL Portland Cement Samples 1-72 
a. Funneling in the IQ range is apparent for the autoclave expansion test (ASTM C151).

b. A discretization effect is apparent for the Vicat time of set test (ASTM 191).

c. Modulation in the IQ range is shown in the Vicat time of set (ASTM 191) and heat of hydration (ASTM C186) tests.

d. Cement types effects are apparent in the air content (ASTM C185) and fineness tests (ASTM C204 and $\mathrm{Cl15}$ ).

e. Unusual outlier patterns are apparent in the following tests:

- Vicat time of set test (ASTM C191) shows more highliers than lowliers.

- Autoclave expansion test (ASTM C151) shows more highliers than lowliers for the first 40 samples, and more lowliers and highliers for the remaining samples.

- Heat of hydration test (ASTM C186) shows a relatively even distribution of outliers.

\subsubsection{Box Plots of Chemical Components}

Figures $6.3 \mathrm{a}$ and $6.3 \mathrm{~b}$ are assemblages of sequential box plots for the chemical components of portland cement presented in Chapter 5. The components shown on the vertical scale generally have different scales, while the sample sequences on the horizontal scale are the same. The vertical axes are all in common units (percent mass), but the scales differ.

Figures $6.4 \mathrm{a}$ and $6.4 \mathrm{~b}$ are assemblages of sorted box plots for chemical components of portland cement presented in Chapter 5. The sample sequence number on the horizontal axes differs from box plot to box plot.

The following observations may be made from Figures $6.3 \mathrm{a}$ and $6.3 \mathrm{~b}$ :

a. The Type III cements and sample 66 (Type IA) have the highest $\mathrm{SO}_{3}$ content which may give an indication of the amount of $\mathrm{CaSO}_{4}$ needed to counter the degree of 'flash set introduced by the finer grinding.

b. The $\mathrm{MgO}, \mathrm{SiO}_{2}, \mathrm{~K}_{2} \mathrm{O}, \mathrm{Na}_{2} \mathrm{O}$ and Insoluble Residue box plots show many outliers from the primary range of data. 

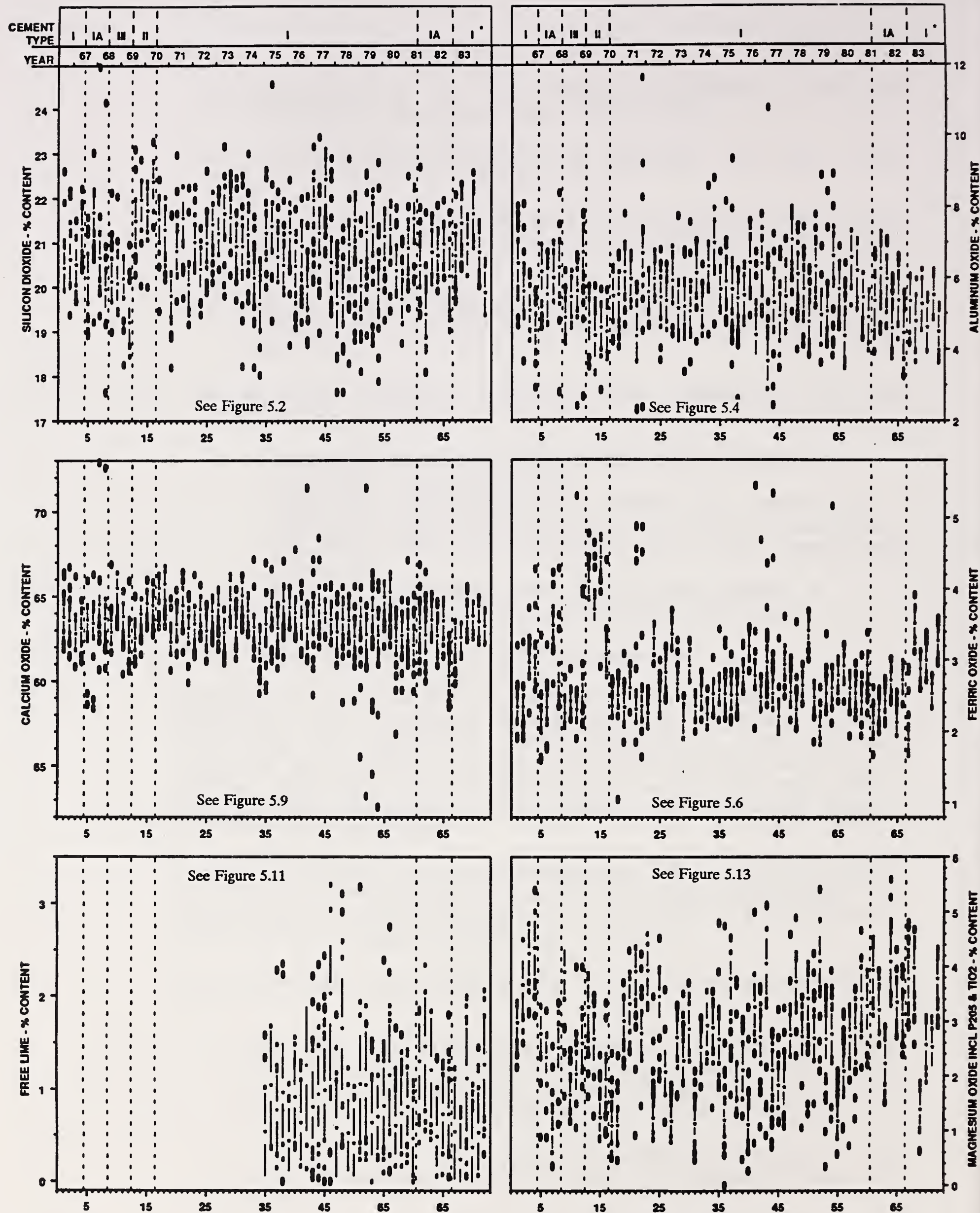

See referenced figures for box plots at larger scale

-Sample 68 Type III

Figure 6.3a Assemblage of Sequential Box Plots For Chemical Components of CCRL Portland Cement Samples 1-72 

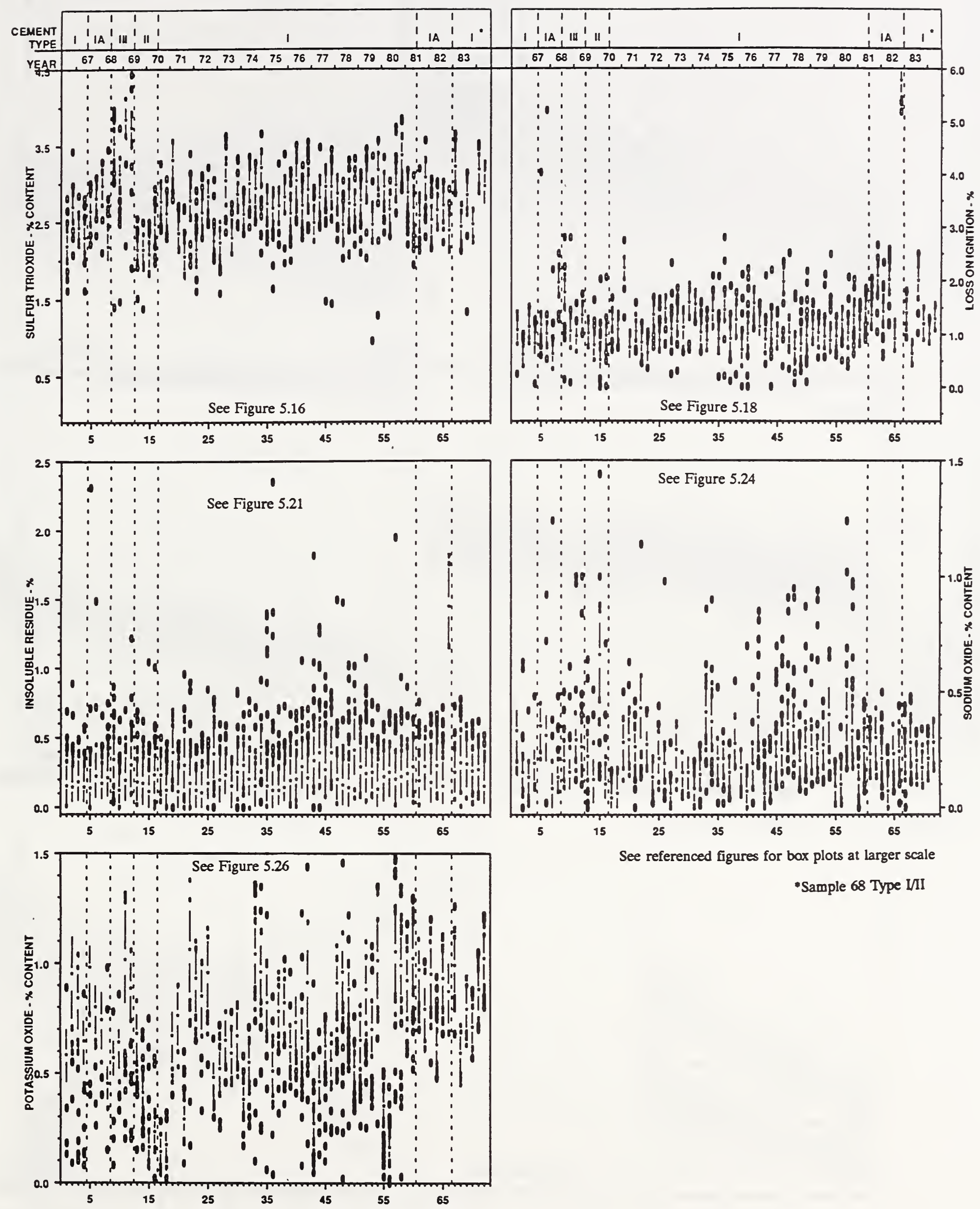

- Sample 68 Type I/II

Figure 6.3b Assemblage of Sequential Box Plots For Chemical Components of CCRL Portland Cement Samples 1-72 


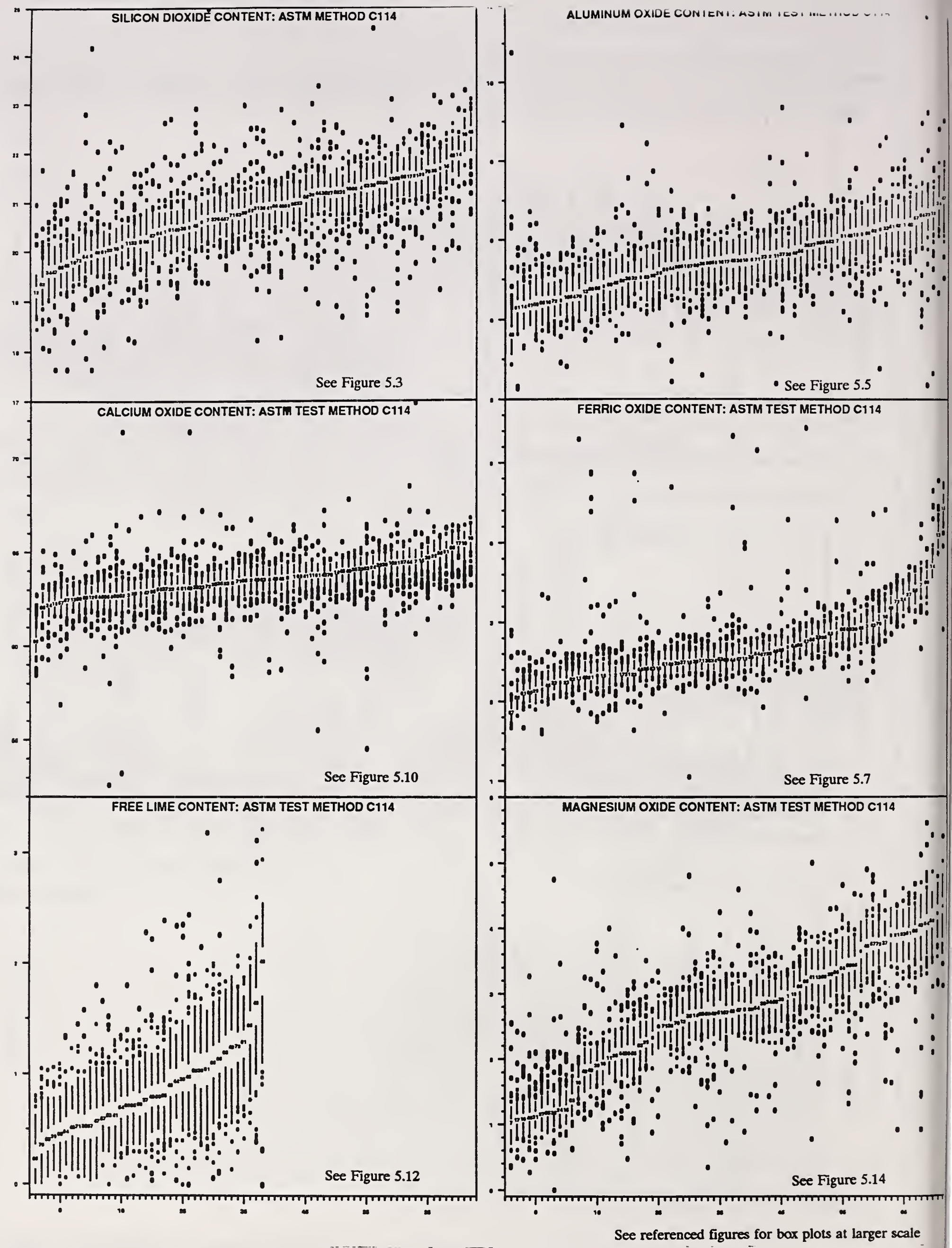

Figure 6.4a Assemblage of Sorted Box Plots for Chemical Components of CCRL Portland Cement Samples 1-72 


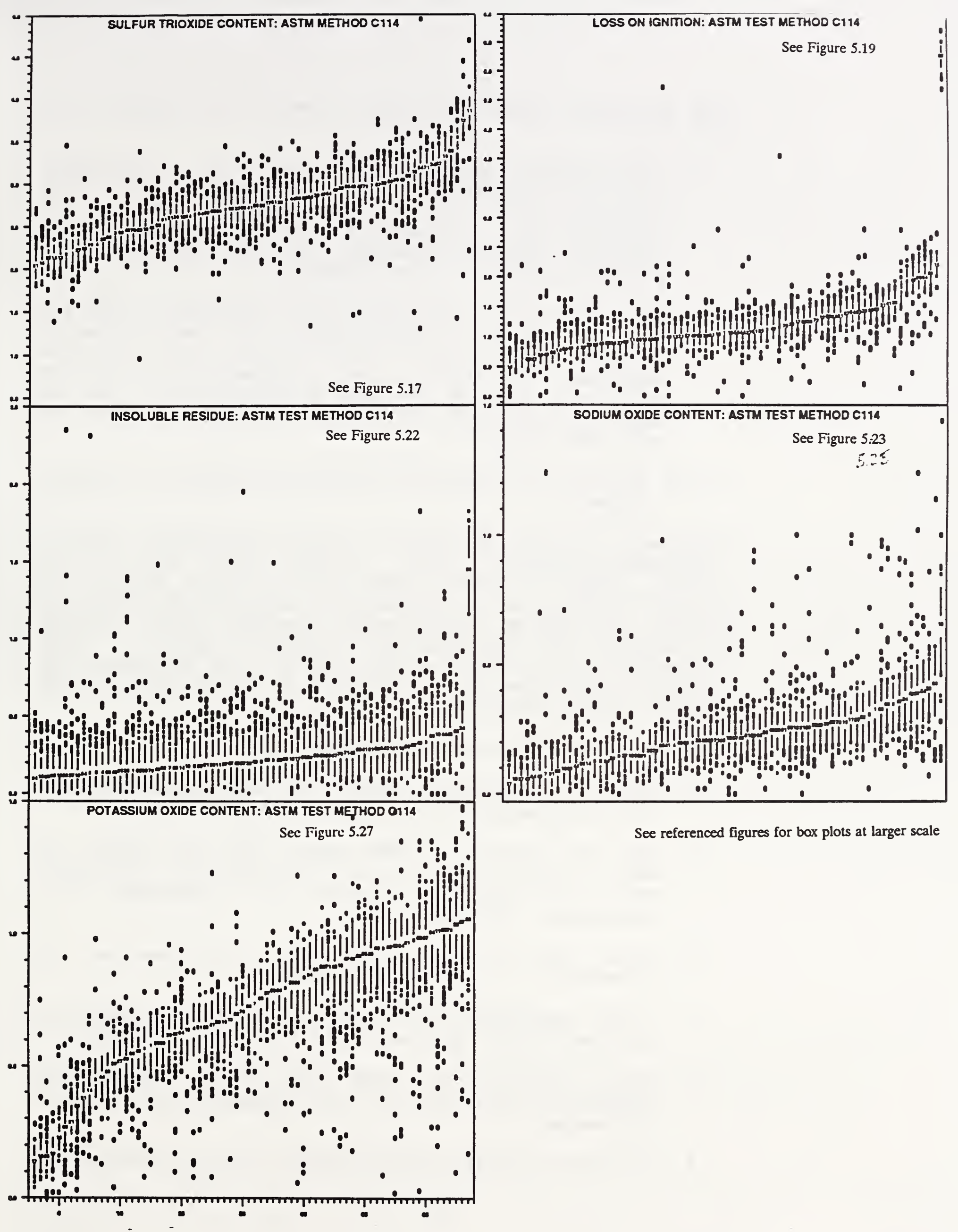

Figure 6.4b Assemblage of Sorted Box Plots for Chemical Components of CCRL Portland Cement Samples 1-72 
The following observation may be made from Figures 6.4 a and $6.4 \mathrm{~b}$ :

a. The ranges of median values are: $\mathrm{SiO}_{2}-3$ percent, $\mathrm{Al}_{2} \mathrm{O}_{3}-3.4$ percent, $\mathrm{Fe}_{2} \mathrm{O}_{3}-1.6$ percent, CaO - 5.5 percent, Free Lime - 1.8 percent, Mgo - 3.3 percent, $\mathrm{SO}_{3}-1.8$ percent, Loss on Ignition - 1.7 percent, Insoluble Residue - 0.3 percent, $\mathrm{Na}_{2} \mathrm{O}-0.4$ percent, and $\mathrm{K}_{2} \mathrm{O}-0.9$ percent.

b. The slope of a line through the medians of the $\mathrm{K}_{2} 0$ box plot changes significantly at the thirteenth sample. Similarly, a displacement upward in the medians in the Mgo box plot is apparent at the same location. Five of the same samples $(15,17,18,31$ and 56) are among the first thirteen samples of both box plots.

6.2.3 Box Plot of Physical Properties Sorted on a Single Property

Figures $6.5 \mathrm{a}$ and $6.5 \mathrm{~b}$ display normal consistency ( $\mathrm{C187}$ ), autoclave expansion (C151), initial Vicat time of set (C191), 3-day and 7-day compressive strength (C109), air content (C185), heat of solution and heat of hydration (C185), and wagner turbidimeter fineness (C115) plotted on sorted air permeability fineness (C204). This representation allows a single sample to be evaluated for all the properties shown since the box plots of the same sample align vertically.

The following observations may be made:

a. Autoclave expansion (ASTM C151) decreases slightly as air permeability fineness increases.

b. Heat of hydration (ASTM C186) does not appear to show a relationship to air permeability fineness; heat of solution appears to decrease with increasing fineness.

c. Vicat time of set (ASTM C191) decreases as air permeability fineness increases.

d. 7-day compressive strength (ASTM C109) appears to increase as air permeability fineness increases.

e. Normal consistency (ASTM C187) water requirement appears to increase as air permeability fineness increases.

f. Fineness by Wagner Turbidimeter (C115) increases as 


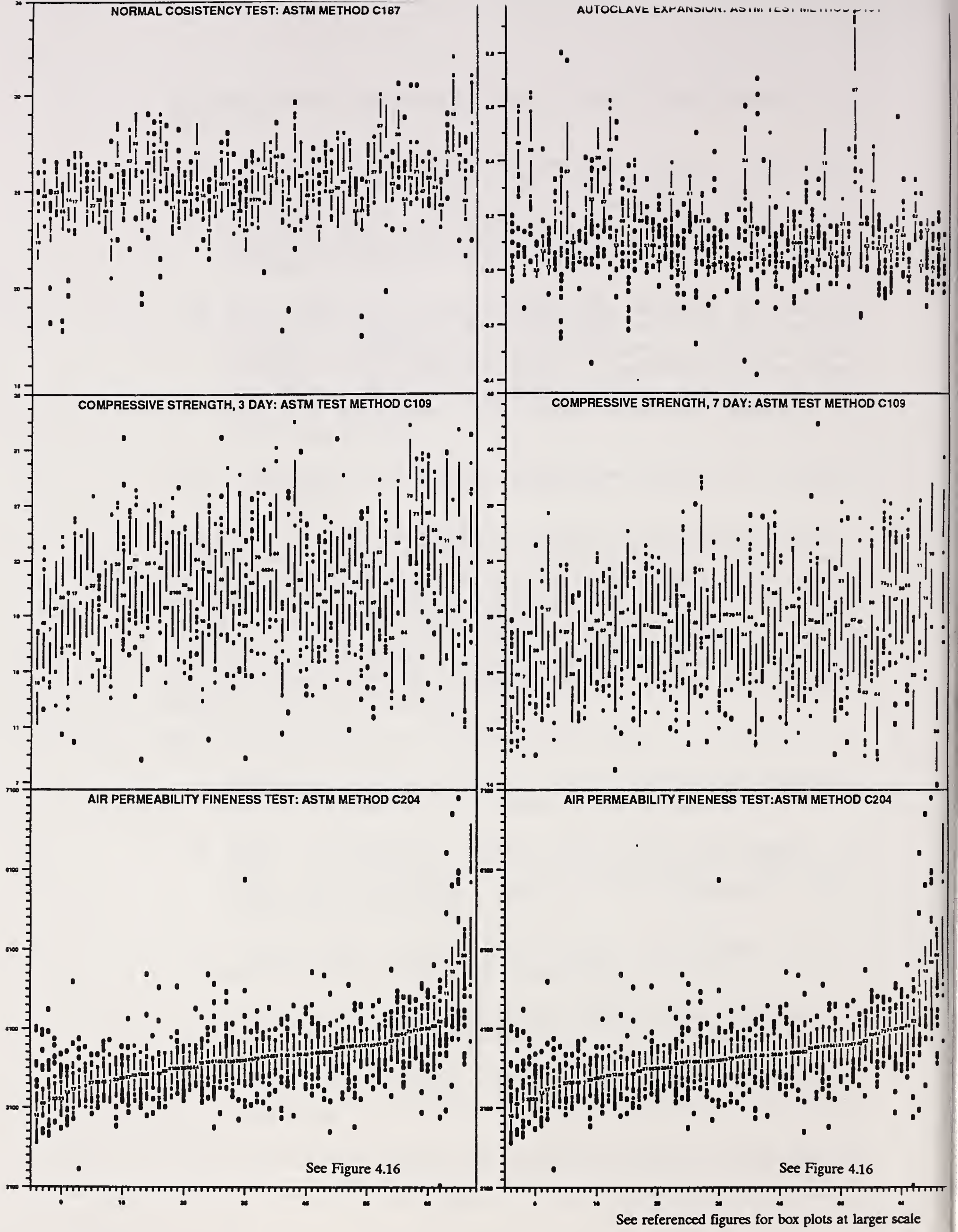

Figure 6.5a Box Plots of Various Physical Properties Sorted by Air Permeability Fineness Results (ASTM C204) 


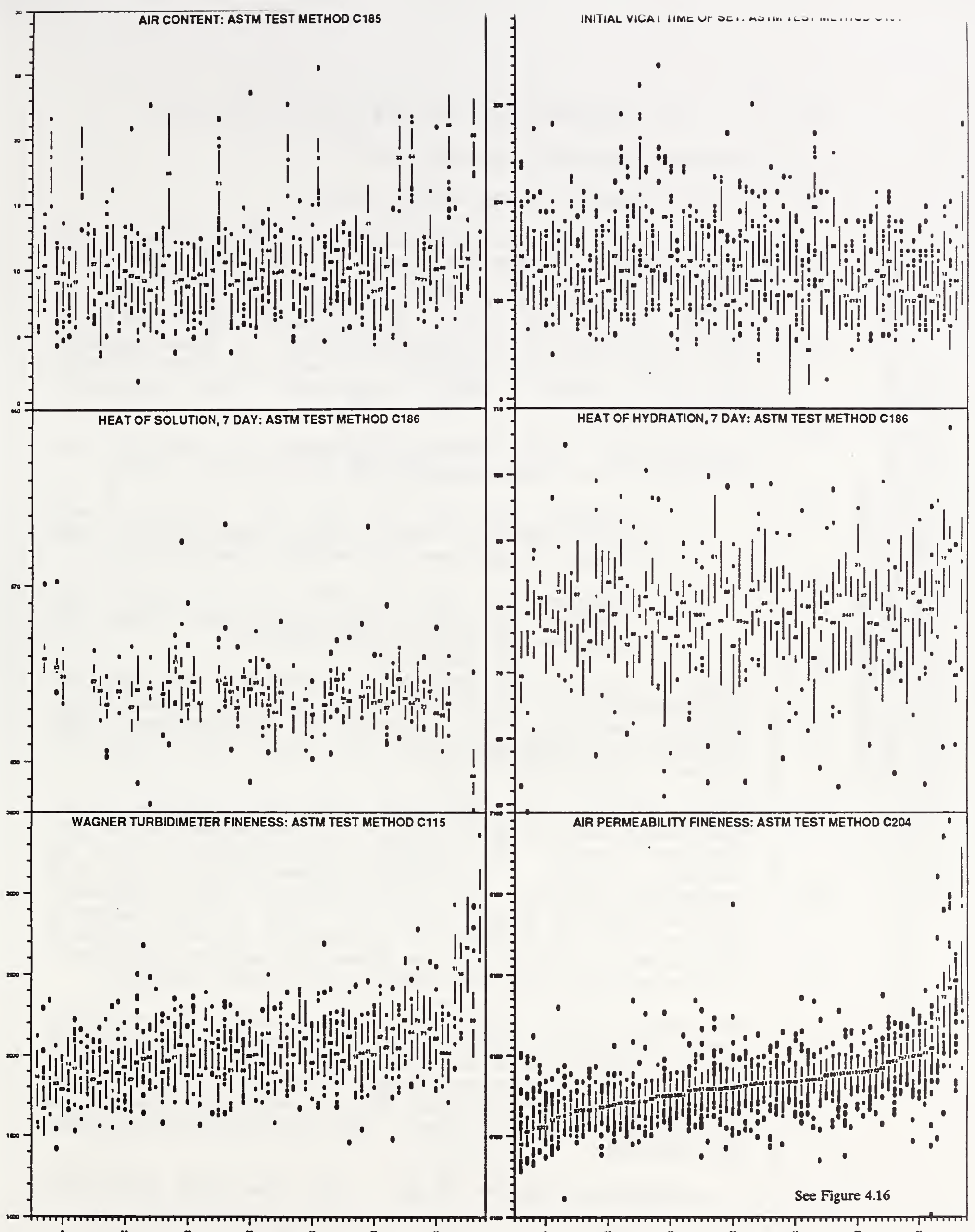

Figure 6.5b Box Plots of Various Physical Properties Sorted Air Permeability Fineness Results (ASTM C204) 
Air Permeability Fineness (C204) increases.

\subsection{Study of Specific Relationships}

\subsubsection{Fineness Versus Water Demand}

It is generally accepted that the finer a cement, the more water it should take to achieve the same consistency. [8.14] Figure 6.6 is the box plot for Normal Consistency (C187) plotted against a base of sorted air permeability fineness (C204) which will be used to evaluate this "rule of thumb". A least-squares fit to the medians (Figure 6.7 ) shows a significantly positive slope, which supports the suggested relationship.

Observations from selected cements in Figure 6.6 illustrate the usefulness of box and profile plots.

1. Samples $24,26,41,55,62,64$ and 66 are finer cements that require appreciably less water to achieve the normal consistency.

2. Samples $22,25,33,42,54,57$ and 65 are coarser cements requiring more water to achieve the normal consistency.

These 14 samples can be used to investigate the apparent differences in water needs for normal consistency. Chemical make-up might explain the differences. The information contained in profile plots can be used to compare sample properties.

Information on the samples is profiled in Figure 6.8 in the manner described in section 3.4 and Appendix $C$. The combined profile for chemical components of the 14 samples is shown. The samples appear together at each component profile. The top 7 profile bars represent cements needing less water; the lower 7 those needing more water. (Note that all 14 samples do not include a Free Lime profile line since Free lime was not determined in the earlier portland cement proficiency samples.)

The profile plot in Figure 6.8 is divided with vertical dash lines at 33 percent and 67 percent. The numbers used to generate this figure are given in Table 5. Sample results are categorized as being low (left of the $1 / 3$ line), medium (between the $1 / 3$ and $2 / 3$ lines), and high (right of the $2 / 3$ line). The following observations can be made:

a. Potassium Oxide $\left(\mathrm{K}_{2} \mathrm{O}\right)$ - All the high water/low 


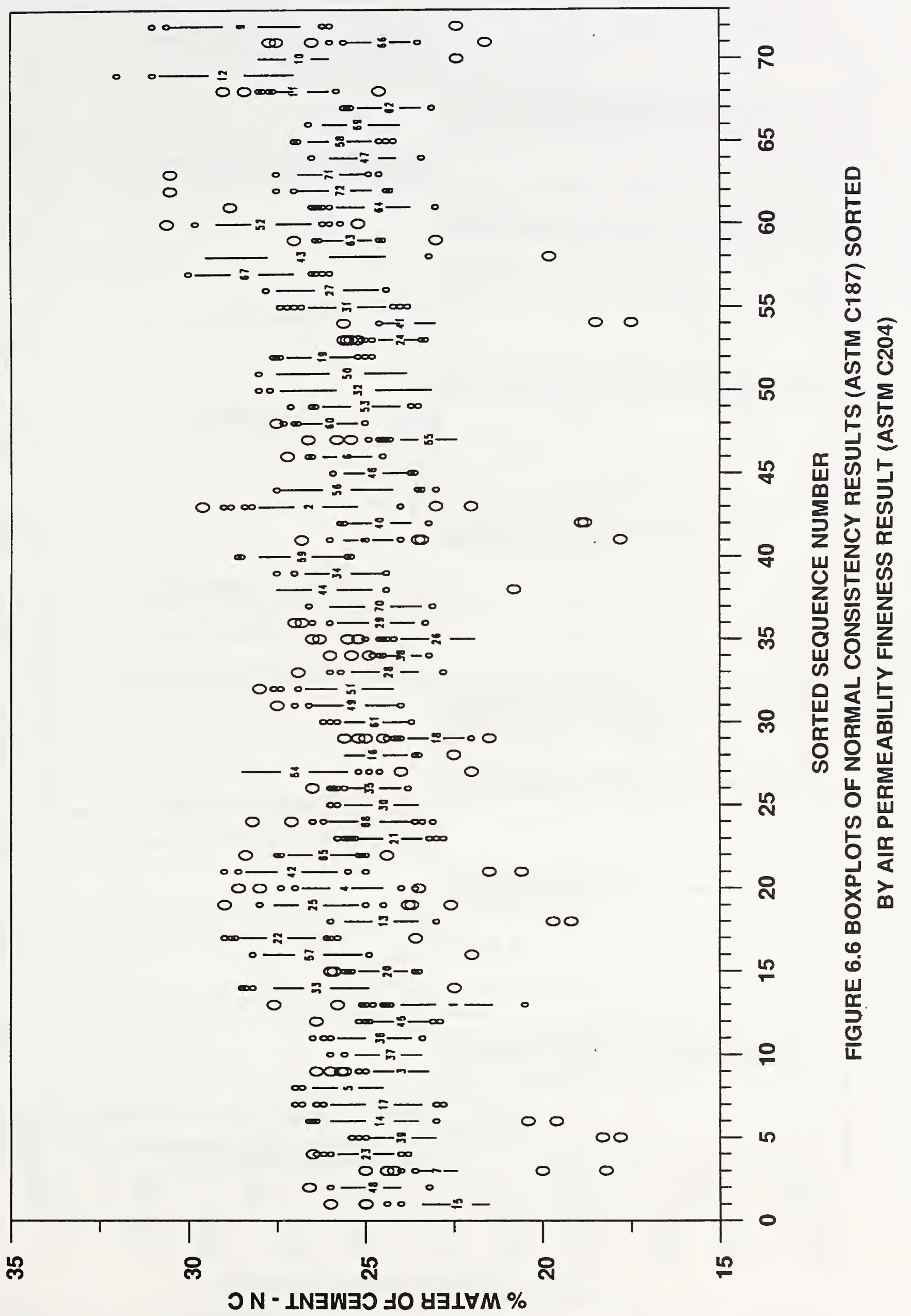




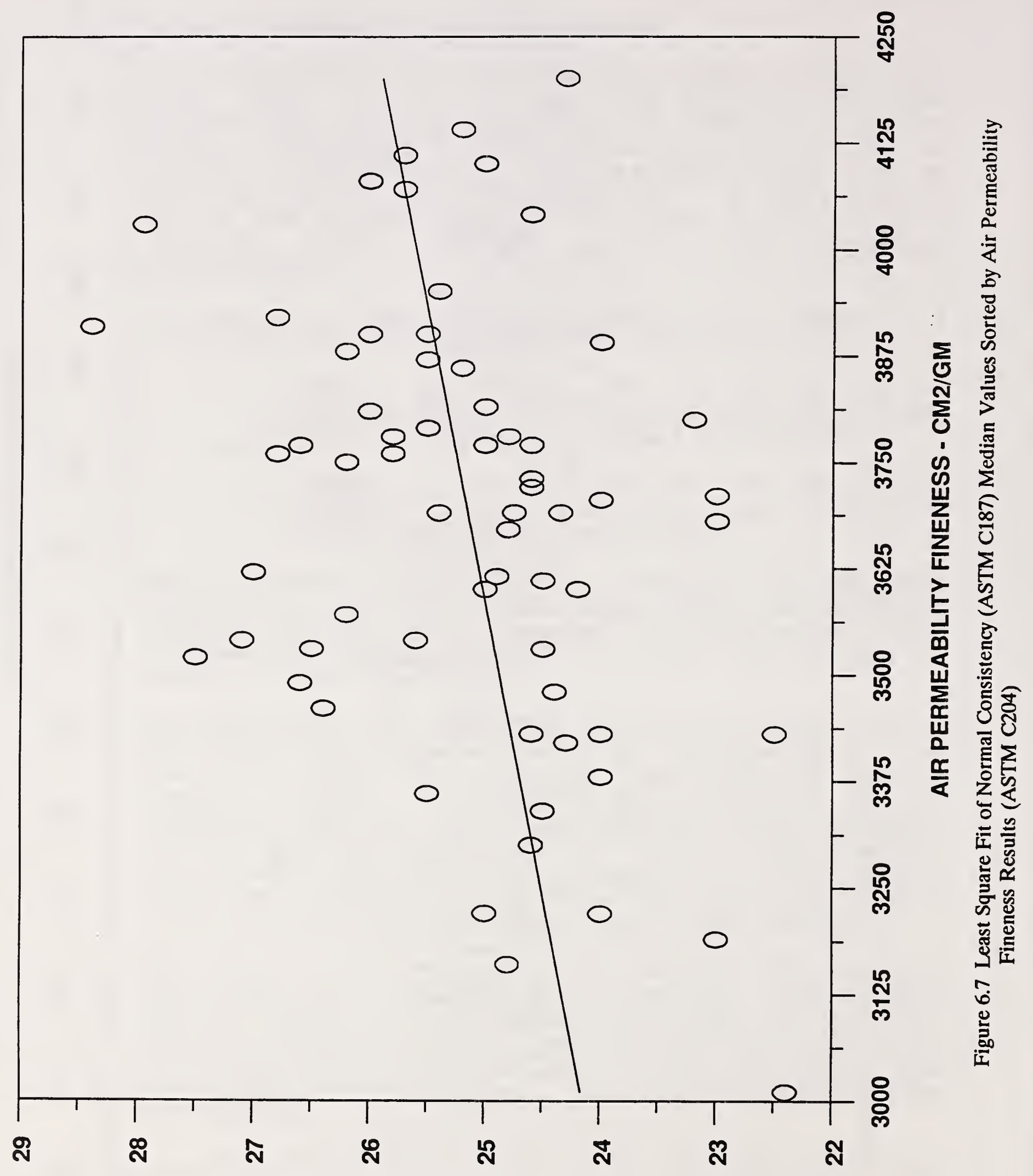

$\forall \exists \perp \forall M \%-\wedge O N \exists \perp S I S N O \supset 7 \forall W H O N$ 


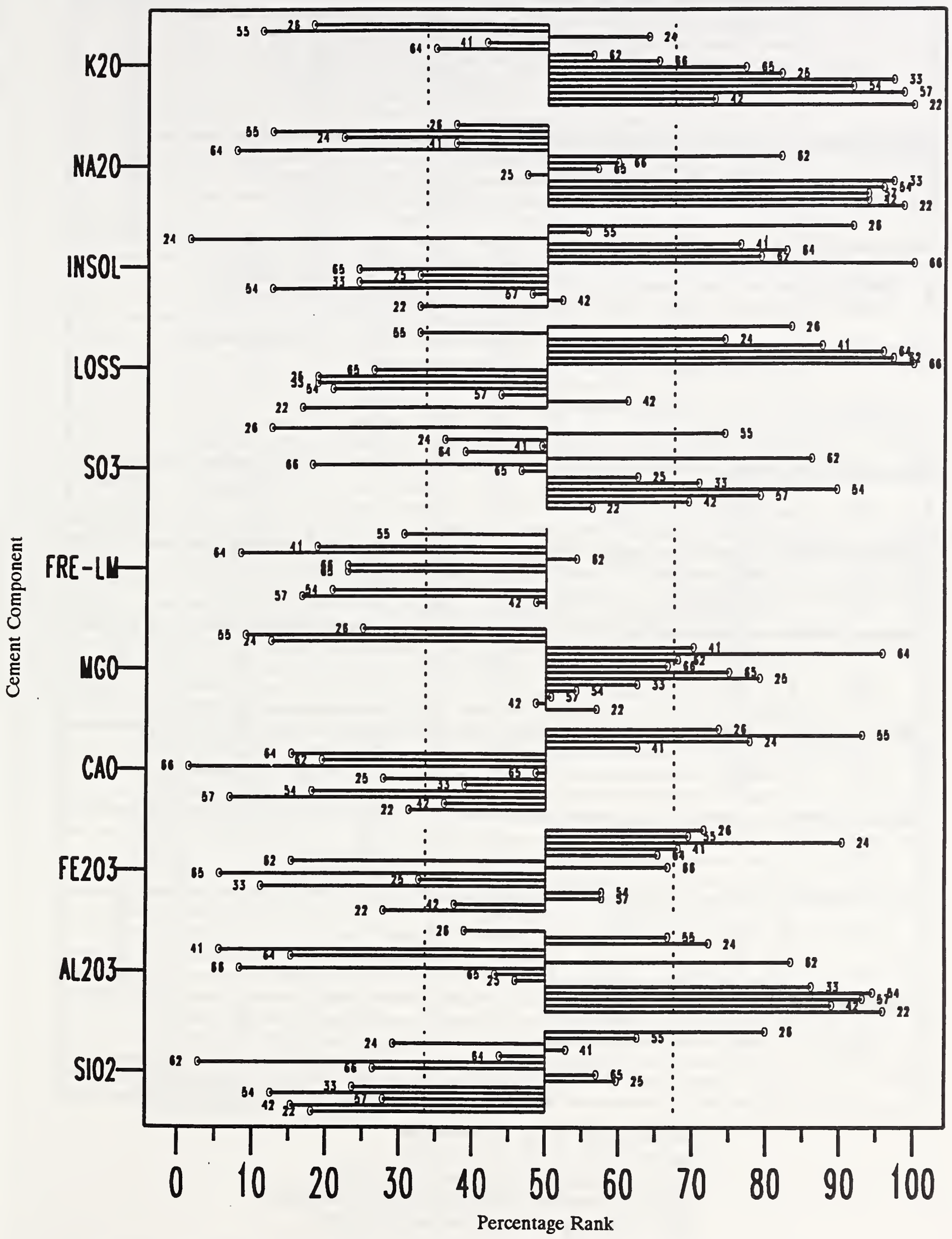

Figure 6.8 Chemical Profiles of 14 Cements Selected to Evaluate Chemical Composition and Water Requirement 


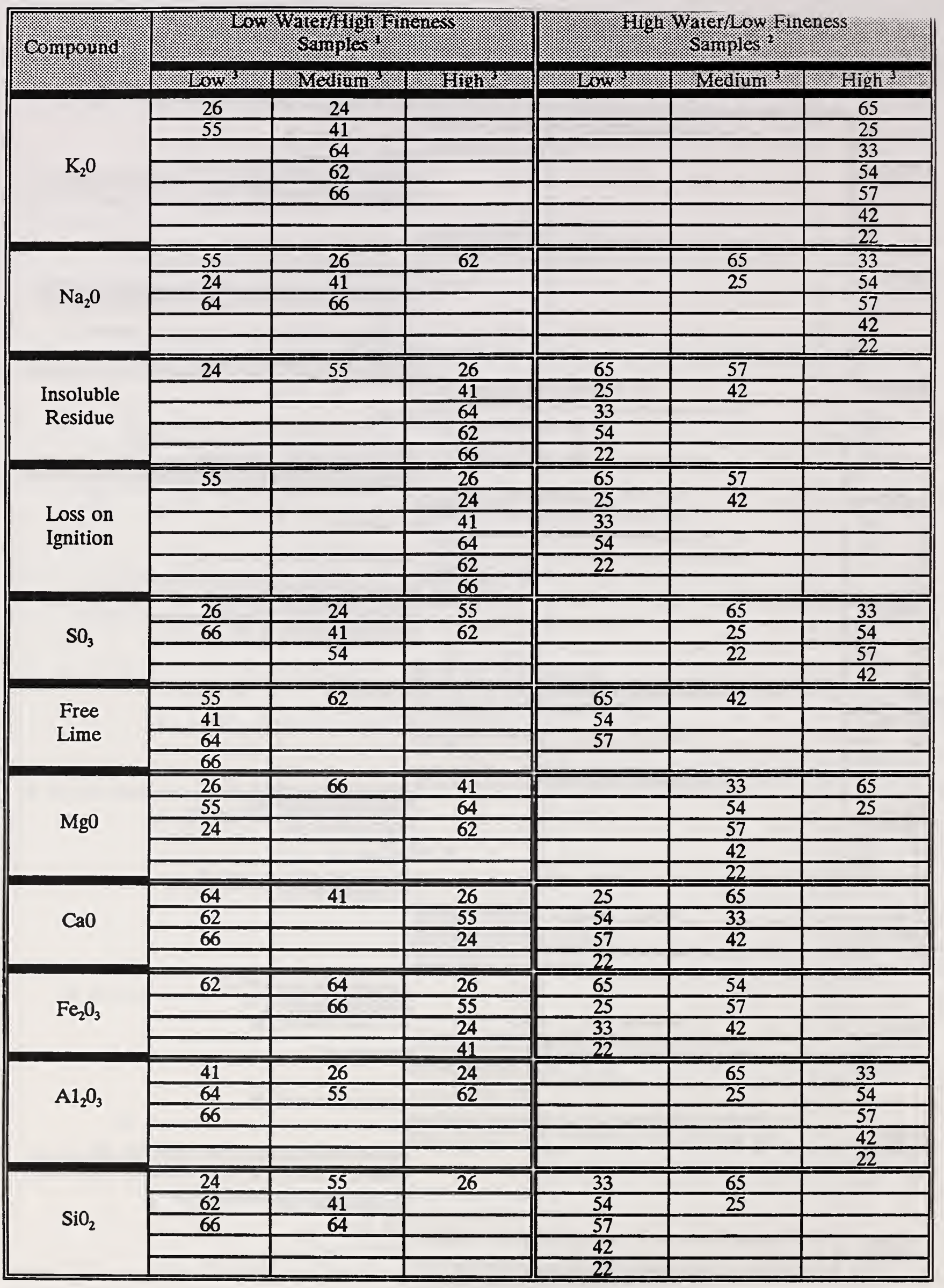

1 Samples 24, 26, 41, 55, 62, 64 and 66.

2 Samples 22, 25, 33, 42, 54, 57 and 65.

3 Low - Percentage ranking from 0 to $331 / 3 \%$

Medium - Percentage ranking from $331 / 3$ to $662 / 3 \%$

High - Percentage ranking from $662 / 3$ to $100 \%$

Summary of Chemical Profiles for 14 Cements 
fineness samples are in the high category; while 5 of the 7 low water/high fineness samples are in the medium category. A similar situation exists for sodium oxide $\left(\mathrm{Na}_{2} \mathrm{O}\right)$.

b. Insoluble Residue and Loss on Ignition - In both cases 5 of the 7 low water/high fineness samples are in the high category; while 5 of the 7 high water/low fineness samples are in the low category.

This illustrates the use of the profile graphics as an investigative tool. Limited to reasonable numbers of samples for representational purposes, any combination of samples and any combination of test results can be profiled.

\subsubsection{Other Relationships}

Figure 6.9 is a box plot of the 7-day Compressive strength (ASTM C109) results sorted on the 3-day Compressive strength. Good correlation is shown, as would be expected.

Figure 6.10 is a box plot of Normal Consistency (ASTM C187) results of samples 35 through 72 sorted on Free Lime test (ASTM C109) medians. There are more lowliers further away from the primary range of data than highliers. No other trends are apparent.

\section{Conclusions and Recommendations}

The CCRL is conducting a long-term study with the objective of improving the understanding of portland cement and concrete technology through evaluation of a large database of laboratory test results. This database consists of over 200,000 pieces of data collected from laboratories that tested portland cement proficiency samples distributed by CCRL from 1966 to 1984. These data consist of physical and chemical properties determined by laboratories using standard ASTM test methods. Selected techniques for graphical representation of the data are described and used to present the data in a form suitable for evaluation. Certain presentations are meant to illustrate how these statistical tools may be used to study known or theorized information about cement and concrete technology. This analysis is not meant to be exhaustive but rather to stimulate those interested in the technology to consider further applications. The authors are prepared to work with others in applying the tools and information presented here in further analysis of the CCRL or other databases. 


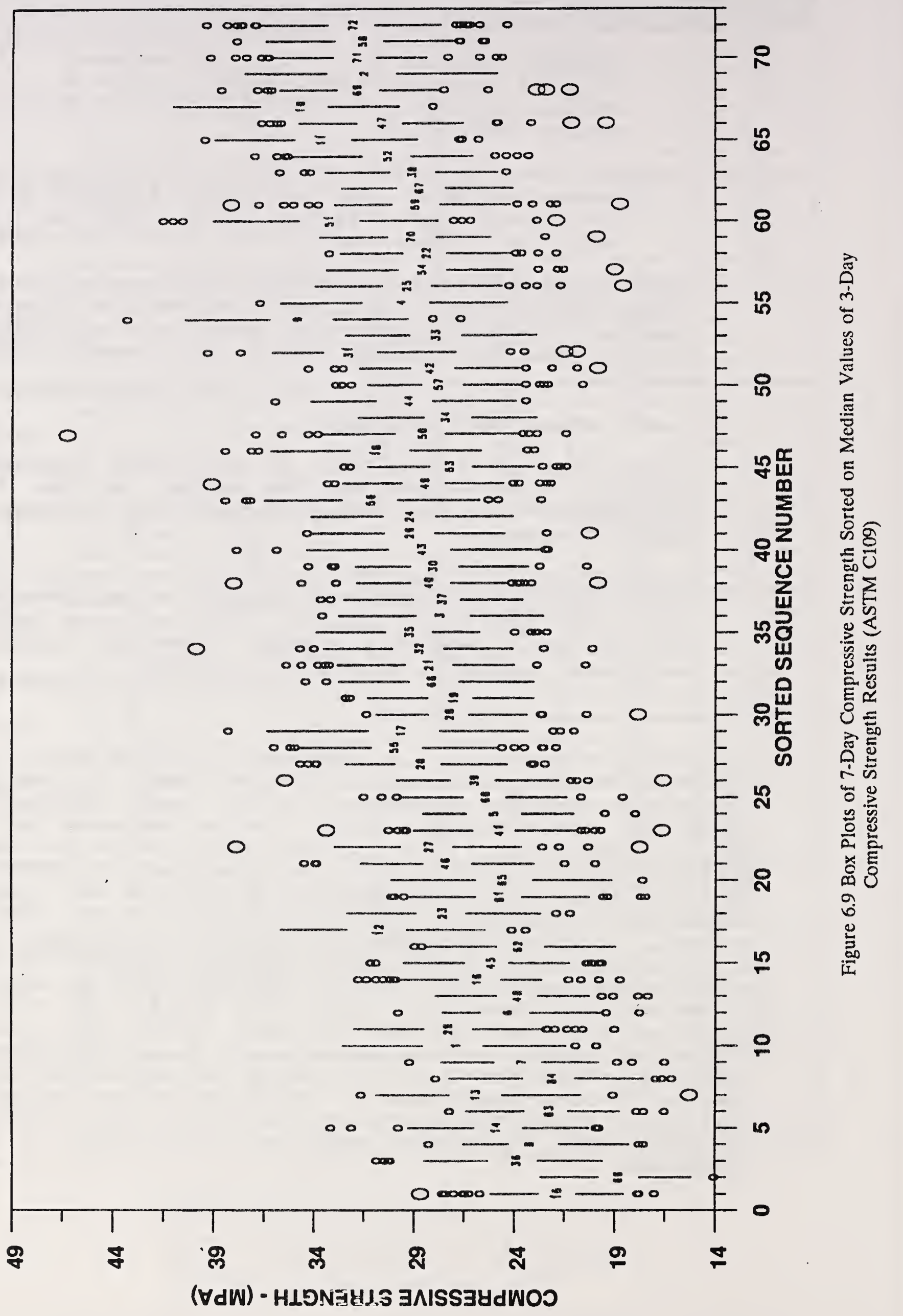




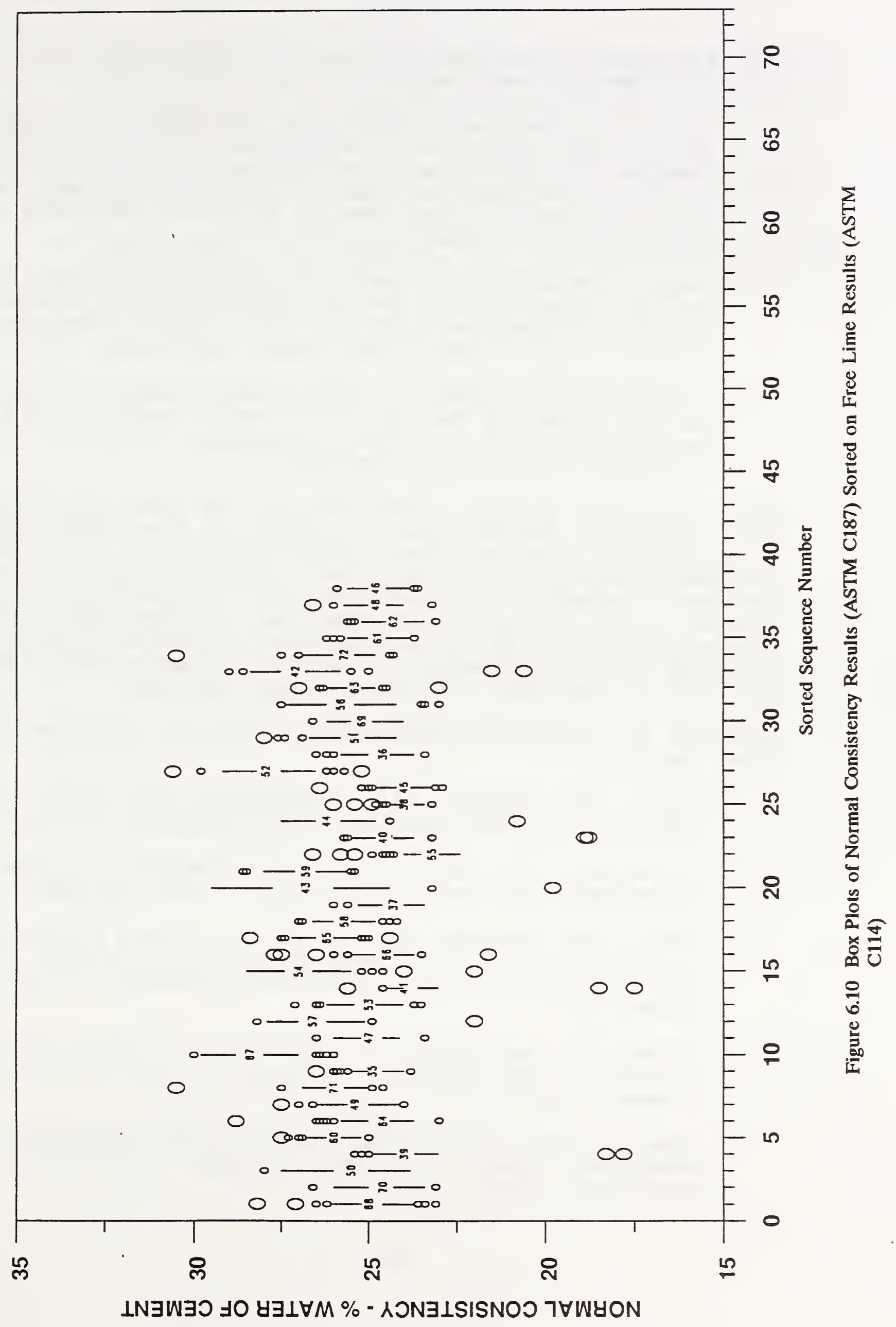


The statistical presentations used in this study will be useful in the following ways:

a. Standards committees may use the results in this report and periodic displays of subsequent proficiency sample results to track the precision of test methods; to evaluate the impact of changes in standards over time; and to determine where new or improved techniques and equipment may be required.

b. Cement researchers and producers will gain insight into the characteristics of the test methods and relationships of cement properties which will aid in their endeavors to obtain a higher quality and better performing product.

c. Testing laboratories will gain a better understanding of factors effecting the quality of cement testing, and will be able to adjust their procedures to obtain more consistent and accurate results.

The information gained in this part of the study provides a basis for the second part, a study of the (analytical) relationships among portland cement properties. This will include transforming the data from its original forms to forms designed to simplify representations and to expose patterns or trends. The use of transformations coupled with modern multivariate modeling tools represents a potentially powerful approach to reveal structure in complex databases such as that provided by the CCRL Proficiency Sample Program.

Examples of follow-up studies which could be conducted with these data are:

1. Study the impact of eliminating the data from laboratories whose results are consistently outliers.

2. Correlate the CCRL Laboratory Inspection Program conformance data to the precision of test methods.

3. Obtain phase analysis data on past and future proficiency samples and introduce it into the modeling process. Look for refinements in Bogue value determinations in light of these data.

4. Investigate variations in precision of test data in relation to the degree of fineness of the current NIST fineness standards.

5. Catalog known relationships between cement properties and determine their validity through evaluation of proficiency sample data. 
6. Investigate groupings of portland cements of similar chemical make-up to evaluate the influence of similarity of composition on the precision and character of the physical test properties.

7. Study the relationship between portland cement fineness, loss on ignition and normal consistency test results.

8. Study wide variations in precision of Vicat time of set test results in relation to similar variations in autoclave results. Does cement fineness play a part? 
8.1 Blaine, R. L., Arni, H. T., et al, "Interrelations Between Cement and Concrete Properties, Part 1," NBS Building Science series No. 2, National Bureau of Standards, Gaithersburg, MD, 1965.

8.2 Blaine, R. L., Arni, H. T., et al, "Interrelations Between Cement and Concrete Properties, Part 2," NBS Building science Series No. 5, National Bureau of Standards, Gaithersburg, MD, 1966.

8.3 Blaine, R. L., Arni, H. T., et al, "Interrelations Between Cement and Concrete Properties, Part 3," NBS Building Science Series No. 8, National Bureau of Standards, Gaithersburg, MD, 1968.

8.4 Blaine, R. L., Arni, H. T., et al, "Interrelations Between Cement and Concrete Properties, Part 4," NBS Building science Series No. 15, National Bureau of Standards, Gaithersburg, MD, 1969.

8.5 Blaine, R. L., Arni, H. T., et al, "Interrelations Between Cement and Concrete Properties, Part 5," NBS Building science series No. 35, National Bureau of Standards, Gaithersburg, MD, 1971.

8.6 Clifton, J. R. and Mathey, R. G., "Interrelations Between Cement and Concrete Properties, Part 6," NBS Building Science Series No. 36, National Bureau of Standards, Gaithersburg, MD, 1971.

8.7 ASTM Book of Standards, Volume 4.01, American Society for Testing and Materials, Philadelphia, PA

8.8 Filliben, J. J., "Dataplot - An Interactive High-Level Language for Graphics, Non-Linear Fitting, Data Analysis and Mathematics," Computer Graphics, Vol. 15, \#3, August, 1981.

8.9 Chambers, J. M., Cleveland, W. S., Kleiner, B. and Tukey, P. A., "Graphical Methods of Data Analysis," Wadsworth, Monterey, CA, 1983.

8.10 Tukey, John W., "Exploratory Data Analysis," AddisonWesley, Reading, Massachusetts, 1977.

8.11 Gonnerman, H. F., "Development of Cement Performance Tests and Requirements," Portland Cement Association Research Bulletin 93, Skokie, Illinois, 1958.

8.12 Bean, B. L. and Dise, J. R., "Causes of Variation in 
Chemical Analyses and Physical Tests of Portland Cement," NBS Building Science Series 17, Washington, D.C., 1968.

8.13 "Guide to the Selection and Use of Hydraulic Cements," Report of ACI Committee 225, ACI Journal, Detroit, MI, November-December 1985.

8.14 Popovics, S., "Concrete-Making Materials," Hemisphere Publishing Corporation, Washington, DC, 1979.

8.15 ASCE 11-90, Guideline for Structural Condition Assessment of Existing Buildings, American Society of Civil Engineers, New York, NY., 1990.

8.16 Mehta, P. K., editor, "Cement Standards - Evaluations and Trends," ASTM STP663, Philadelphia, Pennsylvania, 1978.

8.17 Lea, F. M., "The Chemistry of Cement and Concrete," Chemical Publishing Co., Inc., New York, New York, 1971.

8.18 Blanks, R. F., and Kennedy, H. L., "The Technology of Cement and Concrete," John Wiley \& Sons, Inc., London, 1955.

8.19 Lea, F. M., and Desch, C. H., "The Chemistry of Cement and Concrete," Longmans, Green \& Co., New York, NY, 1935.

8.20 Klein, A. A., and Phillips, A. J., "Hydration of Portland Cement," Technologic Papers of the Bureau of Standards, No. 43, National Bureau of Standards, Gaithersburg, MD, 1914 .

8.21 Isberner, A. W., and Klieger, P., "History and Status of Specifications and Tests for Strength," ASTM STP 963, Philadelphia, Pennsylvania, 1978.

8.22 "NIST Standard Reference Materials Catalog," NIST Special Publication 260, Gaithersburg, MD.

8.23 Wagner, L. A., "A Rapid Method for the Determination of the Specific surface of Portland Cement," ASTM Proceedings 33, p. 553 Part II, Philadelphia, PA, 1933.

8.24 Bogue, R. H. " "The Chemistry of Portland Cement," p.591, Reinhold Publishing Corp., New York, NY, 1955.

8.25 Shartsis, L., and Newman, E.S., "A Study of the Heat of Solution Procedure for Determining the Heat of Hydration of Portland Cement," ASTM Proceedings 43, p. 905, 1943.

8.26 Taylor, H. F. W., "Cement Chemistry," Academic Press Inc., San Diego, CA, 1990 
8.27 Gebhardt, R. F. (Editor), "Rapid Methods for Chemical Analysis of Hydraulic cement," STP 985, ASTM, Philadelphia, PA, 1988.

8.28 Dise, J. R., "Significance of the Test for Normal Consistency of Hydraulic Cement," Cement, Comparison of Standards and Significance of Particular Tests, ASTM STP 441, ASTM, Philadelphia, PA, 1968.

8.29 Dise, J. R., "The Cement Reference Laboratory (19291959)," Proceedings, American Society for Testing and Materials, Volume 59, Philadelphia, PA, Vol.59, 1959, pp. 369-377.

8.30 Pielert, J. H., "Construction Materials Reference Laboratories at NIST," ASTM Standardization News, American Society for Testing and Materials, Philadelphia, PA, December 1989, pp. 40-44.

8.31 Youden, W. J., "Statistical Aspects of the Cement Testing Program," Proceedings, American Society for Testing and Materials, Philadelphia, PA, Vol. 59, p. 1120.

8.32 Crandall, J. R. and Blaine, R. L., "Statistical Evaluation of Interlaboratory Cement Tests," Proceedings, American Society for Testing and Materials, Philadelphia, $\mathrm{PA}$, Vol. 59, 1959, pp. 1129-1154.

8.33 Haupt, R., "Compilation of statistics from the CCRL Proficiency Sample Programs from 1966 through 1988," Cement and Concrete Reference Laboratory, Gaithersburg, MD. 1989 (Unpublished)

8.34 Pielert, J. H. and Spring, C. B., "Application of CCRI Data in the Development of Cement standards," ASTM STP961 - Uniformity of Cement Strength, American Society for Testing and Materials, Philadelphia, PA, 1987.

8.35 ASTM Subcommittee C01.94 on Statistical Methods, "Use of CCRL Reference Sample Results for Precision Statements," Cement, Concrete and Aggregates, Vol. 2, No. 1, summer 1980 , pp. 50-52.

8.36 Pielert, J.H., Haverfield, J. W. and Spellerberg, P. A., "Application of CCRL Data in the Formulation of Precision Estimates for Selected Cement standards," Cement, Concrete and Aggregates, Vol. 7, No. 1, Summer 1985, pp. $37-42$.

8.37 Hamming, R. W., "Numerical Methods for Scientists and Engineers," McGraw-Hill, 2nd Edition, New York, NY, 1973. 
8.38 Jolliffe, I. T., "Principal Component Analysis," Springer-Verlag, New York, NY, 1986.

8.39 Mosteller, F. and Tukey, J. W., "Data Analysis and Regression," Addison-Wesley, Reading, Massachusetts, 1977.

8.40 "Compilation of ASTM Standard Definitions," ASTM, Philadelphia, PA. 


\section{Appendix A}

\section{overview of the cement and Concrete Reference Laboratory}

In the early part of this century it was recognized in the United States that results from tests made on cements conducted by different laboratories varied greatly. In an attempt to alleviate this problem, various technical organizations, including the National Institute of standards and Technology (formerly the National Bureau of Standards), the U.S. Army Corps of Engineers, the American Society of Civil Engineers, American society for Testing and Materials (ASTM) committee C-l on cement, and the Portland Cement Association, began efforts to improve and standardize the specifications and methods for testing portland cement, and to improve the proficiency of laboratory testing [8.29, 8.30]. This eventually led to the establishment of the cement Reference Laboratory (CRL) in April 1929 at NIST with ASTM Committee $\mathrm{C}-1$ as its sponsor. ASTM Committee $\mathrm{C}-9$ on concrete and Concrete Aggregates became a joint sponsor in 1958 when concrete and concrete materials were added to the CRL programs. The name cement and concrete Reference Laboratory (CCRL) was adopted in 1960.

The CCRL has four major functions directed toward an improvement in the quality of testing materials used in construction based on ASTM standards: (1) inspecting laboratories that test cement, pozzolan, concrete, concrete aggregates, and reinforcing steel; (2) conducting proficiency test sample programs for portland cement, pozzolan, blended cement, masonry cement, and portland cement concrete; (3) participating in the work of technical committees such as those of ASTM and the American concrete Institute (ACI): and (4) studying testing problems related to the testing of construction materials.

The CCRI proficiency sample program had its origin in several interlaboratory testing studies. The first began in 1936 with 45 testing laboratories participating. This cooperative testing program was concluded in 1958 at which time 300 laboratories were regularly participating. It was followed by a separate series of interlaboratory studies involving 103 laboratories testing 12 different cements distributed in pairs at bimonthly intervals over a period of a year. The results of this testing program were reported by Youden [8.31], and Crandall and Blaine [8.32].

A formal CCRL portland cement proficiency sample program was initiated in 1960 for the purposes of evaluating laboratories, evaluating methods of test used for acceptance of cement, and providing data on test reproducibility. Samples were distributed at varying intervals until 1966 when a continuing program was initiated with two pairs of samples distributed at regular intervals each year. Participating laboratories submit the samples to chemical and physical tests based on ASTM standard methods. The 
results of this extensive testing, where all laboratories test the same materials at bi-yearly intervals, are returned to the CCRI and accumulated in an archival database. The potential value of this database in improving understanding of the performance of cements and test methods themselves becomes clearer when it is considered that these samples are tested on an ongoing basis by an average of 200 laboratories.

The CCRL periodically provides a compilation of numerical statistics from its proficiency sample programs to appropriate ASTM committees [8.33]. These data can be used by standards committees to assess the adequacy of test methods, determine the impact of revisions in standards, and to evaluate the precision of test methods [8.34]. A statistical procedure prepared by ASTM Committee $\mathrm{C}-1$ and incorporated in 6670 , standard Practice for Preparing Precision and Bias statements for Test Methods for Construction Materials provides a method for formulation of precision statements from CCRL proficiency sample results [8.35]. Pielert, Haverfield and Spellerberg prepared estimates of precision for selected ASTM cement test methods based on this procedure [8.36].

$\mathrm{A}-2$ 
Appendix B

Modeling

\section{Introduction}

Hamming states that "the purpose of scientific study is insight, not numbers." [8.37] The CCRL database being considered in this study presents far more numbers and latent information than can be readily digested mentally. It is the purpose of modern graphical and analytic data analysis tools to assist in analyzing such complex collections of latent information, to help separate the concealed signals from the noise, and ultimately to make inferences about the broader validity of the signals elicited.

One can distinguish between designed studies, where data is collected relevant to a specific set of questions, and undesigned studies where data that happens to become available are used for general analysis purposes, possibly including purposes for which it was not originally intended. This study is an example of the latter.

Modern data analysis divides broadly into exploratory and confirmatory analysis. Although the dichotomy is not always so neat in practice as the words suggest, broadly exploratory analysis is the initial "data grubbing" portion of a data analysis project. The observed or measured variables in the study are first divided into response variables (those we desire to model or explain, e.g. compressive strength or normal consistency), and explanatory variables that we hope will serve to predict the response variables. This is followed by an exploratory modeling phase which is iterative in nature since initially we may have only the vaguest intuition about the structure we hope to model.

Over the past quarter century, with the advent of high speed computing and computational power, a broad set of techniques have evolved which combine graphics with sophisticated analytic tools. The applications of current graphical techniques are limited only by the recurring difficulty of presenting high-dimensional data in a readily comprehensible form that the human eye and brain can clearly interpret. The database in this study with its eleven chemical and ten physical variates is such a case. While certain generic ways of achieving this dimension reduction have evolved and are widely used, this dimensional "bottleneck" is probably still the chief obstacle to the rapid interpretation of clear patterns in highly dimensioned data. This study uses box plots and profile plots to reduce a high-dimensional database to forms which can be easily interpreted.

The confirmatory stage of an analysis refers to the use of classical or modern statistical inferential techniques such as hypothesis testing, point estimation and interval estimation. It employs formal probability calculus-based machinery for making probabilistic statements about the likelihood of a given tentative 
conclusion being generally valid or not.

Graphical does not always mean exploratory and analytic does not always mean confirmatory. Suitably employed, an appropriate box plot (see section 3.3) can be every bit as confirmatory as a formal slippage test (e.g. t-test). Even more important, the box plot graphical device does not require the validity of certain assumptions concerning the data that the more formal analytic tests require, such as normality, or equality of variances. A number of classic or modern multivariate analytic techniques, such as principal component analysis', where the mathematical inference (distribution theory) has not yet been completely worked out, are essentially used by practitioners in an exploratory mode, all the high-powered mathematics notwithstanding.

Despite continuing progress in the graphical representation of complex data in mathematical statistics and in mathematical and multivariate analysis, as well as database design and expert systems, the day is still far away when one can simply feed a complex set of data into a black box and expect intelligible meaningful output. The most realistic approaches to complex multivariate data sets still remain the ones that incorporate a good deal of iteration and hands on effort. Application of good scientific insight into the nature of the data and the likely nature of the relationships between response and explanatory variables are necessary.

The first step in the approach to the analysis of a multivariate data set is to look at the variables one at a time. In doing this, one attempts to get a feel for a number of important factors that will affect the direction of the subsequent analysis. These factors include the types of variates involved (category scale vs ordinate scale vs ratio scale); the range of values available for each variate; the intercomparability of variates; and the possibility of transforming the variates. This is the approach used in this study.

A second step in this iterative approach would be to look at bivariate, and possibly trivariate, relationships among the variables. This is accomplished by computing correlations and multiple correlations of variates with other variates or pairs of variates, both raw and transformed (see section 3.2). This gives first insights into which variates are likely to provide "explanatory power" for the response variate fluctuations. Guidance to potentially meaningful combinations and suggestions for physically useful transformations can be derived from knowledge of the subject matter including the physics and chemistry of cements and concretes. Rules of thumb regarding relationships between the properties of cements, can provide potentially useful entrees in to

\footnotetext{
${ }^{7}$ Principal components analysis is a technique used to assess in a highdimensional "cloud of points" the principal orthogonal directions giving the best coverage/explanation of the scatter/variation in the data. [8.38]
} 
the data analysis.

Finally, one can proceed to full-blown models; using both exploratory and confirmatory tools such as all possible subsets regression with transformation of the variables. The details of this approach will be treated in a future study.

The approach as described here is fairly natural and simple, although somewhat laborious. It mimics in a straightforward way the natural way of learning about complex systems: starting a component at a time, working up through understanding of interactions of various groupings of components, ultimately resulting in an understanding of the global working of the system.

\section{Transformations}

An important feature of modern exploratory data analysis is the need to reconfigure data from its originally presented form to some different transformed form to expose patterns or trends. Examples of transformations abound in science and everyday life: decibels make use of $\mathrm{log}$ scale relationships giving simple decimal numbers rather than a long string of digits or an exponential term, while $\mathrm{pH}$ is the log value of the concentration of $\mathrm{H}+$ ions in solution.

Statisticians typically employ transformations to (1) induce normality, (2) induce symmetry, or (3) uniformize (stabilize) variance. The use of judicious transformations may be dictated by rule of thumb considerations, statistical considerations, physical model considerations, or in some instances even by historical or common usage considerations. But whatever the motivation, the use of transformations coupled to modern multivariate modeling tools such as all possible subsets regression or principal components analysis - represents a powerful general approach to the elucidation of structure of complex many-variable data.

A growing body of experience in data analysis for transforming to handle different kinds of generic situations is being accumulated. The book by Mosteller and Tukey [8.39] is an excellent reference. 


\section{Appendix C \\ Statistical Tools}

\section{Box Plots}

The box plot is useful for providing indications of location of the underlying distributions (of the batches), spread of the underlying distributions, and extremes of the given distributions. The median (or center sort value) is used as the indicator of location of each batch of numbers. The median is used primarily because of its resistance to outliers, where an outlier is a "value far enough from other results in a series to be suspected of not belonging to the particular population under consideration." [8.40] An extremely large outlier pulls the mean (average) in the direction of that number, while the same large number has no effect on the value of the median.

An example of how a box plot relates to the body of data is shown in Figure C.I. A set of data is first represented by a histogram (for some prefixed class width), and the information is then schematically condensed into a box plot. The interquartile (IQ) range, or middle half of the data, represents the body of the distribution of the numbers in each batch. The IQ range, represented by a box, is the distance between the values of the upper and lower quartiles of the data. Specifically, the data represented is sorted. The median is marked by the sample number on Figure C.I. The lower end of the box (QI) is the highest number of the lowest 25 percent of the data, and the upper end of the box (Q3) is the highest number of the lowest 75 percent of the data.

Many variants and refinements of the box plot are possible. other statistics can be used to measure the spread of the distributions, such as the interdecile range which is the distance between the lst and 9 th decile. Box plots can be constructed using other proportions, such as the box section representing \pm one standard deviation from the median, or \pm 20 percent of the data from the median.

In this report the box representing the IQ range is represented by a space because of space limitations on the box plots. The lines extending from the ends of the gap represent the range of results extending to (1) the largest observation that is less than or equal to Q3 plus $1.5 \mathrm{x}$ IQ range, and (2) the smallest observation that is greater than or equal to $Q 1$ minus $1.5 \mathrm{x}$ IQ range. The lengths of the lines relative to the IQ range give an indication of the spread of the tails of the distribution. Outliers between $1.5 \mathrm{x}$ IQ range and $3.0 \mathrm{x}$ IQ range above $Q 3$, and between $1.5 \mathrm{x}$ IQ range and $3.0 \mathrm{x}$ IQ range below $Q 1$ are represented by small circles. Outliers more than $3.0 \times$ IQ range above $Q 3$, and $3.0 \times$ IQ range below $Q 1$ are represented by large circles.

A box plot on two samples constitutes a visual t-test, a test for slippage of location parameters that is considerably more robust 


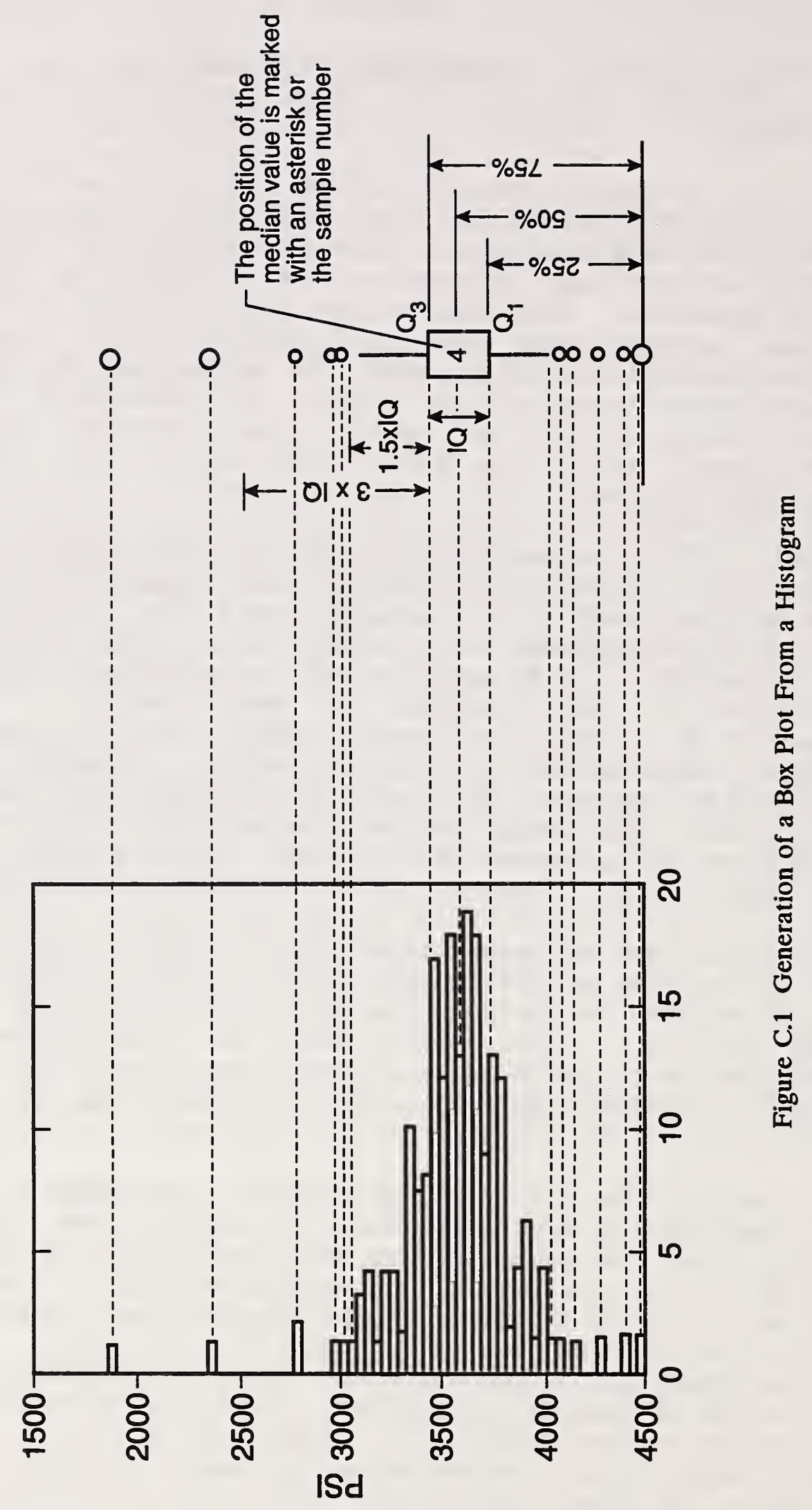


than the standard numerical test. [8.10] The classic t-test is robust with respect to departures from the assumption of normality (of the distributions underlying the two samples of numbers), but is known to be extremely non robust with respect to departures from the assumption of equal variances. The box plot makes the inequality of variances visually obvious, serving as an immediate caution on identifying an observed pattern as a slippage.

In the case of the normal distribution, $N\left(\mu, \sigma^{2}\right)$, the IQ centered symmetrically on the mean is between $(\mu-0.674 \sigma)$ and $(\mu+0.674 \sigma)$ where $\sigma$ is the standard deviation. The standard deviation ( $\sigma$ ) of the normal distribution is $0.74 *(Q 3-Q 1)$. While such simple numerical equivalences enable us to do a translation from the less familiar IQ-based statistics employed in this study to the more familiar standard deviation multiples of normal theory, inspection of the typical histograms in Figure 3.2 cautions against assuming normality (Gaussianity) with the data. It is precisely because of the nonnormal - skewed and multimodal - representations observed in these plots that more robust/resistant statistics are employed to graphically represent the data, the median for location and the IQ for spread.

Box plots provide information useful for model development. Combining box plots of a test method is useful in sifting through data in search of transformations that may be applied simultaneously to batches of numbers to achieve some objective, such as equalizing ("stabilizing") variance among the batches. It should be noted that values of the indicator variable can be grouped according to (almost) constant level of the plotted batch variable. This can be used to select representative data levels of variables for use in regression and cross-validation exercises.

\section{Profile Plots}

The development of a typical profile plot is illustrated in Figure C. 2 which shows sorted box plots for silicon dioxide $\left(\mathrm{SiO}_{2}\right)$ and calcium oxide $(\mathrm{CaO})$. It can be seen that the lowest silicon dioxide median value is approximately 19.1 percent and the highest value is about 22.3 percent. The sorted box plot ranks the samples from the lowest to highest based on median values of the property represented. In profile plots, the samples are further characterized using the rank percent of the test results among all 72 samples. For example, in Figure C-2 the rank percent of sample 13 for $\mathrm{CaO}$ is $10 \%(7 / 72 \times 100)$ where 7 is the rank of the sample among the 72 samples. The rank percent of each sample is calculated as shown on Figure C.2 for sample 13. The profile plot consists of a bar chart made with these rank percentages for each parameter. The number of parameters depicted in a profile plot is limited only by the need for visual clarity. The bars may be ordered or grouped in various ways within the profile plot to facilitate interpretation. 

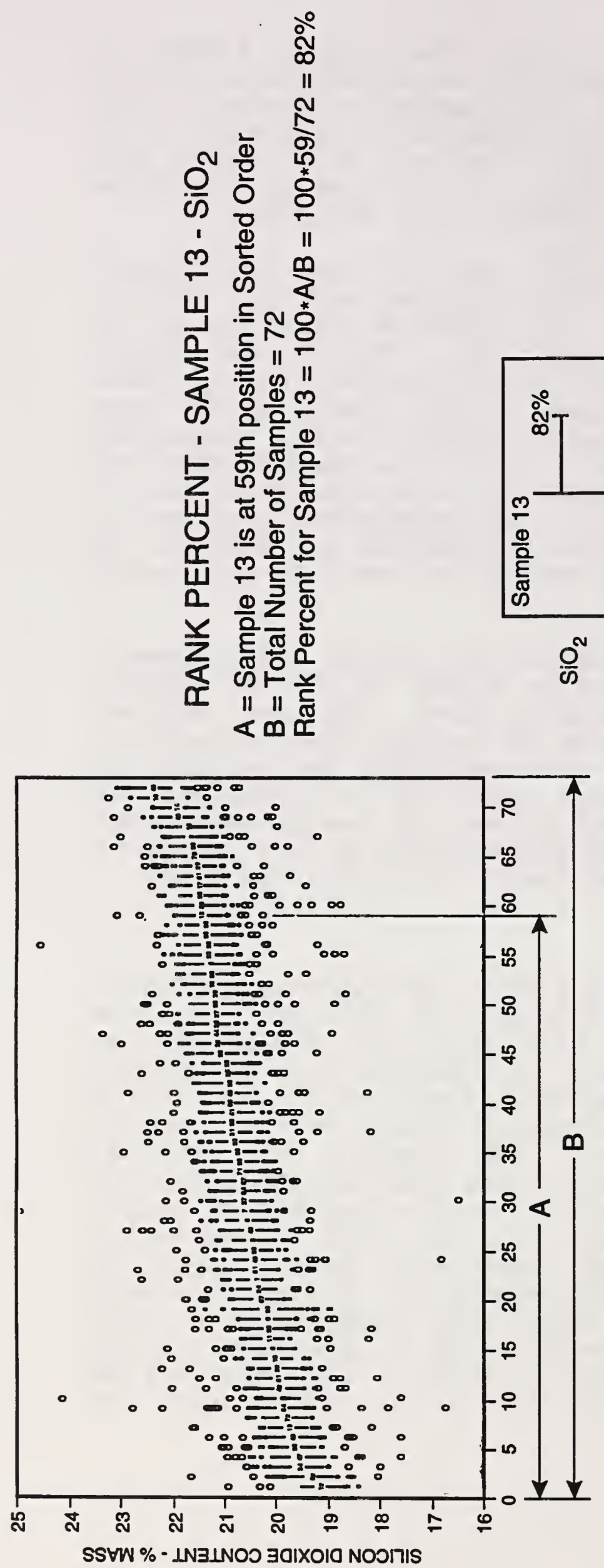

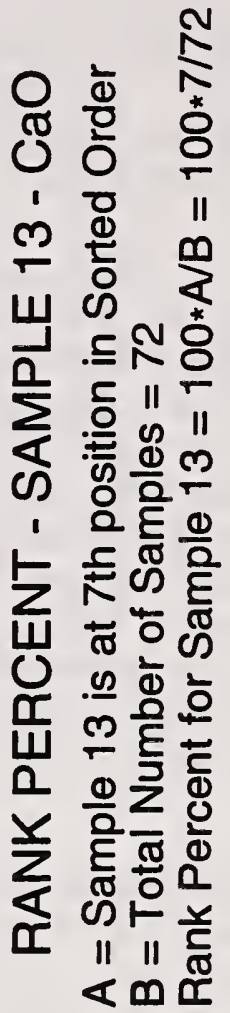

告

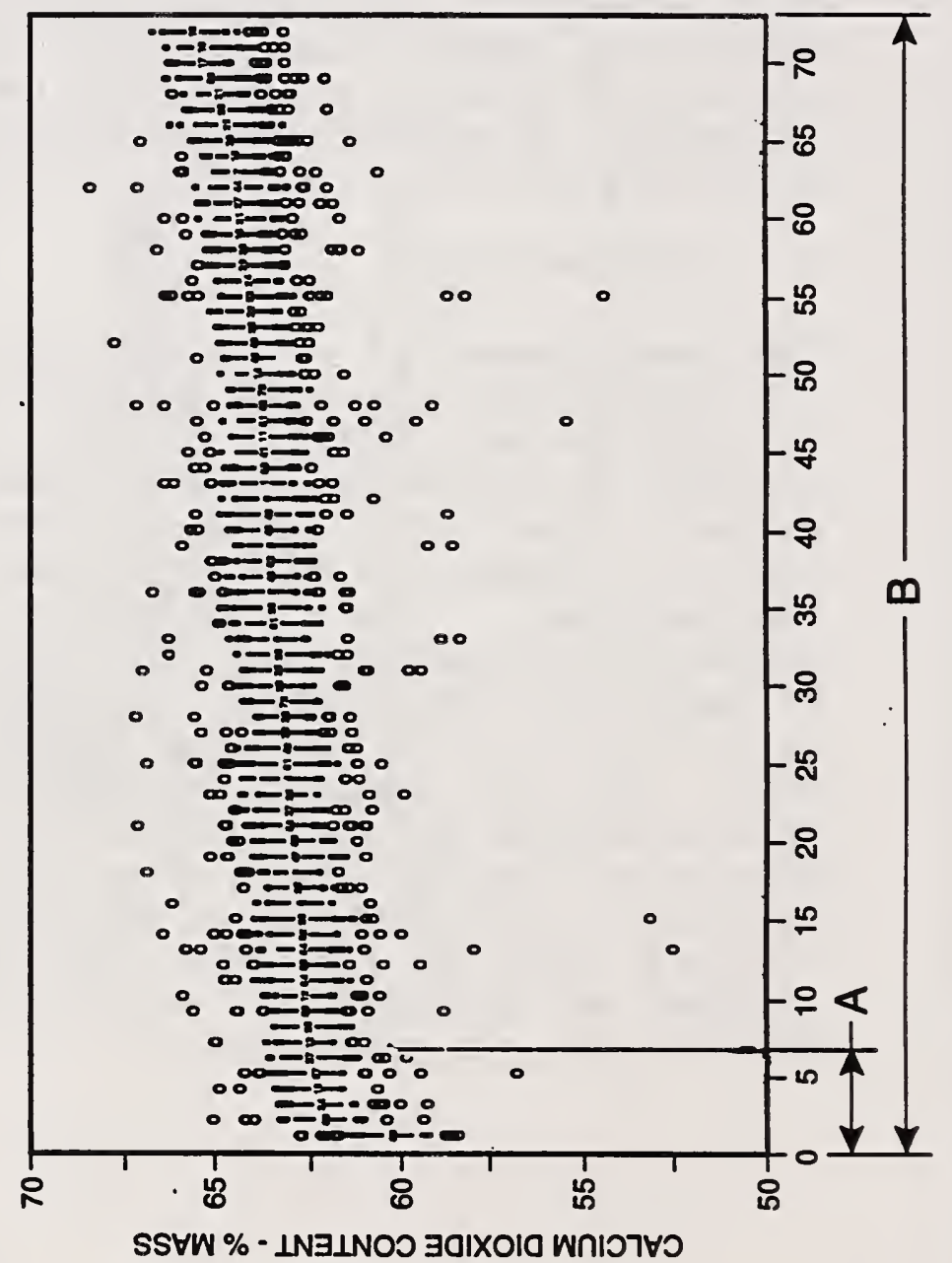




\section{Comparison of Precision statements in ASTM Standards to Those Computed From CCRL Data}

It is of interest to compare the projected uncertainties cited in the ASTM Test Methods with estimates of uncertainty actually obtained from the CCRL proficiency sample data [8.33]; based on 90 samples. As examples of such comparisons the uncertainities for two test methods for hydraulic cement are discussed: standard Test Method for Compressive Strength of Hydraulic Cement Mortars (C109); and Standard Test Methods for Heat of Hydration of Hydraulic Cement $(\mathrm{C} 186)$.

\section{Background}

ASTM C670-91a [8.7] distinguishes between the constant-variation (homoscedastic) case and the proportional-variation (heteroscedastic) case as follows:

Homoscedastic Case

"6.1 Manner of Expression - If the test data on which the precision statement is to be based indicate that the standard deviation is essentially the same for all levels of the property being tested for which data are available, the one-sigma limit and the difference twosigma limit shall be given in the precision statement expressed in the units of the measured property."

Heteroscedastic Case

"6.1.1 If the standard deviation is essentially proportional to the average for different levels of the property in question (that is, the coefficient of variation is essentially constant), then the "one-sigma limit in percent" (1s\%) and difference two-sigma limit in percent ( $22 \mathrm{~s} \%$ ) shall be given. "One-sigma limit in percent" is, for the purposes of this practice, the same as the coefficient of variation. It is determined by dividing the standard deviation by the mean (average) value of available results and multiplying by 100 . Similarly, "difference two-sigma limit in percent" is obtained by dividing (d2s) by the mean and multiplying by 100. When neither of these conditions is met, the applicable limits for specific ranges of the property shall be stated together with the specific ranges for which they are appropriate."

"The one-sigma limit in percent (1s\%) is, the appropriate standard deviation (1s) divided by the average of the measurements and expressed as a percent. The difference twosigma limit (d2s) is the difference between two individual test results that would be equaled or exceeded in the long run in only 1 case in 20 in the normal and correct operation of the method. The d2s percent index is the difference between 
the individual test results expressed as a percent of their average that meets the same requirements. These indices are calculated by multiplying the appropriate standard deviation (1s) or coefficient of variation (15\%) by the factor $2 \sqrt{2}$."

II. Compressive Strength (ASTM C109)

Table 2 of C109-90 gives the expected multilaboratory precision $^{8}$ for portland cements as follows.

Test Age,

Days

3
7

AV.
Coefficient of

Variation (1S\%)
Acceptable Range of Test Results, (D2S\%)

19.2

18.1

18.7

The above statistics can be compared to comparable statistics computed from the CCRL Data [8.33].*

Untrimmed (A11 data)

\begin{tabular}{||c|c|c|c|c||}
\cline { 2 - 5 } \multicolumn{1}{c|}{} & \multicolumn{2}{c|}{$15 \%$} & \multicolumn{2}{c||}{ D2S \% } \\
\hline AGE & ASTM C109 & CCRL & ASTM C109 & CCRL \\
\hline $3-$ daY & $6.8 \%$ & $\sim 6-10 \%$ & $19.2 \%$ & $-18-25 \%$ \\
\hline $7-$ day & $6.4 \%$ & $\sim 6-8.5 \%$ & $18.1 \%$ & $\sim 17-23 \%$ \\
\hline
\end{tabular}

$*$

The ranges of $\%$ under the CCRL columns are the approximate minimum and maximum $15 \%$ and D2S\% statistics read directly from the relevant tabulation(s) in reference 8.33 .

${ }^{8}$ Multilaboratory Precision is defined in ASTM C670 as "A measure of the greatest difference between two test results that would be considered acceptable when properly conducted determinations are made by two different operators in different laboratories on portions of a material that are intended to be identical, or as nearly identical as possible." 
Trimmed (Outlier Data Deleted)

\begin{tabular}{||c|c|c|c|c||}
\cline { 2 - 5 } \multicolumn{1}{c|}{} & \multicolumn{2}{c||}{ 1S $\%$} & \multicolumn{2}{c||}{ D2S \% } \\
\hline AGE & ASTM C109 & CCRL & ASTM C109 & CCRL \\
\hline $3-$ day & $6.8 \%$ & $-6-8.5 \%$ & $19.2 \%$ & $\sim 17-25 \%$ \\
\hline $7-$ day & $6.4 \%$ & $-5.5-7.5 \%$ & $18.1 \%$ & $\sim 16-22 \%$ \\
\hline
\end{tabular}

These comparisons suggest that the ASTM projections of uncertainties in $\mathrm{C} 109$ tend to be a bit optimistic compared to the values one obtains in actual laboratory practice as represented by the CCRL data.

If we use the results of section 4.4 for compressive strength to compare the ASTM and CCRL estimates of precision, we can say the following:

3-day Compressive Strength

The Interquartile (IQ) range of $200 \mathrm{psi}$ (1.38 MPa) - 400 psi $(2.76 \mathrm{MPa})$ units would translate, if the data were normally distributed, into roughly $150 \mathrm{psi}(1.03 \mathrm{MPa})$ $300 \mathrm{psi}(2.07 \mathrm{MPa}$ ) 1s values (using the $\sigma=0.74$ IQ range). This in turn for, say $1500 \mathrm{psi}(10.3 \mathrm{MPa})-4500$ psi $(30.9 \mathrm{MPa})$ represents a 10 percent -6.5 percent range of is percent values which agrees nicely with the computed is percent values.

7-day Compressive Strength

Following the same reasoning for 7-day compressive strength, a range of 8.5 percent - 11.5 percent for $15 \%$ Values is obtained.

III. Heat of Hydration (ASTM C186)

Section 10.2 of c186-86 gives multilaboratory precision as follows:

\begin{tabular}{|c|c|c|}
\hline & $\begin{array}{l}\text { Coefficient of } \\
\text { Variation (1S) }\end{array}$ & $\begin{array}{l}\text { Acceptable Range of } \\
\text { Test Results (D2S) }\end{array}$ \\
\hline Heat of Solution & $4.42 \mathrm{cal} / \mathrm{g}$ & $13 \mathrm{cal} / \mathrm{g}$ \\
\hline Heat of Hydration & $4.03 \mathrm{cal} / \mathrm{g}$ & $11 \mathrm{cal} / \mathrm{g}$ \\
\hline
\end{tabular}

Comparing the CCRL data [8.33] for heat of hydration with ASTM C186 precision statement: 


\begin{tabular}{|c|c|c|c|}
\hline & & Sample $1 *$ & Sample 2* \\
\hline \multirow{2}{*}{$\begin{array}{c}\text { No. } \\
\text { outliers } \\
\text { (Trimmed) }\end{array}$} & $\begin{array}{l}\text { CCRL } \\
\text { Data } \\
\end{array}$ & $3.0-6.0 \mathrm{cal} / \mathrm{g}$ & $2.0-8.0 \mathrm{cal} / \mathrm{g}$ \\
\hline & $\begin{array}{l}\text { ASTM } \\
\text { C186 } \\
\end{array}$ & $4.03 \mathrm{cal} / \mathrm{g}$ & $4.03 \mathrm{cal} / \mathrm{g}$ \\
\hline \multirow{2}{*}{$\begin{array}{c}\text { Outliers } \\
\text { Present }\end{array}$} & $\begin{array}{l}\text { CCRL } \\
\text { Data }\end{array}$ & $4.0-7.0 \mathrm{cal} / \mathrm{g}$ & $4.0-7.0 \mathrm{cal} / \mathrm{g}$ \\
\hline & $\begin{array}{l}\text { ASTM } \\
\text { C186 }\end{array}$ & $4.03 \mathrm{cal} / \mathrm{g}$ & $4.03 \mathrm{cal} / \mathrm{g}$ \\
\hline
\end{tabular}

* The CCRL Proficiency Sample Program sent two samples of slightly different material to laboratories for testing.

The CCRL results agree reasonably well with the ASTM C186 projection, although the CCRL experience is somewhat more variable.

The observed IQ range of $2-7 \mathrm{cal} / \mathrm{g}$ would translate to a standard error range of $1.5-5 \mathrm{cal} / \mathrm{g}$ which brackets the ASTM value of $4.03 \mathrm{cal} / \mathrm{g}$. 

